UC-NRLF

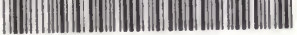

\$B ? I 515 

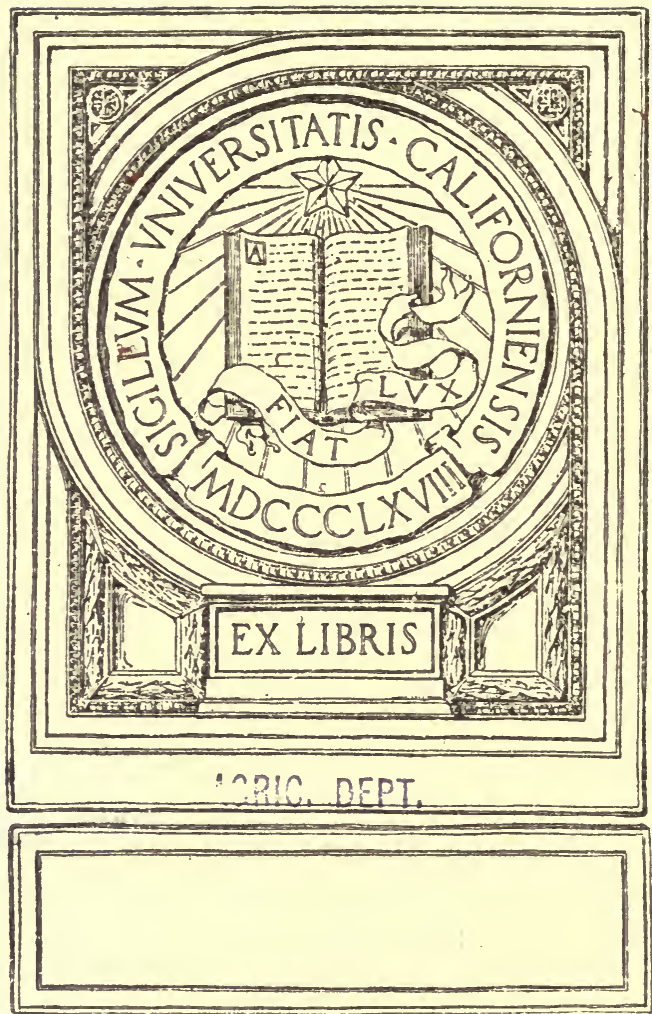





\title{
Fndian Tea Association.
}

\section{THE}

\section{TEA SOILS OF ASSAM,}

AND TEA MANURING.

BX

\author{
HAROLD H. MANN, B. Sc.,
}

Scientific Officer to the indian Tea Association.

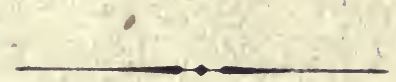

CALCUTTA :

PRINTED BY W. NEWMAN \& CO.,

AT THE CAXTON STEAM PRINTING WORKS, 1, MisSion ROW. 





\section{Fndian Tea Association.}

\section{THE}

\section{TEA SOILS OF ASSAM,}

AND TEA MANURING.

BY

HAROLD H. MANN, B. Sc.,

Scientific Officer to the indian Tea Association.

CALCUTTA :

PRINTED BY W. NEWMAN \& CO.,

At THE Caxton Steam PRINTINg WORKS, 1, Mission ROW. 
M 3 


\section{THE TEA SOILS OF ASSAM}

\section{AND TEA MANURING.}

\section{CHAPTER I.}

\section{INTRODUCTION.}

The successful production of any plant or of any vegetable product is influenced for good or for evil by a number of conditions. Soil, climate, "breed" of plant, conditions of culture, prevalence of pests and blights, may each play a preponderating rôle in deciding the possibility or impossibility of profitably growing a plant in a given situation. But among these natural conditions there is perhaps none (except that of climate-and this is entirely beyond our control) which plays a more fundamental part in determining the character of the cultivated plants in a country or a district than that of the soil. Its character in England, for instance, determines whether land shall be devoted to wheat or to barley, to turnips or to some other root crop, to pasture or to arable culture. In India likewise, entirely apart from climatic questions, it determines the paramount suitability of a district for rice, for millet, for cotton, for sugar, or for tobacco.

Its influence is not less paramount in the case of tea. In many parts of the tea districts it might be said that every condition has been favourable except that of soil, but as a result of bad soil conditions in certain Assam districts garden after garden has passed entirely out of cultivation. It might be thought that the essential importance of a suitable soil was too obvious to need that stress should be laid on it, but I have noticed quite a number of pieces of tea put out during the past three years in total ignorance of the character of the subsoil-which really proved to be very unsuitable,- and also in positions where the tea can never flourish nor do well. Such incidents seem to indicate that there is room for insisting on the soil requirements of the tea bush, and for further investigating those soil conditions which answer the purfose best. 
Not that it could be maintained that one class of soil and one alone is satisfactory. Far from it. The tea plant has a marvellous faculty of adapting itself to conditions - within certain limits. But even in these limits great care has to be taken to adapt the type or jat of plant, and the culture of the crop to the soil conditions. For instance it would only be to court failure to attempt to plant one of the delicate jâts of Upper Assam on a Cachar or Sylhet bheel-or even on the heavier and more difficult soils of some of the lower districts of the Brahmaputra Valley itself. Then again the amount and kind of culture given in the extremely sandy soils of some parts of Jorhat-magnificently suitable as they are for tea-would be totally inadequate if applied to the stiffer soils of Nowgong or even of the Tezpur bank; and would again be far too great under the peculiar root conformation found in tea grown in peat land.

\section{MY INVESTIGATIONS.}

My own investigations into the subject of this report have been conducted during two tours in the Assam Valley, one of which lasted from May 28 to July 3, 1900, and the second from November 3, 1900 to January 19, 190I, the latter being especially devoted to the investigation of the soils. From the end of January to the end of July 1901 (excluding June when my time was otherwise engaged in Assam), I have been occupied with an attempt to work up some of the large amount of material collected during this tour,-but after all the results here presented only give the more obvious part of an extremely. complicated and difficult subject. For reference purposes it will be well to put on record the course of my second tour, which was as follows :-

(1) Mangaldai District-November 4 and 5, Bhutia Chang; November 6, Orangajuli; November 7, Hattigor; November 8, Singramari.

(2) Tezpur District-November Io and II, Bindukuri and surrounding gardens; November 12, Hathibari and Nahor Kani ; November 13, Addabari; November 14 and 15, Sonajuli.

(3) Bishnath District-November I7 and 18, Majulighur; November 19, Pertabgurh and Dikorai; November 20, Mijikajhan. 
(4) North Lakhimpur District-November 22, Anniesbarie, Merbheel and Harmutty; November 23, Sillonibari; November 24, Dejoo ; November 25, Joyhing; November 26, Lilabari.

(5) Dibrugarlh District-November 29, Chubwa; November 30, Balijan (Eastern Assam Tea Co.) ; December 1 and 2, Panitola ; December 3 and 4, Woodbine; December 5 and 6, Tingri (Hoogrijan, Noholia and Keyhung).

(6) Doom Dooma District-December 7 and 8, Pabbojan and Beesocopi; December 8 and 9, Talup; December 10, Hukanguri and Hilika and back to Talup; December 11, Talup and return to Chubwa.

(7) Nougong District-December 14, Koliabar; December 15 , Secoree and Solal; December 16 and 17, Salonah and Borghat; December 18, Amluckie; December 19, Rangamati; December 20, Kellyden.

(8) Jorhat and Gologhat Districts-December 22, Nigriting; December 23 to 27, Cinnamara ; December 28, Badulipar; December 29, Numaligarh and Bor Sapori ; December 30, Hautley; December 31 and January I, 1901, Moabund; January I, Panbarrie ; January 2, Duflating ; January 3, Heeleaka and Kotalguri ; January 4, Noakachari ; January 5, Naganijan ; January 6, Seleng.

(9) Naziva District-January 8, Ligri Pukri, Mazengah, Mackeypore; January 9, Bamon Pukri and Suntok.

(10) Sonari District-January I0, Towkok ; January 11, Jaboka ; January 12, Borahi ; January 13, Suffry and Napuk; January 14, Mutrapore; January 15, Nahorhabi.

(i1) Gauhati District-January 19, Burdwan.

\section{DETERIORATION OF OLD TEA.}

In a report presented to the Indian Tea Association in July 1900 after my first preliminary tour in Assam, I made use of the following language :-

"The most striking observation made during my tour, and which was repeated in every district to which I went, was the manifest deterioration of the older parts of the garcien, whatever the seed may have been with which they were originally planted. In fact the question of most immediate importance seems without doubt to 
be: How can the vitality and yield of the bushes, together with the quality of tea produced, be kept up for a longer period than is at present the case? Whether the cause of this deteriorationwhich, though only suspected at the time of Dr. Watt's tour in 1895 , is now obvious on almost every garden-be exhaustion of soil on the one hand, or old age of the bush on the other, or a combination of both, is left for experiment to solve. There is, however, little or no doubt in my own mind, even now, that exhaustion of the soil plays a very great part in the matter, and this is confirmed by the fact that in those gardens which possess soil of an exceptionally favourable and lasting character, or in which means have been adopted for keeping up its fertility, the deterioration of the bush and consequent loss is much less than in other cases. This conclusion, I am afraid, involves the belief that manuring, in one form or another, will have, in future, to be a regular adjunct to tea culture on all but the youngest gardens."

To every word of this opinion I still adhere. There is absolutely no doubt that the gardens in Assam do deteriorate as they get older, with very rare exceptions, and it is only according to reason that they should do so unless an attempt is made to keep them up to their original fertility. As a rule, however, no such attempt is made except by means of very deep cultivation, which is only a method of staving off the evil day; or by topdressing with bheel or hullah soil, which if correctly done with good material is one of the best operations which has become at all general in the valley in the past few years. Even here, as I shall show later, a vast amount of expense and labour has been employed in putting absolutely useless material on to the land, and I can only urge very great caution in deciding whether or not it is worth while to spend a large amount of money in lifting any particular material.

I cannot consider that for many years to come any but a comparatively small quantity of the manure required will be in the form of artificial manures, unless it be to a certain extent as phosphates. In other respects as far as most places in the province are concerned, Assam is abundantly capable of supplying, if means were taken to utilise it, practically the whole of what is needed. I have yet to see any place where the vast amount of cattle manure is preserved with any reasonable care, and yet each cow will produce 2,000 lbs. 
of manure, - and useful manure,-per annum-the whole of the valuable constituents being obtained from land outside the tea area. Mustard is extensively grown in the province, and though much oil is used in the valley, a large proportion of the seed is exported to Calcutta and the oil reimported, instead of the seed being pressed on the spot, and the cake used as manure. Green manuring is still in its infancy, and so on.

But beyond this, experiments are necessary every where to determine the best means of keeping up the standard of a garden. Laboratory analyses can show in some measure where the soil is deficient, but in their application to a new crop and especially one in the tropics there always must remain very grave doubts as to the conclusions only removable by actual culture trials in the field. One thing is now practically certain. It is inn. possible to apply without very great modification the experience of temperate climates to the condition of the tea industry. Plant nutrition is here very likely governed by somewhat modified rules The conditions of the soil during the rains, that is, the growing season, is entirely different from what it is during the comparatively dry weather,-again the growing season,- used for the production of the ordinary crop in Europe, or even of the Kharif crop in India.

In general the principle of culture adopted in most instances in Assam has been nothing more nor less than "juming"- the system adopted by the Nagas in the hills above. In brief it consisted of opening out virgin land, putting in the crop, utilising this land until it ceased to be profitable, and then again abandoning it to jungle and planting out more. The best managed gardens put out ten, twenty, thirty or more acres per annum to make up for the falling off in the old tea, and as a result had a constantly increasing acreage with a constant produce. As an example I may say that in one case which has come before my notice, a garden practically made the same crop in 1899 from 833 acres, as it made in 1893 from 525 acres. Making every allowance (say 20 per cent.) for increased fineness of plucking, a system which produces reșults like this cannot be called either sound agriculture or sound business. It means that the additional area added has to be worked and this must cause the use of extra labour and hence 
extra expense. It also handicaps the new land by the extra cost of carrying or carting leaf from a greater distance to the factory. And further, it means either more expensive or less adequate supervision. This principle, in addition, creates a tendency to ignore vacancies, and often has the statement been made to me that it was easier to plant out new land than to fill in vacancies, heedless of the fact that the vacancy land though producing nothing cost just as much to work as that producing the maximum crop. I think it must once and for all be recognised that the practice of making new clearances to take the place of the deficiencies of old tea still kept in cultivation is illogical and based on unsound principles. And as a natural consequence it must be laid down as an absolute rule that extensions are inexcusable unless the tea already in existence is producing the maximum it is capable of producing of the quality of tea desired. I do not mean to say that one can always expect 20 years old tea to give as good a yield of as good tea as ten years old plant. This is, to say the least of it, very doubtful. But if the yield of a plot of land shows a gradual tendency to fall lower and lower, it is time to deal with that plot and bring it up to the standard laid down before any further extension is carried out.

If such be not the recognised principle of culture it would be far better to frankly recognise that our tea culture is "juming" pure and simple, and abandon an equivalent for the tea coming into bearing. This would at least be a confession that it paid better to put out new tea than to keep tea up to a certain yielding power, but the system of constantly extending area at increased cost for working, with greater difficulty in working, and with less capacity for supervision is utterly wrong as an agricultural principle, and may be said to be non-existent in any other agricultural industry.

In brief then agriculturally the only sound system would be never to put out new tea until the old is yielding its maximum. If this old tea cannot be profitably kept up to the standard required either uproot and replant the plot, or plant out fresh tea with a view to the abandonment of an equivalent area so soon as the new plant comes into bearing. I am very doubtful whether this latter alternative will be necessary in many cases, unless some grievous errors have been made either in the original plant or in the subsequent treatment. 
EFFHCT OF CHANGES OF SYSTEM OF WORKING.

And here, as part of the introduction, to the study of the con. ditions existing in tea soils and their improvement, I cannot help remarking that, given the best soil in the world, a constant change in the system of dealing with the bushes will so ruin the tea that a time will come when it will no longer be possible either by prun. ing or by treating the soil to bring them back to anything like a reasonable yield. Such tea must be uprooted and replanted, or abandoned. But it seems a very great pity that tea should be allowed to get into such a condition. I know there are many different ways of dealing with a tea bush -all, it may be, equally or almost equally good. Two of the best gardens I know on the south bank of the Brahmaputra have been treated by almost entirely opposite systems of pruning, but the same system has been applied for many years in each case-and an equally good result is obtained.

It would almost seem, if such a system were feasible-and I hardly see why it should not be-that a plan should be laid out ahead for five or ten years for pruning every plot of tea, and this whatever manager were in charge, should only be altered for some very special reason. The present method of going round each plot with a knife in December, and there and then deciding the year's pruning without reference to the past history of the bush is, I think, far ton casual an arrangement for an industry in which the bushes represent both capital and stock in trade.

SUMMARY.

Summarising therefore it may be said that-

(1) The older parts of the Assam gardens are gradually deteriorating in yield, and it may be also in quality.

(2) It is unsound to try and make up for this loss in yield by putting out new clearances.

(3) This deterioration can be largely stopped by the judicious use of manures, principally obtained locally.

(4) No new elearance should be put out unless the old area is producing its maximum, or it is intended to abandon an area equivalent to the new clearance. 
(5) A system should be laid down for the future pruning and treatment of every plot on a garden, only to be departed from for very trenchant reasons

In the consideration of the subject which follows one can only be said to have just opened the matter. We are ludicrously ignorant on almost every point on which I have touched, and were it not for the results obtained by $\mathrm{Mr}$. Bamber both here in India and also more recently in Ceylon, it vould almost be impossible to obtain any independent testimony on any question relating to tea soils which could be discussed. I have undoubtedly drawn illustrations, especially in that part devoted to the physical properties of tea soils, from results obtained both in England and America, but this is entirely because such data are non-existent for India and Indian conditions. The questions of the relation of soil to quality are still practically untouched except for Mr. Bamber's Ceylon results, and my view here reported, but altogether they form a most inadequate commencement to the study of the most difficult part of tea culture. Not until one can settle in the tea districts in a position where one can daily watch the influence of various conditions on the plants, conduct experiments-perhaps utterly unpractical in appearance-on the growth of the bushes under varying conditions, study the relationship of various conditions-not to quality as a whole, for this is a complex property, but to the relative amount of various constituents in the leaf; not till then will one be able to give out anything but more or less general platitudes as to the relationship of cultural, soil, or manurial conditions to quality of tea.

Such an investigation or series of investigations is for the future. In this report I have tried to indicate the present state of the question; the methods by which certain difficulties can be removed; some warnings against the probable results of continuing the use of methods now in vogue; some suggestions for making greater use of materials at hand than is now done; a discussion on the basis of $\mathrm{Mr}$. Bamber's results and my own of the relationship of the constituents of soil to quality of tea and luxuriance of the tea bush; and finally a series of notes on the special needs, manurial or otherwise, of each district, so far as I know it, in the Brahmaputra Valley. A great $^{\circ}$ many of the results may be 
applicable to other districts, but I have preferred for the moment to speak more specially of those parts of the Indian Tea area which I know best, leaving to a future date, after a separate and careful examination of the soils of other sections, the presentation of special reports on those districts.

On these lines I have divided the consideration of the subject into chapters as follows:-

(I) Physical properties of Assam Tea soils.

(2) Chemical characteristics of Assam Tea soils in relation-

(a) to luxuriance of bushes.

(b) to quality of tea.

(3) Manures available and their utility for producing-

(a) quantity of tea.

(b) quality of tea.

(4) Notes on the Tea soil of each district of Assam and its improvement. 


\section{CHAPTER II.}

\section{THE PHYSICAL PROPERTIES OF TEA SOILS.}

Before proceeding to consider the chemical needs of the Assam Tea soils, the equally important matter of their physical condition-their stiffness, the fineness of their particles, their relation to water, to heat, \&c.-must be dealt with. This is a matter which has in the past largely been neglected. Even to this day there are practical and experienced men holding diametrically opposite views as to the character of the soil best suited to tea, and the means of keeping that soil in the best condition. It should however be at once recognised that a soil may be rich in all the elements of plant food, and yet be quite infertile. "If " "roots are to develop in a healthy and vigorous manner, there must be a suitable soil climate. The conditions as to air, moisture, and temperature within the soil are quite as essential for vigorous plant growth as are the corresponding conditions in the atmosphere above." * It is, in fact, becoming more and more abundantly clear that one cannot judge entirely the value of a soil from a chemical analysis-its physical properties will possibly do more to determine, in the first instance at any rate, its fertility than its chemical composition.

\section{HISTORICAL NOTES.}

What then are the physical conditions of soil which have by actual experience been shown to be of most value for tea? The early writers were inclined to state that almost any type would be satisfactory, and in the tea boom in the sixties an enormous area of quite unsuitable land was put out. But commencing from Colonel Money in 1870, a very correct idea seems to have been given of what was required. Money wrote, "a light sandy loam is perhaps as good a soil as any out of the Himalayas. It ought to be deep, $* * *$ if deep enough for the descent of the taproot, say 3 feet, it matters not much what the subsoil is, otherwise a yellowish red subsoil is an advantage. This subsoil is generally a mixture of clay and sand. Where the loam is of a greasy nature (very different to clay), with a mixture of sand in it, it is superior to the above, for it has more body." Colonel Money was, however, entirely mistaken in imagining that the subsoil below 
3 feet deep was of no importance. It is, as I shall show later, a very important factor in determining the suitability of land for tea, He goes on, "to be avoided are stiff soils of every kind, as also those which, when they dry, after rain, cake together and split. Avoid also black-coloured, or even dark-coloured earths. All soils good for tea are light-coloured. If, however, the dark colour arises from decayed vegetation, that is not the colour of the soil, and, as observed, vegetable matter is a great advantage." The instruction given as to the colour of soils (especially as the dark colour is almost always due to vegetable matter) is delightfully vague, but apart from this, the general principles laid down by Colonel Money are admirable.

A writer in the Tea Cyclopadia (1882) gives his views as follows: " $* * *$ an essential feature of a good tea soil will be porosity and friability down to a depth of at least five feet. If a heavy and impermeable clay stratum intervenes above that depth, the rootlets of the tea plant will be unable to overcome the resistance offered and will spread horizontally: the plant will become more or less a surface feeder, and will be easily affected by droughts or extreme cold. If such a soil is on a level, the evil will be increased by the presence of stagnant water, an invariable result of a clayey stratum in the subsoil "More valuable advice could not be offered to-day, and one can only wish that it had been more taken to heart in laying out many gardens.

Long experience since the time at which these extracts were written has confirmed, as I have said, their substantial correctness, and one may now look upon it as absolutely settled that for its greatest luxuriance tea requires (1) a loose friable soil, (2) a deep easily penetrable subsoil, (3) a soil whose water-level approaches the surface at no time of the year, and yet possessing a moist subsoil at all times of the year. If these conditions do not exist in a garden, it is our object in this chapter to show how in some measure they can be produced.

\section{CAUSES OF THE FRIABILITY OF SOIL.}

The looseness or friability of a soil may be produced by various causes. In the simplest case the soil itself consists of little else than large particles, that is to say, it is a coarse sand. The following physical analyses of three soils show how this factor will 
account for many soils doing excellently with comparatively little culture. All are Tea soils.

On No, I the Tea does very well and gives tea of medium high quality and does not need much cultivation.

On No. II the Tea also does excellently, but requires deep and heavy cultivation.

On No. III the Tea lives, but does not yield at all well, nor do the bushes flourish, as the soil is so fine as to cake together after every rain shower.

All stones larger than $\frac{1}{16}$ inch were removed previous to the analyses.

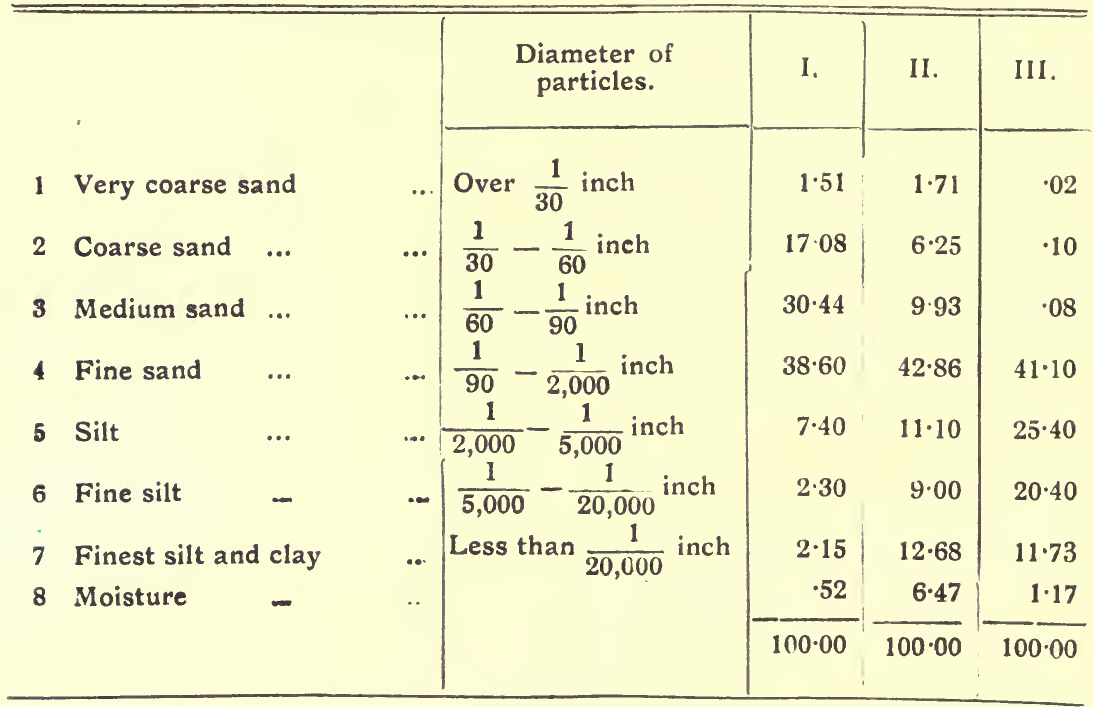

The difference is at once seen. It may be considered roughly that the particles down to $\frac{1}{2} \frac{1}{\delta \sigma}$ inch in diameter make the soil looser, while those below sol $\frac{1}{\sigma} \sigma$ inch make the soil stiffer. We have thus :-

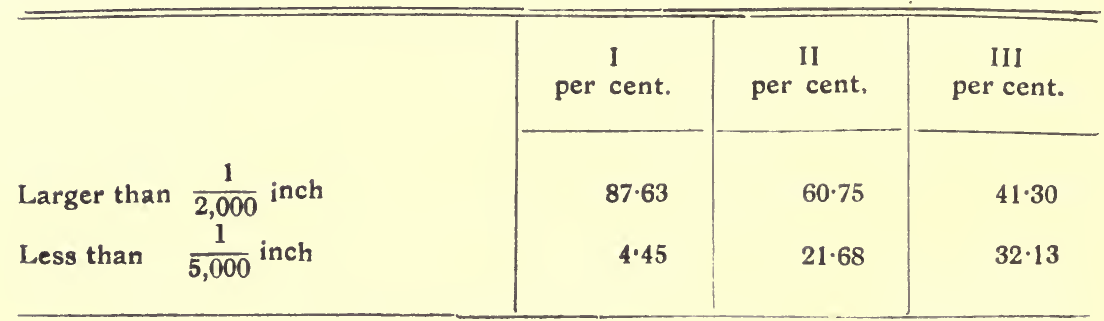

Taken in connection with the fact above stated that in No. I the tea is naturally luxuriant, in No. II a large amount of cultivation 
is necessary to make it so, and in No. III no amount of cultivation gives real luxuriance to the bushes, these figures form a strong argument in favour of a light fairly coarse sandy soil being the condition preferred by the tea plant.

I will quote another example. The figures which follow refer to two adjacent gardens in the Dibrugarh District, both good ones and giving good tea, but the first of which is and has always been more luxuriant than the second. Chemically the analyses are almost identical, but the size of the particles is quite different.

\begin{tabular}{|c|c|c|c|c|c|}
\hline \multirow{10}{*}{$\begin{array}{l}1 \\
2 \\
3 \\
4 \\
5 \\
6 \\
7 \\
8\end{array}$} & \multirow{10}{*}{$\begin{array}{l}\text { Very coarse sand } \\
\text { Coarse sand } \\
\text { Medium sand } \\
\text { Fine sand } \\
\text { Silt } \\
\text { Fine silt } \\
\text { Finest silt and clay } \\
\text { Moisture }\end{array}$} & \multirow{10}{*}{$\begin{array}{l}\cdots \\
\cdots \\
\cdots \\
\cdots \\
\cdots \\
\cdots \\
\cdots\end{array}$} & & \multirow{2}{*}{$\frac{\begin{array}{c}\text { I } \\
\text { Very luxuriant tea. } \\
\text { per cent. }\end{array}}{5 \cdot 27}$} & \multirow{2}{*}{$\frac{\begin{array}{l}\text { II } \\
\text { Less Luxuriant tea. } \\
\text { per cent. }\end{array}}{1 \cdot 10}$} \\
\hline & & & & & \\
\hline & & & .. & $8 \cdot 23$ & 3.05 \\
\hline & & & .. & $12 \cdot 83$ & $7 \cdot 24$ \\
\hline & & & & $45 \cdot 30$ & $43 \cdot 20$ \\
\hline & & & & $18 \cdot 30$ & $31 \cdot 70$ \\
\hline & & & & $5 \cdot 70$ & $9 \cdot 20$ \\
\hline & & & ... & $3 \cdot 10$ & 3.66 \\
\hline & & & & $1 \cdot 27$ & $\cdot 85$ \\
\hline & & & & 100.00 & $100 \cdot 00$ \\
\hline
\end{tabular}

Thus we have again-

Larger than $\frac{1}{2,000}$ inch

Less than $\frac{1}{5,000}$ inch

\begin{tabular}{|r|r|}
\hline $\begin{array}{l}\text { I } \\
\text { per cent. }\end{array}$ & $\begin{array}{c}\text { II } \\
\text { per cent. }\end{array}$ \\
\hline 71.63 & 54.59 \\
8.80 & 12.86 \\
\hline
\end{tabular}

While it would have been impossible to explain the difference between the two gardens on chemical grounds, yet this determination of the size of the particles in the two cases at once made clear the cause of the difference in luxuriance.

USE OF SAND TO RENDER SOIL, FRIABLE.

Among other means suggested for bringing about this looseness of the surface soil, the addition of sand has been indicated to me by. more than one planter, and no donbt the beneficial effect of much of the top-dressing done on stiff soils in recent years has been, not the result of the intrinsic richness of the material applied, but rather 
the effect of the sandy nature of this material, put on in large quantities, on the texture of the soil. One or two striking cases of this have been brought to my notice. In one case a distinctly rich top-dressing soil was applied to a stiff clayey soil, but as the top-dress. ing soil itself was likewise very clayey, to the surprise of all concerned practically no benefit was noticed. In another district, a top-dressing soil submitted to me was not really rich-but sandy-and hence on a heavy clay soil showed some beneficial effect the following year.

Nevertheless, I cannot recommend the application of mere sand as a rule to land to make it lighter, and it always makes one shudder at the waste when one sees mere sandy subsoil without any other value being lifted on to the top of land as top-dressing. The dressing is very expensive, it adds nothing which is itself of vital importance to the soil, and it is only more or less temporary in character. There are, I think, other means of obtaining a friable soil less costly, and more effective than the plan used, I am afraid, in many places during the past two or three years, of putting even several inches of sand on the surface of the soil.

\section{TILTH.}

But the soil may be friable without the particles being of large size, as in the above cases. During the growing season one may say that it always is friable on a well-conducted English farm, though this may be composed of a tenacious clay soil, - and this condition of friability is known as "tilth." Without it, is almost impossible to grow any crop well, tea not excepted, on many soils, and the more perfect it is the more luxuriantly, other things being equal, will the crop grow. This favourable texture is due to the formation of compound particles in the soil. One may regard a soil as being composed of a mass of particles of all different sizes, and there are constant tendencies for these to form themselves unto groups, and other causes tending to keep them separate. The more the former predominate the more the soil will approach a coarse soil in type, and hence be more friable, and more suitable for tea : the more the latter the less valuable will the soil be for our purpose. In fact it may be said that a soil in good "tilth," if this tilth can only be retained (even if its particles are not so coarse as those given above as very suitable), represents the very best condition of surface soil for growing tea. 
METHODS OF PRODUCING TILTH.

In temperatề climates this condition is brought about principally through the agency of frost. To this agent we cannot appeal here, but we have other means almost equally effective. Mere exposure of the turned-up soil to varying temperature and to varying conditions of moisture improves the tilth worderfully, provided that enough rain does not fall to cause it to puddle again. This is one of the principal reasons for deep-hoeing the garden in the autumn, especially in stiff lands. By exposure of the soil, as turned up, to the weather, it gradually takes on a more friable condition, and at the com. mencement of the following season is capable of forming a loose soil which will be deeper or shallower according to the depth of the autumn hoe. Hence this deep-hoeing should be done as soon after the rains are over as possible, so long as it will not get trampled down again by people plucking, and as little as possible by people pruning.

A second method by which the tilth of a soil can be improved is by the continuous presence of the roots of plants. To have a crop of annual or perennial plants continually on the ground is, however, out of the question in the case of tea, and I only mention the method here as a means of making land ready to plant again if formerly abandoned, if such is desired to be done. Such land should be cleared, planted, say, with sensitive plant (Mimosa pudica) or something similar which requires no attention, left for a couple of years, ploughed up and planted. The tilth will be found to be very much improved.

But by far the most generally applicable means of improving the tilth of a stiff soil is by the addition of organic or decaying vegetable matter. Green manuring affords the simplest and cheapest means of doing this, and I have reports from planters in hand stating that its effect, when put in on my recommendation, has been very great in this sense. I shall deal with the question of green manuring in another chapter, but it is necessary here to call attention to the marvellous increase in the friability of a stiff soil following a crop of "Mati kalai" (Phaseolus aconitifolius) hoed into the land.

Instead of utilising a green manuring crop for adding organic matter to the soil, the same may be done by burying jungle, or by 
burying prunings, but here the danger, at any rate in the latter case, is very great of spreading blights over the garden, and one cannot recommend it as a system and as a rule. In bringing jungle into the garden for burial there is danger likewise of spreading an enormous number of weed seeds, which will grow most vigorously, and take many years to eradicate. Nevertheless, there are cases where the burial of jungle will be advisable, and of these we will treat in another chapter (IV).

One more method of increasing the tilth in a soil remains, but it should be used sparingly. Lime has a very powerful effect in forming compound particles in a soil, and the improvement of clay soils by this means is a method well known in agriculture. Lime however seems to be of little benefit to the tea plant, and if much is present it may do positive harm. I doubt whether there is much opening for its use as a means of dealing with stiff tea soils in Assam.

\section{DESTRUCTION OF TILTH.}

Tilth, however produced, can be speedily destroyed. Careless cultivation of stiff soil when wet is fatal to its continuance; as under these circumstances the conditions of the pugmill of a brick yard are more or less produced. Cultivation where there is a difficulty in obtaining good tilth-as there is in Nowgong, in parts of Jorhat, in many gardens in Sibsagar, in some places near Sonari, \&c. \&c.- should be done only when the soil is half dry or more, and at any rate never during heavy rain, as is often actually the case. Long standing of water on the surface will also ruin the tilth-an important argument in favour of drainage, which would remove this standing water in the vast majority of cases.

\section{DEPTH OF TEA SOILS.}

The second matter in connection with the physical nature of the soil of especial importance for tea is its depth. Here the greatest mistakes have been made. I have seen tea growing in Assam with less than 2 feet of soil separating it from a layer of solid rock, and it could neither get through, nor round, nor by the obstacle-and hence at every drought it nearly died, and one wondered why it continued to exist at all. In other cases a friable surface soil lays over a hard clay subsoil,--and still has been put 
out to tea. The most surprising point of all is the fact that where tea is being put out no trouble has often been taken to ascertain the nature of the subsoil.

\section{CHARACTER OF THE SUBSOIL.}

I cannot too strongly insist on the character of the subsoil being known by every manager for a good distance down. A distinguished American authority, * speaking of a district which, while absolutely differing from that of Assam in many things, yet resembles that of the lower valley in some respects, writes relative to this matter. "It cannot be too strongly insisted upon that in our *** climate farmers should make themselves more thoroughly acquainted with their subsoil sown to the depth of at least four, but preferably six or eight feet." This may be said to be practically a necessity of practical agriculture where a large part of the root action is to be carried on at a good depth. To take an example. I have in my mind one or two gardens on the North Bank of the Brahmaputra which are composed of fine light sandy loam, but within a few feet of the surface there is a bed of impermeable clay-blue in colcur and stinking in character. For some years the tea does well. Then it receives a check, and sometimes when not more than ten years old begins to deteriorate. The roots have, in fact, touched the above clay layer, heen thrown back into the comparatively shallow good soil, the plant food in this used up, and deterioration commences. The result is inevitable on such a soil, and I look upon these gardens put out on sand overlaying clay of this sort as probably likely to be as short lived, without manure, as any in the valley.

Undoubtedly the best circumstances are those in which a subsoil of the same physical type as the surface exists for a great depth. Such is one of the reasons which gives its pre.eminence to the Doom Dooma ridge. There we dug eighteen feet, and the soil was still the same--somewhat sandier perhaps--but of the same general character nevertheless. Such is also the Tezpore Bankthe soil seems practically of the same character right down to the ordinary patta level. The same occurs in parts of Jorhat and no doubt in many other places. But such can only be the case under exceptional circumstances and especially in very sandy soils. In 
almost all other cases there is a strong tendency for the subsoi] to be stiffer than the topsoil in rainy districts, and this tendency will be likely to have the most pronounced effect in these districts, where the rainfall is medium and not very excessivesay from sixty to eighty inches. Apart from occasional deep cultiva. tion-or really on account of constant cultivation to the same depththere results a hard layer at a distance from the surface varying with the depth of the cultivation. This layer is known in England as "pan," in America as a "plowsole." In many cases in already exists before the land is cultivated at all, owing simply it the effect of the rain washing the fine particles into the subsoilbut the stiffer the soil the more liable such a "pan" layer is to be found. So hard does this sometimes get in the arid districts of America, that in order to break it up dynamite is regularly usedand were the weather always dry in Assam as it is in the cold weather, I know gardens where this would be almost the only method of breaking it up here. The effect of such a hard "pan" is to prevent the roots descending, and hence to keep them in the surface layer of the soil, which means that their range for water is restricted, as well as their range for food. Figures I \& II (repeated from my report to the Indian Tea Association on Red Rust in Tea) show this condition of things exceedingly well. Hence plants on land like this are starved for want of water, and also ultimately for want of food; are subject to drought and yet feel the evil effect of excess of rain; and are, in consequence of these things, subject to blights of many kinds, of which the worst is probably Red Rust, though these are the conditions, in Assam at any rate, under which Red Spider is seen in its most serious form. Further such a "pan" becomes the cause of the retention of a very large amount of standing water in the subsoil which is not required, and causes this subsoil to be non-aerated, to become rapidly sour, and from every point of view unfit for the penetration of the delicate tea roots.

\section{SURSOIL DRAINAGE.}

Since, however, subsoil root development is necessary for the culture of luxuriant tea (except in few exceptional cases which hardly concern us here and now), by some means or other this hard "pan" must be got rid of, partially at any rate, where it exists, and prevented from forming where it has not been yet produced. As I 


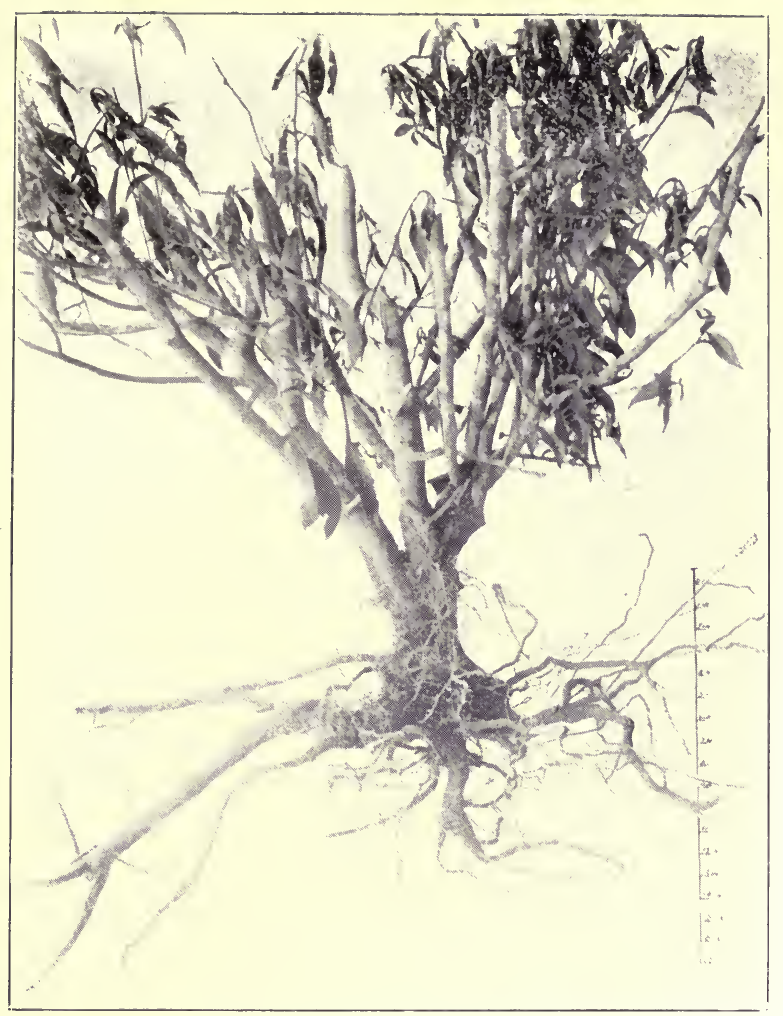

FiG. I. - Bush shewing formation of roots on hard pan subsoil.

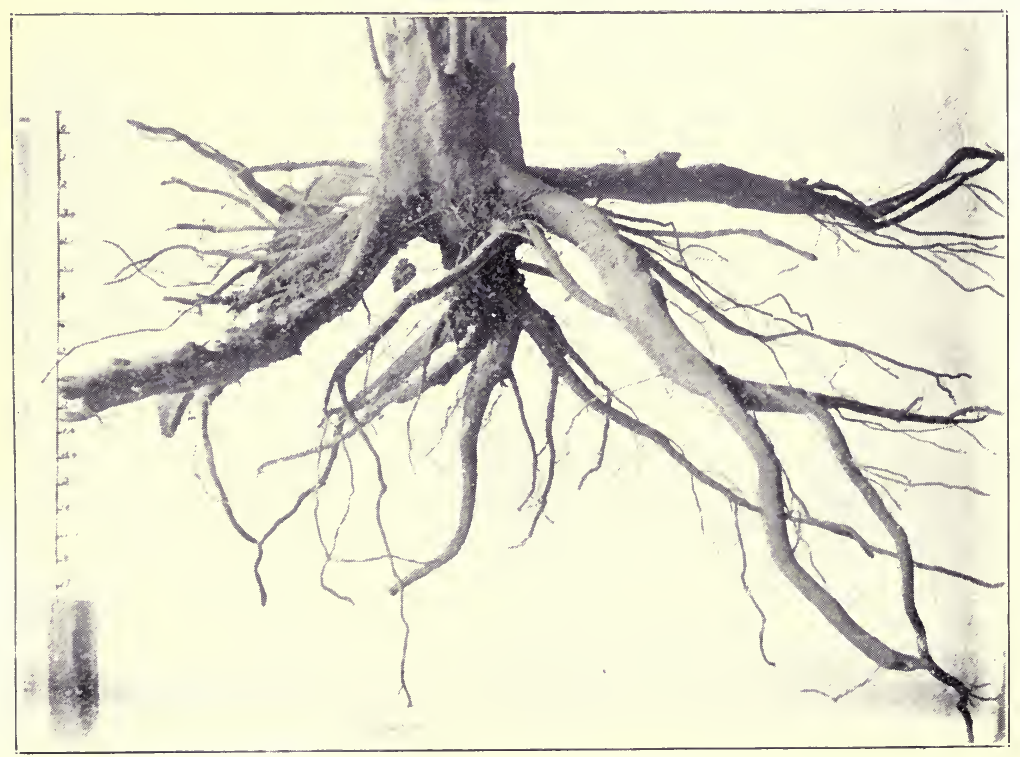

Fig. II,-Roots of bush on hard pan subsoil. 

have already stated in another of my publications, the primary means for bringing this about is by means of subsoil drainage. It is not my intention here to lay down again in detail the principles on which such drainage should be carried out. The matter has been very fully dealt with from a scientific point of view in Dr. Watt's "Pests and Blights of the Tea Plant," (pp. 66.94), and with the general principle he lays down there I am in perfect agreement. It may be well, however, to insist that drains are not intended to be channels into which the water runs from the surface. Every drop which does so is so much evidence of the unsuitability of the drains, and all should run through the soil and not over it to get into them. In land with a stiff subsoil such as I am now considering the drains should be at least 3 feet deep (often far more than this if they are in sand overlying clay-for then they must go down to the clay), as narrow as possible, banked upon each side if on flat land, or on the upper side if running across a slope, and never with a fall of more than one in three hundred. Such drains as these tend to form a deep soil. There is a simple charnel for the water to run away, and they absolutely prevent if properly made, the rise of the ground water above their own level.

Subsoil drains form the fundamental method of deepening a soil, and of making it penetrable to plant roots to a greater depth. There are other means which taken together have a similar effect, but none of these-nor all together-can replace a rational drainage system.

\section{VERY DEEP CULTIVATION.}

Very deep cultivation is one of these methods. The whole question of very deep cultivation and its value has been so much discussed in recent years that it may be well to consider here its meaning and purpose-and so ascertain where and where not it is profitable to carry out extremely deep hoeing.

Deep cultivation where applied in tea culture appears to have three objects in view-(1) the production of a layer of loose soil on the surface which will retain the moisture during the very dry season from November to March, and which will do this better the thicker the loose layer is; (2) the prevention of the formation of trunk roots branching in any direction from the bush above the depth to which the cultivation penetrates; $(3)$ the prevention of the formation of a hard pan. 
With the first object we will deal later on. The other two may perhaps almost be considered as one, because if there was no danger of a natural hard "pan" forming and so preventing the descent of the roots in a normal fashion, there would be little need for hindering the formation of laterals in the first foot of the soil. In this matter one may so easily become too dogmatic. After visiting Tezpore one would be inclined to say that the presence of lateral roots in the first 12 or 15 inches of the soil is distinctly inadvisable, and for that soil with its hard though very good subsoil one would be right. On the other hand, where there was perfect freedom for the roots to descend to any extent, and where no tendency to form a shallow root system occurred, as on the sandy parts of the Doom Dooma ridge, the question as to whether the laterals should be formed at 6 inches, at 9 inches, at 12 inches deep, or even lower, is really a matter almost of indifference. For, primarily, the object of preventing the formation of trunk lateral roots near the surface is to force the roots as a whole to penetrate the hard subsoil or hard pan which already exists. Where, therefore, will the exceptionally deep cultivation which has formed so marked a feature of planting at Tezpore be necessary or advisable? Simply and solely where there is a hard subsoil, a hard "pan," or where there is a tendency for such hard subsoil or hard pan to form. In other places an ordinary "double hoe" should be enough every year, and even where the excessive 15 -inch to 18 -inch hoe is given, it should only be used once in three years at the most.

On soil such as I have described with a tendency to the formation of a hard pan subsoil one may consider deep cultivation as absolutely necessary in all new land and young tea. To save money by avoiding what appears to me to be an obvious duty is a suicidal policy, and I cannot urge too strongly that when one is forming the plant's root system during the first three years of its life, the war on all lateral root growth near the surface should be continuous. By this means a kind of root such as is desired will be formed, and little difficulty will afterwards be found in retaining it. A very different problem is shown by old gardens on these hard subsoil lands which have already grown and been used for many years without any effort to produce the best class of roots. Is it worth while in these cases to carry out very deep cultivation at all costs, 
though it may mean the destruction of a large part of the plant's existing root system? The result in some cases in which this has been done have not been very encouraging, and it generally means that the first effect is that the plant is poorer and yields less than before the treatment commenced. This is only to be expected, for by destroying the lateral roots in the surface soil one removes the trunks up which the food collected by its fine rootlets pass. But the second year after such change of system the bushes recover and ultimately are much the better of the treatment, always provided (1) that the bushes were not previously too weak, too old, and too deteriorated to recover from such a severe shock, and (2) that the subsoil is in a fit state for the penetration of the roots. By being in a fit state, I mean that water is absent and drains have been present long enough to make it permeable to tea roots by removing a great part of finest silt which formerly cemented the mass.

It is also essential that such a radical change of system be not undertaken at the same time as the plot is collar-pruned. If collarpruning is anticipated, the deep cultivation should take place not less than two years previous if such deep cultivation is a new policy; if hard cutting only is to be gone in for, then the previous year will probably be sufficient. To violently hack at roots which have probably been essential parts of the plant for many years and to cut down to the ground together on a soil which itself is probably not the most suitable for tea, is decidedly consonant neither with reason nor science. Once however such a deep cultivation as part of the garden's system has been inaugurated, and the new root system has got into working order, the cultivation may, I think, be carried on in the regular scheme with little regard to the pruning of the bush.

TRENCHING VERSUS VERY DEEP CULTIVATION.

Is there, however, any other method of driving the roots into a lower layer without adopting such an expensive and drastic method as that just described? By going back in part to what was a method of cultivation many years ago, but which has now, 1 believe, long been abandoned nearly everywhere, I think this may be done. According to Mr. Bamber ("Chemistry and Agriculture of Tea"), it was in his time the custom to fill the old drains with prunings and dig fresh ones between the next rows. While I do not believe in such a system of 
altering the drainage channels, I see no objection to deep cultivate between alternate rows each year by digging a trench and filling in. An ordinary deep hoe would be made and the soil thrown out into the row of bushes, and then a deep hoe would be done at the bottom of the trench, say one kodalli wide, thus formed, and then the whole of the surface soil would be drawn back into the trench. We should thus have a trench hoed between every second row of bushes during one season, between the remaining rows in the second season, and across the other way of the land during a third and fourth season in a similar manner. By this means, - for, made in the manner I suggest, the trenches would be 18 to 24 inches deep,- the roots would be forced into a lower level almost, if not quite, to the same extent as if deep cultivation were resorted to, and the cutting of the roots would be reduced to a minimum.

Green organic matter or farmyard manure might well be put into the trench at the same time to attract and feed the descending roots of the bush. I have seen the method above described working out very well, and I am confident that in many situations, where a very deep 15 -inch hoe all over is next door to an impossibility, such a method as I described would be found of considerable benefit and lead to the formation of a root system descending far more than would otherwise be the case. Cut in the way I suggest, and with blind ends, they would not either interfere with the regular drainage system. There seems, however, a difficulty in dealing with slopes on which the lines of plants do not run straight across the slope, nor yet up and down, but diagonally. This also forms a difficulty with draining itself in such circumstances, and the habit of so planting is strongly to be condemned: A way out of the difficulty may perhaps be found on the spot, but it is essential that trenches such as I have suggested do not become drainage channels.

\section{OTHER METHODS OF BREAKING UP HARD PAN.}

There are one or two other methods of dealing with a hard or hard pan subsoil. The first of these is the planting of trees, and of course a tree which is itself beneficial to the tea is to be preferred if it answers the purpose in view. What is wanted is a tree with a deep tap root and deep lateral roots which go right through the hard layer and so to a certain extent break it up. One would naturally at the first onset suggest the "Sau" tree (Albizzia stipulata), but on 
a soil such as we are considering, the root development seems almost as restricted as that of the tea, and it does not seem to have the power to penetrate the stiff layers. Other leguminous trees might do better, as the "Koroi" (Albizzia odoratissima) or the "Medeloa" (Dalbergia assamlca), but I have no definite experience. I should like to have these tried on such a soil. Though not leguminous, the Silver Oak (Grevillea robusta) might answer this purpose, especially we know that it does no harm to the tea among which it is grown.

The last method of influencing and breaking up the subsoil is by means of annual green crops grown among the tea. I am not here going into the question of green manuring, but the value of plants as a means of breaking up of the subsoil should be kept in view in any choice of those suitable for green manuring. At present we have no knowledge of what plants would be suitable. "Mati Kalai" (Phaseolus aconatifolius) only seems, on such heavy soil, to penetrate ten inches deep - which is a isolutely no good for this purpose-and none others have, to my knowledge, yet been tried. Some plant suited to the conditions undoubtedly exists, ${ }^{*}$ and it would well repay experiment to find it Possibly one of the lupins might be found to answer, but it demands trial to find whether under Assam conditions they retain the long subsoil roots which are one of their special features elsewhere.

INFLUENCE OF THE WATER IN THE SOIL.

We now come to the relationship of the moisture content of the soil and of the water level in the soil to the luxuriance of the tea. A large amount of water continually present is of course absolutely essential, by far the greatest part of the plant's weight being formed of this substance. Thus green crops as à rule contain 60 to 80 per cent. of water, and including all the woody parts the percentage in a whole tea bush is probably not much below fifty. Practically the whole of this is absorbed through the roots, and the leaves may be said to take no part in providing it, but are, on the other hand, getting rid of it at a great rate through the whole period of growth. The following figures give an idea of the amount actually evaporated by the leaves of a single crop during its growth. A crop of meadow hay dissipates about 527 tons of water per acre during growth.

*A wild variety of "Kalai"-Phaseolus velutinus - has been recently sent to me from Nowgong, whose roots are 3 to 4 feet long. This might possibly prove useful in the above sense. 
Wheat would give off about 260 tons per acre. Other crops would give off corresponding amounts. It appears that cruciferous crops like mustard and rape probably give off more than any other class of plant. But nevertheless the amount of evaporation from the I taves of a tea bush must be very great, and probably accounts for the absorption of water corresponding to a good many inclies of rainfall during the season.

It might be thought, however, that such questions were entirely unpractical atd beside the point in the tea districts, where the necessary rainfall is so extremely high as to make it appear that, prim $\hat{a}$ facie, a tea planter should be independent of these considerations. Doubtless such is the case in most of the Upper Assam districts. Away from these districts, however, the conditions are quite different, for here, although the rainfall is very great, yet it is so unevenly distributed, that while at one time the great question may be removal of water with the greatest speed possible, yet at another, really only a few weeks later, the cry goes out that the tea plants are dying for want of moisture. We have, in fact, a combination of a rainy and an arid district, of a high rainfall and a scanty water-supply, of rain in more than sufficient amount at one season of the year, and of long droughts, often lasting six months, with hardly any appreciable rain, for the remainder. It is necessary to consider therefore both the means of removal of excess of water in the rains and the conservation of the precious soil water supply in the dry weather.

\section{REMOVAL OF WATER BY SUBSOIL DRAINS.}

The removal of the excess of soil water, and especially of subsoil water, is the most important and primary function of subsoil drains, whatever other purpose they may incidentally serve. It is not often enough recognised that the proper object of drainage of the kind used in tea gardens is not so much to take the water falling on the surface as to prevent a rise in the level of the ground water, and that hence the water ought to rise into the drains from below to a greater extent than it soaks in from above. Be this as it may, and the point is not one of great importance, it is now generally appreciated that the presence of ground water at a certain depth is an indication that such depth is the absolute limit of the depth of tea root development. Of course those soils in which the water level is so far below the surface as to cause no 
anxiety as to whether the growth of the tea roots will be interfered with, are in far and away the best position in this matter, but wherever the water level approaches within measurable distance of the surface during the rains, it must be recognised that its highest level represents the usual limit of the root development, a limit which cannot be increased except by deepening the drains or by getting rid of the ground water by another method.

If the drains reach the ground water at 3 feet, 3 feet 6 inches, or 4 feet, then, though tea grows, and in many cases glows very luxuriantly, the depth is not such as to produce a permanently healthy plant, and certain diseases like canker (Nectria camellice, Watt) are probably very closely connected with this restricted root and with the presence of the ground water. In such cases the only means available of increasing the dryness of the soil or subsoil in the wettest part of the year is by deepening the drains to the utmost, an operation essential under such circumstances.

\section{CONSERVATION OF SOIL MOISTURE.}

We are not in quite such a helpless condition when the question of the conservation of soil moisture during the periods of drought is to be dealt with, and yet, in spite of this, the damage annually done by the drought in some districts is very great, and this principally occurs where root development is only shallow as a result of hard subsoil or a ground water level near the surface as above described. There are probably no districts in India liable to be worse affected by droughts than the bheels of Cachar and Sylhet, where the ground may become so dry as to actually burn bushes and all, and yet here the creation of the garden has been only possible by draining in a thorough and monumental fashion unknown elsewhere, and where, in the strictest sense of the word, the depth of the drains indicate the possible depth of the root development of the plant.

That crops with shallow roots will be likely to suffer from drought would be naturally to be expected, but it is not so generally known how even annual plants grown in the cold weather usually protect themselves from the drought. Such crops as mustard, mati kalai, etc., grown in native culture at that time of the year, naturally form a much deeper root than when grown at other seasons, as for instance for green manuring in April, May and June,-and it 
may generally be said that very deep root development is characteristic of the weeds and crops of dry lands and dry seasons every. where.

Under such conditions it is essential to conserve what soil moisture is retained at the end of the rainy season. Of course the retentive power of the soil itself varies very much. Other things being equal, a sandy soil will retain least and a peat soil the most, the amount retained increasing on the one hand with the fineness of the soil, and on the other with the amount of organic matter (or decaying vegetable matter) it contains. Thus to take an American example among tobacco soils given by Whitney (U. S. A. Department of Soils, Bulletin 3), we have-

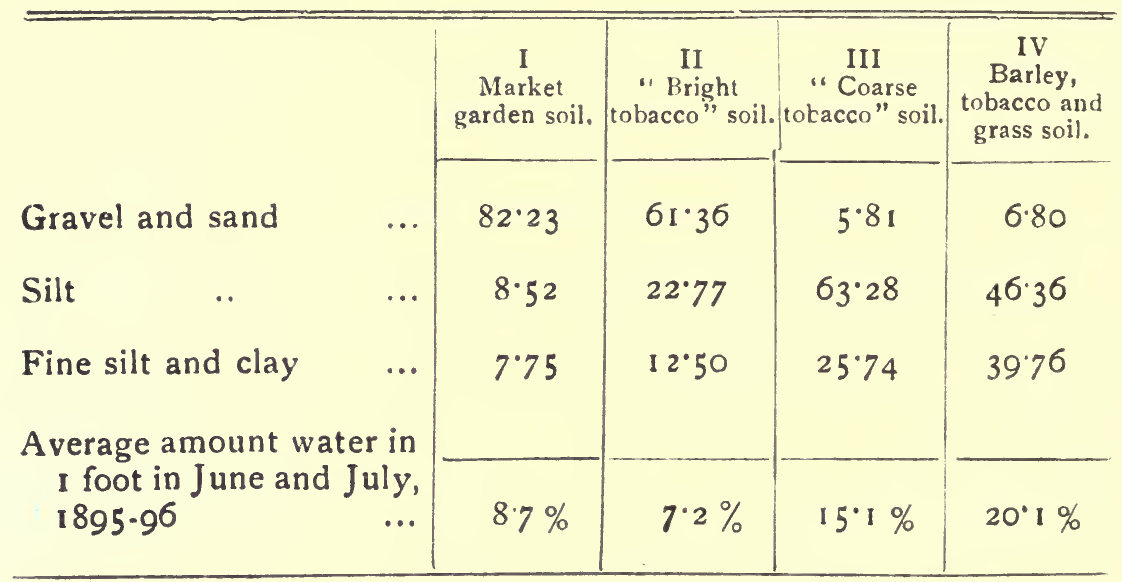

These figures may however in themselves be somewhat illu. sive, because a clay soil, though it naturally retains a much greater proportion of water than a sandy soil, possesses part of it in such a form (termed hygroscopic), that it is not available for vegetation. Thus, for instance, taking again some American results (R. H. Loughridge. Report, California Experiment Station, 1897-1898), we have for some soils growing oranges.-

\begin{tabular}{|c|c|c|c|c|c|c|c|}
\hline Yellow Loam Soil & 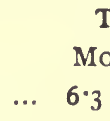 & $\begin{array}{l}\text { TAL } \\
\text { STURE. } \\
\text { er cent. }\end{array}$ & $\cdots$ & $\begin{array}{l}\text { Hyar } \\
\text { Mo } \\
3 \cdot 1\end{array}$ & $\begin{array}{l}\text { SCOPIC } \\
\text { TURE. } \\
\text { r cent. }\end{array}$ & $\cdots$ & $\begin{array}{c}\text { USEFUL } \\
\text { MOISTURE. } \\
3^{\cdot 2} \text { per cent. }\end{array}$ \\
\hline Dark Red Clay & . 154 & " & $\cdots$ & $8 \cdot 6$ & " &.. & $6 \cdot 8$ \\
\hline Black Clay (adobe) & .. 10.0 & , & ... & $10 \%$ & , & $\ldots$ & none. \\
\hline
\end{tabular}

Here it is evident that the black clay soil is, from a plant's point of view, perfectly dry, though really it contains far more 
water than the yellow loam. In spite of this, however, one may say that as a general ruie a stiffer soil retains useful moisture better than a sand, and a soil full of vegetable matter better than either.

There is however such a very close relationship between the luxuriance of a plant and the amount of useful moisture contained in the soil, that no effort should be spared to retain it in the land if an early spring growth is wished. The following examples, taken from the same source as the last, illustrate very well this point.

\begin{tabular}{|c|c|c|c|c|c|c|}
\hline \multicolumn{2}{|c|}{ Crop. } & \multicolumn{2}{|l|}{ Soil. } & $\begin{array}{l}\text { Condition of } \\
\text { trees. }\end{array}$ & $\begin{array}{c}\text { Percentage } \\
\text { useful } \\
\text { moisture. }\end{array}$ & $\begin{array}{c}\text { Useful } \\
\text { water Tons } \\
\text { per acre. }\end{array}$ \\
\hline Plums & $\ldots$ & S Red loam soil & ... & Poor fruit ... & 0.5 & 40 \\
\hline & & I Grey sandy land & $\cdots$ & Good fruit ... & 1.8 & 144 \\
\hline Peaches & $\ldots$ & Red soil & $\cdots$ & Poor & 1.8 & I 44 \\
\hline & & ( Red son & $\cdots$ & Good & 32 & 256 \\
\hline Apricots & $\cdots$ & Gravelly loam & $\cdots$ & $\begin{array}{l}\text { Excelient } \cdots t \\
\text { Poor }\end{array}$ & 9.2 & 736 \\
\hline Almonds & & $\int$ Loam & $\ldots$ & Leafless & $\begin{array}{l}19 \\
14\end{array}$ & $\begin{array}{l}152 \\
112\end{array}$ \\
\hline Rninonds & $\cdots$ & | Loam & $\ldots$ & New growth & $2 \cdot 6$ & 208 \\
\hline
\end{tabular}

This being the case, how can we retain the precious water in the soil so that when the plant begins to put forth its new spring growth, and when the sap begins to rise again, there shall, after all the winter's drought, remain sufficient moisture in the soil to give the greatest luxuriance? First and foremost among methods for conserving the soil moisture is the autumn deep hoe. In ordinary land with a com. pacted hard surface the evaporation is very great, and takes place right from the underlying layers of the soil as well as the surface. On the other hand, if there exists a layer of loose soil on the surface, this gets dried itself, but then acts as a very effective covering protecting the lower layers from further evaporation. It is analogous, to take an illustration, to the familiar fact that "while a dry brick (corresponding to the hard surface soil without cultivation) will suck a wet sponge dry, a dry sponge (corresponding to the loose surface soil) is unable to take any appreciable amount of water from a wet brick." Determinations of moisture in the soil after drought, underneath a cultivated and uncultivated surface, show very strikingly the fact that the soil does actually remain wetter under a cultivated and loose surface (Californian Report, loc. cit.). 
Cultivated

Water in 6 feet

of soil ..
Per cent. Tons per acre.

$6 \cdot 3$

756
UnCULTIVATED.

Per cent. Tons per acre

This shows a difference of 244 tons per acre of water after drought as a result of cultivation, and the amount of water is still further increased by deeper cultivation. In English and western climates generally it is considered that 3 inches of pulverised soil is enough to give protection against drought. Here I fancy this will be found altogether inadequate, where there is a drought lasting always, in the districts of which 1 speak, four months, and often six months or over. It is a fact, however, that the deeper the layer of toose soil the greater protection it affords from evaporation. Owing to the non-existence of such records for India, I again give some figures obtained in California. The figures give the moisture in a four foot depth of the land.

\begin{tabular}{|c|c|c|c|c|c|c|c|}
\hline \multirow[b]{2}{*}{ Alluvial Soil } & \multicolumn{3}{|c|}{$\begin{array}{l}\text { No cultivation. } \\
\text { Per cent. Tons per acre. }\end{array}$} & \multicolumn{4}{|c|}{$\begin{array}{l}3 \text { inches cultivation. } 6 \text { inches cultivation. } \\
\text { Per cent. Tons per acre. Per cent. Tons per acre }\end{array}$} \\
\hline & $\ldots$ & $4 \cdot 4$ & 354 & $5 \cdot 4$ & 430 & $6 \cdot 3$ & 504 \\
\hline Alluv & $\ldots$ & & & $5 \cdot 3$ & 422 & $8 \cdot 5$ & 662 \\
\hline
\end{tabular}

Such figures as these afford the very best argument to show that the autumn deep hoe should by no means be neglected or scamped; that the finer and looser the surface can be made the better for the preservation of the water, and the deeper it can be carried out the more effective the protection will be ; and further, that the least possible amount of trampling on the soil should take place afterwards, in order that the loose layer produced by the hoe may be kept as loose and pulverulent as possible.

\section{MULCHING.}

In the districts where even this treatment is not very effective, I see no reason why recourse should not be had to the system of "mulching" the surface with jungle plants. This simply consists in covering the soil with a thin layer of green jungle or of jungle of any kind, and is exceedingly effective in keeping in the water, as the following figures show, from results obtained in New York State. After the year's drought there remained in the soil as follows :-

Water per 100 of dry Soil per cent.

Untouched.

Surface kept stirred to

$\begin{array}{cccc}16.9 & \text { t an inch. } & 2 \text { inches. } & 4 \text { inches. } \\ 16.0 & 19^{\circ} & 19^{\circ} & 20^{\circ} 3\end{array}$

Oat straw

It is thus seen that a one inch "mulch" of oat straw was more 
effective than 4 inches of loose soil, and the excess in one foot of soil was equal to an inch of rain! Mulching of this kind is already done with nurseries in most districts, and while it would be too expensive probably to carry out over extensive areas, it might well be done on exposed pieces of land, say low teelas exposed to the sun, where the drying up effect is at its maximum. An objection has been made to me that while such mulching might be effective, it would be the means of introducing a very large amount of weed seed into the garden, and the objection seems to be valid, but the objectionable result could be reduced to a minimum by selecting the jungle to be used for the mulching of the land.

\section{SHADE FOK CONSERVING SOIL WATER.}

Water may also be effectively preserved by the shade of trees on the soil, and it may be that a small portion of the effectiveness of the sau tree may be due, not to shade in the growing season, but to shade preserving the soil water in the dry weather of the spring. Such trees should always be planted on exposed teelas facing south or south-west, and may be especially valuable on terraced land, where the effect of the sun's ray is much greater than on sloping hill-sides. For the same reason, especially in the climates which are particularly hot, it is wise to try and get the tea bushes themselves to shade the land as much as possible, and if it is not possible to obtain this shading of the soil when the tea is planted the usual distance apart, it should be planted closer to ensure that it should do so.

EFFECT OF IVEEDS ON SOIL MOISTURE.

Such are positive ways of keeping the water. Others of equal importance consist in the avoidance and removal of agencies which remove it The most noxious of these is the crop of weeds so often allowed to grow among the tea in the cold weather. Every plant growing on any land is a means of removing a certain proportion of water. Land after a crop, whether of weeds or of a cultivated plant, contains far less water than the same land which has been kept free from plant growth. To take an example. At Rothamsted (Hertfordshire, England) Sir John Lawes found that the difference between land which had been cropped with barley and the same land left fallow amounted in the middle of the 
growth of the plant to nearly ten per cent. of water on the average in the top three feet of soil, and the difference was felt to four feet deep. Now barley is only a surface-rooted crop, just like a large proportion of our weeds, and the illustration shows what great evil even surface-rooted plants may do to the water condition in the lower layers of the soil. It should therefore be laid down as an absolute rule that weeds growing among the tea after the end of the rains are dangerous, and so far as is possible should be avoided.

The same applies to green manuring crops put in in October and November. Much "Mati Kalai" has at one time or another been grown then in imitation of native culture, but one can hardly condemn the system enough, because it removes soil moisture just when it is required-and in addition, as a matter of fact, very little green matter results at that time of year from its growth. Green manures should be sown, on principle, when the land is increasing in moisture content, and hence in April or May, when rains are expected in greater and greater quantity. They then grow far more luxuriantly, give more green matter for hoeing in, and do not rob the tea plants of the water which they are needing.

\section{EFFECT OF TOO WIDE DRAINS.}

But the needed water is also often taken away from the soil by the existence of very wide drains. On one garden I have visited the drains form by far the best riding roads through the property in the dry weather, and in many others they are almost as wide. In some cases, especially where a sandy soil rests on a clay subsoil, there seems little help for this, as they continually fall in until this soil takes the natural angle of repose, but one could imagine, nevertheless, no more effective means of drying up the land, and so, to a certain extent, drying out the roots. Such drains are, if they can be helped, a mistake-and a serious one. Drains should be as narrow as possible-not more than the width of a kodalli wide if the texture of the soil allows of this-and they should, where it can be done, be so banked up at the top that the sun, with its drying action, penetrates the drain to as small an extent as can be arranged.

\section{IRRIGATION FOR TEA.}

There are, however, cases where all these means do not suffice to retain sufficient water in the soil for the best results. Such a case occurs on the bank of highly fertile micaceous sand which 
lies just beneath the Himalayas in the Mangaldai district, and which runs from this point west right into Kamrup. The rivers descending from the hills, instead of running over its surface, in great measure descend into it and form underground streams for ten miles or so, then again appearing at the southern edge of the bank in question. In the interval the ground water is often 80 to 100 feet at least below the surface, and the soil is an extremely porous sand. It will be seen that in a tract like this the lack of water might be a very serious hindrance to the growth of tea, ${ }^{*}$ and that, if irrigation were at all feasible, such a district would be one in which it would be likely to be advantageous. Some years ago, I believe, $\mathrm{Mr}$. R. N. Davidson suggested the trial of irrigation on tea nurseries in this very district, and this has proved such a success that it is now almost a universal practice on or near this bank to arrange for the irrigation of nurseries, and by this means the young plants are renderen almost independent of weather or of climate in so far as the amount of rain occurring is concerned. The value of irrigating nurseries in all districts subject to drought has now, I think, passed beyond the experimental stage, and one may almost consider it as proved that in many cases by this means a much improved class of plant can be produced for future plantings.

When the irrigation of the tea garden itself is discussed, a much larger question is, however, opened out. At first sight it seems rather paradoxical even to mention irrigation in a province where the rainfall reaches 60,80 , or 100 inches per annum, but I am not sure that it is as paradoxical as it seems, at any rate in such lands as I have just described and in regions where the rainfall is so badly distributed. The profitableness of any method of irrigation can only be determined by experiment. Of one thing I am certain. By its means both in Mangaldai and Nowgong, as well as elsewhere outside the Brahmaputra Valley, the length of the season can be materially increased. Only one experiment has, however, I believe, been conducted in this direction, and this was on the Bhutia Chang tea estate in the district above mentioned in Mangaldai. Tapping a stream three miles above the garden, the water was brought into the land by an open ditch, and finally, having reached the plot it was wished to irrigate, the water was allowed to run in furrows between the rows of tea. The effect in November last (1900), when I examined

* This has actually bappened in the spring of 1901. 
the system, was that the bushes in the section irrigated were looking much better, fresher and greener than the rest of the garden, and were giving more leaf per acre than the remainder of the property.

It seems, however, that there are only two classes of soil on which it would be likely to be of advantage. The first is a deep dry porous sand such as 1 have described, the second is a shallow soil underlaid by a hard pan layer. The former would probably be best dealt with by a system of furrow irrigation with or without ìrains as found necessary ; the latter by a method of basin irrigation (i.e., the land would be banked up round the plot and then looded) combined with deep drains. In either case a thorough hoeing would follow the application of the irrigation water. I should much like to see exhaustive experiments made in these directions in places suitably situated for obtaining irrigation water The method would only be applicable, I think, in comparatively rare instances, but where applicable would be invaluable as a supplement to a rainfall either insufficient in amount or badly distributed in season.

PHYSICAL PROPERTIES OF SOIL AND QUALITY OF TEA.

So far in this chapter I have spoken of the physical state of the soil as affecting the luxuriance of the plants: it remains to treat of it as affecting the quality of the tea. But here one touches on a' subject which has not even been broached from a scientific standpoint. Is it however reasonable to think that the physical state of the soil would have an influence? By every argument of analogy there is little doubt that its influence should be great, if not paramount. The cultivated crop most analogous to tea in many respects is tobacco. There the crop consists of the leaf, there the value partly consists in the content of alkaloid (nicotine) in the leaf, there the aroma and value is developed by a fermenting process, etc., and except that it is an annual crop, the similarity is almost perfect. In that case, however, the connection between the size of the soil particles, the depth of the soil, or the water content of the soil is essential-so essential, in fact, that it is as hopeless to attempt to grow Connecticut tobacco on the Virginia land as to grow the Pennsylvanian product in the Connecticut Valleys. In the Connecticut Valley itself, "where the soil is a heavy clay loam, or for other reasons is normally very moist, the tobacco produces a thick leaf which has considerable oil and gum in its tissues, cures a dark colour, 
and will bear sweating well, but is not well suited for cigar wrappers at present," (I 894 H.H.M.) "because light-coloured, thin-textured wrappers are in demand at this time. Upon light sandy snils the quality is very fine, the texture of the leaf is thin, and the colour is light" (M. Whitney, U. S. A., Yearbook of the Department of Agriculture, I 894). This is just one example of the close connec. tion between the quality of leaf and the physical properties of the soil.

One will be entitled, I think, therefore, to anticipate that a connection will ultimately be made out between physical character of soil and kind of tea. At present we know little or nothing Perhaps other things being equal, the deep sands fairly dry or at any rate never becoming waterlogged present the best condition for preparing a pungent tea; and perhaps also the thickest liquors are obtained on much heavier soils which indeed are too heavy to produce the most luxuriant bushes, but such statements are only the result of actual observations on existing gardens, and it will require very careful and exact experiments to make any progress with the study of these questions. I hope however to be able to broach these questions when time allows, as I believe they are as intimately connected with the quality of the tea as are the chemical needs of the soil with which I now proceed to deal. 


\section{CHAPTER III.}

\section{CHEMICAL COMPOSITION OF TEA SOILS.}

So recently as 1893 , in his book on the Improvement of Indian Agriculture, Dr. J. A. Voelcker who spent some time in India for Government in I889, I 890 and I89I, wrote with regard to Tea Soils as follows :-

"Then, in respect of the Soil, little is known as to its requirements. In the Neilgherries, for instance, there is good reason to believe that a deficiency of lime, if not of available potash also, has had to do with the decadence of tea cultivation there. On almost all sides there is but little known about manures, even about those which are available, such as oilcake and bones; the different oilcakes are classed together just as if they were the same and of equal value; it has nct been established whether bones are useful, whether green manuring is advantageous, and still less on which lands the systems should be or need not be employed. The influence of particular fertilisers, such as nitre or other potash containing manures, or else of phosphatic or nitrogenous manure, upon the quantity and quality of the tea is not definitely known. In regard even to tillage there are questions, for example, as to what depth of soil should be turned up, whether the land should be left in clods or be tilled finely, how far drainage is requisite, \&c."

This extract represents exceedingly well the state of knowledge as to the chemical needs of the tea plant at the time at which it was written. Certainly several desultory investigations had been done in India, or in connection with Indian Tea at an earlier date, but they had been carried out far too much from the point of view of farming in temperate climates to be of much use to the tea. planting community. Of the chemical side in the choice of soil, Colonel Money in his famous prize essay says nothing. In 1875 Professor Camphell Brown of Liverpool published* some analyses of tea soils, and also of tea plants, which are of little use to us now as no indication of their source in the tea districts is given. Suffice it to say, that they are very similar to many recent analyses of Indian Tea Soils but are heavier in type than the average from the Brahmaputra Valley.

The Tea Cyclopædia (1882) abounds in opinions as to the necessary ingredients in a good tea soil. "Tea soils are remarkable for containing much iron and very little lime, with potash in larger, and soda in smaller, quantity. The presence of manganese is one of the peculiarities of these soils" is one of numerous views expressed. Mr. S. E. Peal throws out, in the same publication, an idea which

- Journal of the Chemical Society. 1875. Page 1,219. 
might very well be carried out even now in order to determine the value of tea land. He writes: "An investigation of the number of flushes or rapidity of growth would be a direct and certain mode of ascertaining the suitability or otherwise of a province for tea growing," and he might have very well added that the same test would have given a means of equally well differentiating soils in the same province, if by flushes we mean, as he did, not the number of pluckings, but the number of series of shoots from the same stalk throughout the season.

\section{MR, BAMBER'S INVESTIGATIONS.}

But we owe nearly all we know of the chemical constituents of Assam Tea Soils and of Tea Soils in general up to date, to the investigations of $\mathrm{Mr}$. Bamber in the years preceding 1893 in India, and since 1899 in Ceylon, and he sums up his older results very effectively as follows (Chemistry and Agriculture of Tea, I 893) :-

"The main features to be noticed in all tea soils are :-

1. The great deficiency of lime in almost every case.

2. The almost entire absence of sulphuric acid, or sulphates, their being present only in minute traces.

3. The constant occurrence of manganese (frequently in large proportion, but not estimated in every case,) which is also always present in the ash of the tea.

4. That soils containing the highest percentage of nitrogen are most favourable for the luxuriant growth of tea.

5. That soils of rather open character with free porous subsoils which allow the easy penetration of the roots of the tea bushes and the removal of all stagnant water, are more suitable than those of a compact clayey nature.

6. The very small quantity of salts soluble in water even in the richest soils during the rainy season, which is due, either to their being utilized by the roots of the bushes immediately on their liberation from insoluble com. pounds, or to their being in great part washed away by the heavy rain. fall * - - Most of the phosphoric acid in the soils appears to be in a very insoluble condition, and probably occurs as a basic phosphate of iron, and it has been found that the application of manures containing soluble phosphates is of great benefit to the tea plant."

Since the time of the publication of the above report Mr. Bamber's researches have been carried much further, and his statements have become much more definite in his more recent reports. ( $V$ ide Report on Ceylon Tea Soils, Colombo, March 1900.) 


\section{VALUE OF SOIL ANALYSES.}

Both Mr. Bamber's and my own results are however almost entirely derived from analysis of soils obtained from various tea gardens of Ceylon and Assam, and it remains to consider how far such analyses can be of value in the decision of such points as the suitability of land for planting, or the manuring requisite for such land. In the early days of agricultural chemistry it was supposed that analyses of soil properly conducted would enable one to lay down absolutely and exactly the quantity and kind of manure that any particular soil would require. This was found, however, speedily to be a vain hope-dozens of considerations entered into the question of the fertility of land beyond the mere relative quantity of chemical constituents present or not present, and these often absolutely invalidated the result which the analyses showed. Soil analysis therefore fell into disrepute, and little weight was attached to it for many years. But it must be remembered that they were originally conducted on soils of the most complicated character, on land which had been cultivated for unknown generations, and without a standard of what the land had originally been. The alternative method of valuing a soil by dividing it off into plots and weighing the produce with various manures was, however, extremely cumbrous and was beset with so many possibilities of error that this too has had to be given up as a practical means of testing a soil.

Opinion therefore has veered round in favour of soil analysis with certain limitations, and it is now generally recognised that in dealing with virgin soils, or with soils which have recently been virgin, this method can give results of the utmost importance and value. And I think that one is almost as justified in basing opinions as to the requirements of tea in the shape of soil from the results of the analyses of a sufficient number of samples from virgin and old land, as if a large number of cultural experiments had been performed. The latter method will have to be used before a complete understanding of the question of the nutrition of the tea plant for the production of the maximum amount of the highest quality leaf is obtained, but in the meantime the analysis of the soils will afford a very valuable guide to what is necessary.

It cannot however be expected that soil analysis will ever be able to say exactly how many pounds of such and such manure will make up for deficiencies caused by exhaustion or unsuitability 
of soil. Our methods at the best are but clumsy, and plants, whether they be tea bushes or anything else, are far more delicate in analysis than the best of our laboratory methods. And in the case of a deep-rocted crop like tea questions of the possibility of the extension of roots counterbalancing the poverty of the soil near at hand, enter to a much larger extent than among ordinary annual crops, But one can say even with the crop under consideration :-

(1) that an unusually small proportion of any one constituent necessary for plant growth indicates that a deficiency in that ingredient will first make itself felt ;

(2) that an unusually large amount of any one ingredient indicates that this will be the last one which will need to be applied as manure.

But here in considering Assam soiis one is met at the outset by a difficulty, judged by all standards of English agriculture. Many of the best tea-soils, as shown by the percentage figures, seem much poorer than would be expected of virgin and good tea yielding land, and poorer even than other soil which is really much inferior for tea production. Compare for instance the following analyses, the first being that of an eminently good soil producing per acre 7 to 8 maunds per annum of tea worth ten pence to one shilling per pound in London, and the second being that of land producing much less tea at a lower price in the same market. The third column shows the apparent percentage of the important constituents of sample No. I (good soil) calculated on to the basis of sample No. 2 (poor soil).

\begin{tabular}{|c|c|c|c|c|c|}
\hline & & & No. 1. & No, 2. & $\begin{array}{l}\text { Percentage in } \\
\text { No. } 1 \text { on basis } \\
\text { of No. } 2 .\end{array}$ \\
\hline $\begin{array}{lcc}\text { Organic } & \text { Matter, \&c. } & \ldots \\
\text { Oxide of } & \text { Iron } & \ldots \\
\text { Alumina } & \ldots & \ldots \\
\text { Lime } & \ldots & \ldots \\
\text { Magnesia } & \ldots & \ldots \\
\text { Potash } & . & \ldots \\
\text { Soda } & \ldots & \\
\text { Phosphoric } & \text { Acid } & \ldots \\
\text { Sulphuric Acid } & \ldots \\
\text { Insoluble Silicates (Sand) }\end{array}$ & $\begin{array}{l}\cdots \\
\cdots \\
\cdots \\
\cdots \\
\cdots \\
\cdots \\
\cdots \\
\cdots \\
\cdots\end{array}$ & $\begin{array}{l}\cdots \\
\cdots \\
\cdots \\
\cdots \\
\cdots \\
\cdots \\
\cdots \\
\cdots \\
\cdots\end{array}$ & $\begin{array}{r}3.76 \\
1.72 \\
3.29 \\
.06 \\
.47 \\
16 \\
.24 \\
.05 \\
.02 \\
90.23 \\
100.00\end{array}$ & $\begin{array}{r}6.80 \\
3.54 \\
8.85 \\
.12 \\
65 \\
47 \\
.13 \\
.09 \\
.03 \\
79.32 \\
10000\end{array}$ & $\begin{array}{l}55 \cdot 3 \\
48 \cdot 6 \\
\cdots \cdots \\
50 \cdot 0 \\
\ldots \ldots \\
34 \cdot 0 \\
\cdots \cdots \\
55 \cdot 6 \\
\cdots \cdots \\
\cdots \cdots\end{array}$ \\
\hline * Containing Nitrogen & .. & .. & $\circ 9$ & $\times 5$ & $60^{\circ} 0$ \\
\hline
\end{tabular}


Such a case as I have indicated is by no means an isolated one-such could be found in almost every district of the province. It would seem, at first sight, to indicate that analysis is of no value here, and that the poorer soils chemically are the better ones actually. and agriculturally. But if these analyses be considered in another way the apparent contradiction disappears. There is in every soil a very large amount of sand which acts as a support to the plant, but in every other respect merely as a diluent of the valuable soil constituents. It would, therefore, seem that in order to ascertain the real actual richness of the soil for plant production, one's figures should be calculated not on the soil as a whole, but on that part which is not sand. And if one does this for the soils above given, we have for the valuable constituents of the soil the following figures :-

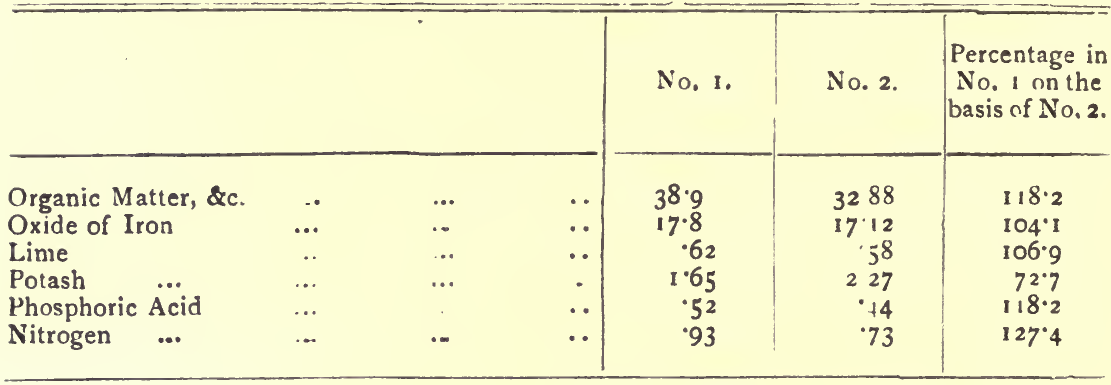

A great change has therefore appeared. What previously seemed to be the worst soil by far, now proves richer in every important ingredient (save the Potash). This is so universal in Assam soils, that one may lay down as a general rule that the power of land to produce luxuriant tea must in the future be determined not by the percentage of valuable matter in the soil as a whole, but rather in the soil less the sand, which latter acts in large measure as a diluent of the other materials.

But in this argument we have lost sight of one important matter. While the amount expressed in percentages of the soil as a whole may not represent the power of giving luxuriance to the plants, it undoubtedly shows the extent of the soil resources, i. e., the ultimate amount of plant food contained in the soil, and (recurring to our example) this is much greater in No. 2 than in No. I, and hence, one would fancy that No. I would be exhausted much sooner than No, 2. Such a conclusion would be justified if 
the soils were of the same depth, and if the roots penetrated as easily in one as in the other. And in practice the conclusion is shown to be just by the rapid exhaustion of sands overlying clay, which at first give exceedingly luxuriant and fine tea, but which become exhausted more rapidly than any other type of land in Assam. Though, calculated in the non-sandy part of the soil, they were vers rich to start with, yet the total amount of plant food was small, and was rapidly exhausted, while the roots were unable to seek fresh supplies further afield because of the underlying clay. In the example I have taken, however, it is ctherwise. The soil No. I has at least tiventy feet depth of soil in which to range without meeting clay or water, and hence produces luxuriant tea at the beginning, and in addition lasts an almost indefinite time.

We have therefore to consider in a soil analysis :-

1. The concentration of the soil constituents, $i$. e., the amount of the valuable matters in the part of the soil other than sand. This determines the luxuriance of the plants and probably the value of the tea.

2. The absolute amount of the ingredients of value as represented by the percentages in the soil as a whole. This determines the permanence of the plant without manuring, but only if taken in conjunction with.

3. The available depth of the soil, which may counterbalance the apparent absolute poverty (No. 2) of the land, if this depth is sufficiently great.

These three ways of looking at the matter must all at least be taken into consideration in interpreting the figures. If they had been so considered in the past, they would often have led to a very different manure recommendation, or to no recommendation at all.

METHODS OF TAKING SAMPLES OF SOIL FOR ANALYSIS.

In sending a soil for analysis, therefore, in order to satisfy consideration No. 3, the character of the subsoil should always be stated, and in addition the depth of the subsoil water, as these may have a paramount influence in determining the meaning of the analysis. The actual sample sent should always be taken in the following manner. Dig a hole in the plot of which an analysis is desired, fifteen inches deep, leaving a block in the centre of the hole 6 inches square. This block is therefore $6^{\prime \prime} \times 6^{\prime \prime} \times 15^{\prime \prime}$ in 
size. Have a box made of these inside measurements and invert it over the block of soil, and then remove the whole,-box, soil, and all,by putting a spade underneath the block. Then fasten a cover on the box and send to the analyst, marking the end of the box which contains what was originally the surface soil. The analyst has thus a block showing the layers of soil as they occurred in situ down to 15 inches deep, and valuable results may often be drawn from mere observation of them, which would be entirely missed if merely a shovelful of soil down to the same depth were sent for examination.

\section{IMPORTANCE OF VARIOUS SOIL CONSTITUENTS}

Although the constituents always present in soil are many in number, yet those which have any interest from an agricultural point of view are comparatively few. Some seem to have no necessary functions in regard to plant life. Such are the Silica, the Alumina and the Soda. Others are, one may say, always present in far greater amount than the plant requires. Such are the Oxide of Iron, the Magnesia, and the Sulphuric Acid, but with these con. stituents it may be that they have to be present in some particular form to be useful to the plant, and thus they may be an essential element in the fertility of a soil. And third there are those ingredients required by every plant, and upon whose absolute and relative quantity depends primarily the fertility of the land. Such are the Organic Matter, the Lime, the Phosphoric Acid, the Potash, and the Nitrogen. We will in the first place consider the Organic Matter and Nitrogen as they are related to the growth of the tea plant in Assam.

ORGANIC MATTER AND NITROGEN.

These two constituents of the soil are intimately connected. In fact the total useful nitrogen in the soil is or has been contained in the organic matter. I say "has been" because at the time the tea plant utilises it, it usually has been converted into nitrates by the microbes of the soil. For many years it has been supposed that this conversion into nitrates always took place before absorption of nitrogen by the plant, and it is only recent investigations which seem to have shown that the nitrogen in the organic matter itself without previous change, may form the food of plants. The determination of the nitrates actually present in soil generally, however, gives little information as to the resources of the soil in food supply since the nitrogen in this form is in so suluble a condition, that the 
first rain storm may wash the whole into the drains. These nitrates are usually present in fairly large quantity in the spring, but during the remainder of the flushing season probably never exist at any one time in more than infinitesimal proportion, unless it be after the rains have stopped. What influence they have on the produc. tion of spring and autumn flavour, is a matter to be investigated. It is certainly possible, if not probable, that the available nitrates present in abundance in the soil may have something to do with this flavour, but apart from the determination of changes through the season, the amount of nitrates is so small and changes so often that its measurement is generally of little utility, and has hence been omitted in my analyses.

But the permanent supply of soil nitrogen is that contained in the "organic matter" or "humus," and the amount of organic matter and nitrogen form the first and most important measure of the fertility of a soil for tea, of the likelihood of its being of permanent value, and also of the probability of its giving high quality tea. Unluckily the amount of organic matter is one of the most difficult things to measure, and the figure in the analyses called by that name is only valuable when a similar class of soils are compared. These constituents are however so essential and important that, unless they are present in large enough quantity, the other ingredients of the soil are all but useless. The best virgin land in Assam invariably contains more than 35 per cent. of organic matter, \&c., and more than 0.8 to 0.9 per cent. of nitrogen in the non-sandy portion of the soil. The following examples of virgin or almost virgin soils selected from several districts show this :-

\begin{tabular}{|c|c|c|c|c|c|}
\hline District & & Garden. & & $\begin{array}{c}\text { Organic Matter, } \\
\text { \&c. }\end{array}$ & Nitrogen. \\
\hline Mangaldai ... & $\cdots$ & $\left\{\begin{array}{l}\text { Nagrijuli ... } \\
\text { Bhutia Chang }\end{array}\right.$ & $\begin{array}{l}\ldots \\
\ldots\end{array}$ & $\begin{array}{l}48 \cdot 11 \\
42 \cdot 61\end{array}$ & $\begin{array}{l}1 \cdot 12 \\
1 \cdot 07\end{array}$ \\
\hline Tezpore $\quad .$. & $\ldots$ & Sonajuli ... & ... & $37 \cdot 72$ & .94 \\
\hline Bishnauth ... & $\ldots$ & Dikorai $\quad \ldots$ & $\ldots$ & $44^{\circ} 94$ & $1 \cdot 24$ \\
\hline North Lakhimpur & $\ldots$ & $\left\{\begin{array}{l}\text { Dejoo } \\
\text { Lilabari }\end{array}\right.$ & $\cdots$ & $\begin{array}{l}39 \cdot 67 \\
36 \cdot 82\end{array}$ & $1 \cdot 30$ \\
\hline Dibrugarh $\ldots .$. & & f Panitola ... & $\ldots$ & $39 \cdot 89$ & $\begin{array}{r}1.02 \\
.83\end{array}$ \\
\hline Dibrugarh ... & $\cdots$ & \{ Balijan $\ldots$ & $\ldots$ & $38 \cdot 84$ & 79 \\
\hline Donm-Dooma & $\ldots$ & Pabbnjan ... & $\ldots$ & 38.90 & 93 \\
\hline Jorhât & & Noakacharie & $\cdots$ & 46.44 & 1.53 \\
\hline Jorhât & $\cdots$ & $\left\{\begin{array}{l}\text { Cinnamara } \\
\text { Moabund ... }\end{array}\right.$ & $\ldots$ & $\begin{array}{l}45 \cdot 56 \\
35.65\end{array}$ & $\begin{array}{l}1.43 \\
1.02\end{array}$ \\
\hline Golaghât $\quad .$. & $\ldots$ & Borsapori ... & $\ldots$ & $37 \cdot 76$ & $\cdot 98$ \\
\hline Nowgong ... & $\ldots$ & Rangamati & $\ldots$ & $38 \cdot 87$ & I \\
\hline
\end{tabular}


On the other hand, the proportion of both these constituents, on gardens which have proved unsuitable and not to give luxuriant bushes, is almost invariably below the limits I have mentioned. The following are the figures for some virgin soils, where experience has proved the tea to be inferior in luxuriance :-

\begin{tabular}{c|c|c}
\hline No. & Organic Matter, \&c. & Nitrogen. \\
\hline I & $28 \cdot 07$ & $\cdot 56$ \\
2 & $30 \cdot 39$ & 99 \\
\hline
\end{tabular}

There are no ingredients which are more quickly used up by the growth of tea than those we are considering. In taking samples of soil, I have made a point in many cases to examine side by side samples from the virgin land and from the same soil which has borne tea for many years. The loss in all these cases is most marked, as the following table shows :-

\begin{tabular}{|c|c|c|c|c|c|c|c|c|c|c|}
\hline \multirow[b]{2}{*}{ No. } & \multirow[b]{2}{*}{ Garden } & \multicolumn{2}{|c|}{$\begin{array}{l}\text { Percentage in } \\
\text { Soil. }\end{array}$} & \multicolumn{2}{|c|}{$\begin{array}{c}\text { Weight per acre } \\
\text { in lbs. }\end{array}$} & \multicolumn{2}{|c|}{$\begin{array}{l}\text { Percentage } \\
\text { Loss. }\end{array}$} & \multicolumn{2}{|c|}{$\begin{array}{l}\text { Actual Loss in } \\
\text { lbs. per acre. }\end{array}$} & \multirow{2}{*}{ 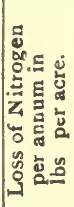 } \\
\hline & & 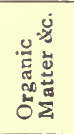 & 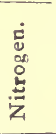 & 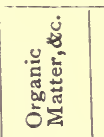 & 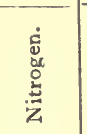 & 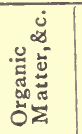 & 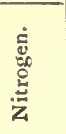 & 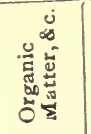 & 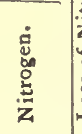 & \\
\hline I & $\left\{\begin{array}{c}\text { Sonajuli Virgin Soil ... } \\
\text { Sonajuli to sears } \\
\text { under tea. }\end{array}\right.$ & $\begin{array}{l}5 \div 59 \\
4 \div 6\end{array}$ & $\begin{array}{l}x \\
x_{4}\end{array}$ & $2,29,500$ & $\begin{array}{l}7,000 \\
5,500\end{array}$ & $15 \cdot 6$ & $21^{\circ} 4$ & 46,502 & $x, 500$ & $153^{\circ}$ \\
\hline II. & $\left\{\begin{array}{c}\text { Dikorai Virgin Soil } \\
\text { Dik,rai } 35 \text { years } \\
\text { under tea .. }\end{array}\right.$ & $\begin{array}{l}3 \cdot 99 \\
3 \cdot 54\end{array}$ & $\begin{array}{l}\text {.11 } \\
\text { 10 }\end{array}$ & $\left|\begin{array}{l}x, 79,500 \\
1,77,000\end{array}\right|$ & $\begin{array}{l}5,5>0 \\
5,000\end{array}$ & $1 \cdot 2$ & $g^{\circ} I$ & 22,500 & 500 & $14^{\circ} 3$ \\
\hline 111. & $\left\{\begin{array}{r}\text { Dejoo Virgin Soil } \\
\text { Dejoo } 35-40 \text { s ears } \\
\text { urder tea .. }\end{array}\right.$ & $\begin{array}{l}6 \cdot 1 \mathrm{r} \\
425\end{array}$ & $\begin{array}{l}.20 \\
09\end{array}$ & $\begin{array}{l}3,05,500 \\
2,12,500\end{array}$ & $\begin{array}{r}10,000 \\
4,500\end{array}$ & 30.4 & $5 ; 0$ & 93,000 & 5,502 & $157 \%$ \\
\hline IV. & $\left\{\begin{array}{c}\text { Chubwa Virgin Soil ... } \\
\text { Chubwa } 64 \text { years } \\
\text { under tea }\end{array}\right.$ & $\begin{array}{l}5 \cdot 89 \\
4 \cdot 60\end{array}$ & $\begin{array}{l}12 \\
10\end{array}$ & $2,94,500$ & $\begin{array}{l}6,000 \\
5,000\end{array}$ & $21^{\circ} 9$ & 16.7 & 64,500 & 1,000 & $15^{\circ} 6$ \\
\hline v. & $\left\{\begin{array}{r}\text { Panitola Virgin Soil } \\
\text { Panitola } 26-23 \text { years } \\
\text { under tea }\end{array}\right.$ & $\begin{array}{l}6.75 \\
5.68\end{array}$ & $\begin{array}{l}\cdot 34 \\
11\end{array}$ & $\begin{array}{l}3,37,500 \\
2,80,5>0\end{array}$ & $\begin{array}{l}7,002 \\
5,5>0\end{array}$ & $16^{\circ} 9$ & $2 r^{\circ} 4$ & 57,000 & $1,5,0$ & $57^{\circ} 7$ \\
\hline vi. & $\left\{\begin{array}{r}\text { Noak 3charie Virgin Soil } \\
\text { Noakacharie } 30-40 \text { years } \\
\text { under tea }\end{array}\right.$ & $\begin{array}{l}2 \cdot 74 \\
1 \cdot 82\end{array}$ & $\begin{array}{l}\circ 9 \\
\circ 07\end{array}$ & $\begin{array}{r}1,37,000 \\
91,020\end{array}$ & $\begin{array}{l}4,500 \\
3,502\end{array}$ & $33 \cdot 6$ & $22^{\prime} 2$ & 46.200 & 1,200 & $33^{\circ} 3$ \\
\hline vII. & $\left\{\begin{array}{c}\text { Cinnamara Virgin Suil } \\
\text { Cinnamara } 4 \text { \} years } \\
\text { under tea }\end{array}\right.$ & $\begin{array}{l}2 \cdot 37 \\
2 \cdot 55\end{array}$ & $\begin{array}{l}\circ 9 \\
.07\end{array}$ & $\begin{array}{l}1,43,5>0 \\
1,27,500\end{array}$ & $\begin{array}{l}4,500 \\
3,500\end{array}$ & $I_{1}=$ & 222 & 16,000 & I, O0J & $25^{\circ} \circ$ \\
\hline
\end{tabular}

- These figures are based on the assumption that one acre of dry soil down to a depth of 15 inches weighs $5,000,000 \mathrm{lbs}$. 
CAUSES OF LOSS OF ORGANIC MATTER AND NITROGEN.

Such a loss as this, amounting, in the extreme case of a garden worked from the beginning at high pressure, to I 50 pounds of nitrogen per annum per acre, or over 2 per cent. of that originally present, cannot be lightly considered. Some part of the loss is due to what is actually removed from the land by the leaf taken from the garden, but as this only amounts, for say ten maunds of tea per acre to about thirty-two pounds of nitrogen per annum, there must be, for the cases in which the greatest loss takes place, an enormous leakage in other directions. Where does this leakage occur? The answer is only too obvious. Wherever very deep constant cultivation has been in vogue for many years, where no weeds are allowed to grow, and where the stock of nitrates formed during the cold weather has not been retained in the spring by green manuring, there the loss is great, and much goes down the drains. As an additional evidence of the connection between a very great amount of cultivation and the greater loss, it will be seen that there is every appearance of this leakage having become greater in recent years.

\section{PREVENTION OF LOSS OF ORGANIC MATTER AND NITROGEN.}

But why should cultivation and the absence of weeds or green manuring cause a loss of nitrogen? In reply, let us consider the soil for a moment as a vast living mass of bacteria or microbes. They occur in such enormous quantities that in a fertile surface soil they are numbered by hundreds of millions to the cubic inch. And all these organisms feed, and utilise the stores of the soil for food. Some, and more especially in unaerated soils, use the organic matter and nitrogen, destroying the usefulness of the latter and giving it off as gas into the air. These have little importance in a tea-soil so long as the land is not water-logged, and is well aerated throughout. Others utilise equally the nitrogen, but form nitrates from it, useful enough in themselves and absolutely necessary for plant growth, but formed largely at a time when they cannot be absorbed by the plant, and which are hence immediately washed into the drains and so away by the first large downfall of the rainy season. These are most active in a thoroughly aerated soil, and hence are increased by a very large amount of cultivation. What then can be done? - the land must be cultivated thoroughly in order to keep the bushes vigorous and flushing regularly, and yet this results in an enormous loss of the most valuable and expensive 
constituent in the soil. To this there is one answer, which, though not entirely by a long way preventing the loss of nitrogen, yet will very materially reduce it. This is the use of green manuring crops. The nitrates are at their maximum in the soil before the rains fully break, the early rain, which just moistens the soil but does not cause the drains to run, only makes their formation more rapid and hence increases the quantity. A crop should therefore be sown at the first opportunity in spring (that is, as soon as the land is moist enough to germinate the seed) and be hoed in, say in the middle of June. By this means a considerable quantity of nitrogen will be retained in the soil which would otherwise be lost. I will defer the consideration of the most suitable crops for this purpose till the next chapter, but here I would insist most strongly on their utility as a means of preventing part, at any rate, of the loss of this most expensive ingredient of the soil.

It has been suggested that allowing a growth of weeds would be just as much to the purpose as sowing a special green manuring crop, as these would retain the nitrates just as well. To a certain extent this would be true, but not altogether, for the natural weed herbage is only very sha!low-rooted, the very common Ageratum (" cold weather weed" of Assam, "ilami" of the Dooars), or many of the natural grasses being examples, and as their faculty for retaining nitrogen is limited by their root range, the effectiveness of such plants is not very great, not nearly so great as many which could be specially sown. Further, even were they equally effective, it must be recognised that the growth of a miscellaneous lot of plants is distinctly risky, for many of the pests of tea find shelter in one or other of the weeds, and are thus enabled to propagate ard go on to the tea at a suitable opportunity. The whole principle of allowing weed growth on a garden in Assam is distinctly wrong, they are themselves a danger, and whatever functions they do perform can be carried out better by the growth of a definite crop of known value.

\section{LOSS IN VALUE OF NEWLY CLEARED LAND.}

The loss in organic matter and nitrogen is most active in newly cleared land. There the conditions are usually most favourable (on good tea-soil) for the growth of the organisms producing nitrates, and the organic matter is in a very suitable state as a medium for their activity. Hence, if such land be left uncovered for a year 
before planting, it is usually much less favourable for the tea seedlings than before. The fact has been brought to my notice by many planters, that land not planted rapidly deteriorates after clearing, and that it should be planted up at once. The explanation is undoubtedly that given above, and the only means of avoiding the deterioration is by planting a crop on all such cleared land, keeping a crop on it as far as possible until the time for putting in the tea seedlings, and hoeing this in before actually planting.

\section{NITROGEN SUPPLIED BY RAIN.}

To counterbalance these sources of loss of nitrogen there are two or three sources of gain. The rain brings a considerable amount of nitrates and salts of ammonia, all of which contain nitrogen, but this only amounts to a fraction* of that required by the plant, and as much of it comes when the water almost runs direct through the soil $i_{\text {nto to }}$ the drains, much less than the apparent amount is useful to the plant. In fact, I think one may neglect this source of nitrogen in determining the means of supplying this material for the tea plant.

FIXATION OF NITROGEN BY THE SOIL AND BY PLANTS.

Various observers, $\uparrow$ however, have found that the soil alone with. out any plant growth has the power of fixing nitrogen,-also by means of soil microbes. The mechanism of this is not very well understood, but it is probable that under suitable circumstances it may have a very great influence in preventing the absolute exhaustion of land. Further, plants of the order Leguminosæ, of which Mati Kalai (Phaseolus aconitifolius), Sensitive Plant (Mimosa pudica) and Clover ( $T$ rifolium spp.) may be taken as the types, are also very valuable as a means of increasing the store of nitrogen in the soil. And beyond this there are certain low green slimy "algæ" which, growing on the surface of the land, lead to the fixation of the constituent in question. Exactly how much value, under normal conditions, may be put on these various agencies has never been investigated in the tropics, but would be a most interesting subject were facilities for such work to be obtained.

EFFECT OF NITROGEN, \&C., ON THE QUALity OF TEA.

Nitrogen and organic matter are the most essential constituents in the soil for luxuriant growth. How does their presence or absence

- Mr. Bamber found the total nitrogen in the rainfall of Colombo to be $7.628 \mathrm{lbs}$. per annum per acre.

+ Winogradsky; Berthelot and André. 
in large quantity affect the quality of the tea? In his recent report on Ceylon Tea Soils," Mr. Bamber has expressed the view that they are one of the influences chiefly at work in determining the value of the tea, and he prints tables showing that, as the organic matter and nitrogen in the soil increase, so does the price. Though perhaps a general statement that the quality increases with the amount of organic matter and nitrogen would be too wide in the case of the Assam Districts, yet, with the exception of certain special types of soils, one may say, I think, that other things being equal, a garden produces higher quality tea (for the district ard hence the climate in which it lies) as the percentage of nitrogen and organic matter in the non-sandy portion of the soil increase, and that the loss of these constituents is followed by a lowering in the quality of the tea, which can only be counteracted by closer, and still closer plucking. This is strikingly illustrated by the way in which the nitrogen increases in the leaves which make the best tea. The following is an example of the way in which the nitrogen decreases as one goes from the tip to the second leaf on a stalk, and this totally independently of the nitrogen present as caffeine. $\dagger$

\begin{tabular}{lc|c|c|c}
\hline & & $\begin{array}{c}\text { I } \\
\text { Total Nitrogen. }\end{array}$ & Nitrogen in Caffeine. & $\begin{array}{c}\text { Nitrogen not in } \\
\text { Caffeine. }\end{array}$ \\
\hline Tip leaf (unopened) & $\ldots$ & 6.63 & 3.62 & 3.01 \\
First open leaf & $\ldots$ & 5.62 & 2.84 & 2.78 \\
Second open leaf & $\ldots$ & 4.57 & 2.05 & 2.52 \\
Stalk ... &.. & 4.00 & 1.87 & 2.13 \\
\hline
\end{tabular}

If therefore one increases the concentration of the nitrogen and hence of the organic matter in a soil, the quality should improve and this observation is in agreement with experience. Nitrogen yielding manures therefore occupy a foremost place in any system for manuring tea both in respect of luxuriance of the bushes and the quality of the product. In the next chapter I will discuss the methods of carrying this out.

One or two exceptions to the above statements must be made. As is well known, bheel soil does not yield good tea, although it yields very luxuriant bushes, and I suspect that this is due to the

- Colombu rgoo.

† These analyses were carried out for me by Mr. D. Hooper, to whom I here tender my sincere acknowledgments. 
acid character of the organic matter in the soil, which prevents the formation of nitrates and compels the plant to absorb its nitrogen in the organic form. This, however, is only supposition, and until I visit Cachar and Sylhet in the spring of 1902, I cannot express a very definite opinion on the subject. A second exception occurs in the case of village sites or busti soils, which practically refuse to grow tea at all, although they contain a large percentage of both nitrogen and organic matter. The following is an analysis of the soil from such a village site side by side with that taken a few yards off on the same property :-

\begin{tabular}{|c|c|c|c|c|}
\hline & & & Busti Soil. & Ordinary Virgin Soil. \\
\hline "Organic Malter, \&c. & .. & .. & $7 \cdot 57$ & 532 \\
\hline Oxide of Iron & .. & .. & 251 & $2 \cdot 74$ \\
\hline Alumina & $\cdots$ & .. & 4.95 & 5.10 \\
\hline Lime & .. & .. & 30 & 03 \\
\hline Magnesia & .. & .. & 47 & 36 \\
\hline Potash & .. & .. & $\cdot 25$ & $\cdot 26$ \\
\hline Soda $\quad .$. & -. & .. & $\cdot 22$ & 23 \\
\hline Phosphoric Acid & .. & .. & 15 & .06 \\
\hline Sulphuric Acid & .. & .. & $\ldots$. & .02 \\
\hline \multirow[t]{2}{*}{ Insoluble Silicates (Sand) } & & $\cdot \cdot$ & $83^{\circ} 5^{8}$ & $85: 8$ \\
\hline & & & 100.00 & $100^{\circ} 00$ \\
\hline * Crntaining Nitroger & .. & .. & 21 & 18 \\
\hline
\end{tabular}

Or calculating on the nor-sandy portion of the soil, we have-

\begin{tabular}{|c|c|c|c|c|}
\hline & & & Busti Soil. & Ordinary Virgin Soil. \\
\hline Organic Vatter, \&c. &.. & & 4611 & $37 \cdot 68$ \\
\hline Lime & . & $\ldots$ & $1 \cdot 83$ & $\cdot 21$ \\
\hline Potash & $\ldots$ & $\ldots$ & $1 \cdot 52$ & $1 \cdot 84$ \\
\hline Phosphoric Acid & . & $\ldots$ & 91 & 42 \\
\hline Nitrogen & $\ldots$ & $\ldots$ & $1 \cdot 28$ & $1 \cdot 27$ \\
\hline
\end{tabular}

Thus, from analysis, the busti soil should be an exceedingly good one, and, in fact, it approaches some of the best Assam land. I had thought that probably it contained a large quantity of the lower oxide of iron, which is poisonous when present in large amounts. A test, however, revealed only 44 parts per 100,000 of the soilan amount much smaller than in many of the best gardens. Nor was the soil acid, and in fact no poisonous substance could be detected. One is obliged to put down the infertility to tea almost entirely to the close texture of the land resulting from the former presence of dwelling houses, and this close texture can be modified, as indicated in a previous chapter, by draining, or by the growth and burial of green crops. Such a method would probably form a perfect cure, in time, for such land-though here again is distinctly 
a matter for experiment. In connection with this matter I have recently been informed that a dressing of the soil with sulphur has been found very beneficial on these village sites, in a few places. This method is worth trial, but it is one the reason for which is somewhat difficult to see.

\section{"LAW OF THE MINIMUM."}

But organic matter and nitrogen are not the only constituents required in the soil for the production of healthy and luxuriant bushes and of high quality tea. For both these results they occupy essentially the most important position, but without other ingredients they would be utterly useless. There is a law in agriculture known as the "law of the minimum," which states that if the minimum required by a plant of any constituent be not obtainable, all others are there in vain and the plant cannot be grown. Inasmuch as the tea plant requires Phosphoric Acid, Potash, Oxide of Iron, and Lime at least, and probably Magnesia as well, it is ab. solutely necessary that these should be present in sufficient quantity and in a sufficiently available form for the plant to grow well. I say "in a sufficiently available form" because they may and often are present, but in such a condition that the plant cannot use them. Thus, for instance, the quantity of Potash in a clay soil is invariably' several times greater than in sandy land, and yet the latter may be actually richer agriculturally in this constituent at any particular moment than the former, simply because in the former case it is so combined in the clay as to be in large measure useless for the plant : again, Phosphoric Acid is always less useful in the presence of large quantities of Oxide of Iron and Alumina than in their absence, \&c. We have a direct test for the actually available amount of these constituents, and this 1 have used in special cases, as will be noticed.

\section{PHOSPHORIC ACID.}

Of the constituents I have named, the Phosphoric Acid is the most important. Its presence in greater or less amounts depends entirely upon the kind of rocks from which the soil is derived. It happens that in the Himalayas, whence the greater part of the alluvial soil of the Assam valley is derived, the rocks as a whole are poor in phosphates, and hence likewise the soils in this valley are compara. tively poor in this constituent. This is generally more marked, though with some striking exceptions, as one descends the river. An amount equal to 25 per cent, at least on the non-sandy part of the 
soil (and a much larger quantity if very high quality tea is to be produced) is demanded, if tea is to be at its best, and the following table showing the average amounts (from my analyses) in the gardens from which I took samples in the several districts.

\begin{tabular}{|c|c|c|c|c|}
\hline \multicolumn{3}{|c|}{ Districts. } & $\begin{array}{l}\text { Phosphoric Acid } \\
\text { in Soil. }\end{array}$ & $\begin{array}{l}\text { Phosphoric Acid in } \\
\text { "Soil, less Sand." }\end{array}$ \\
\hline Tezpur & $\ldots$ & $\ldots$ & 036 & 298 \\
\hline Bishnath & $\ldots$ & $\ldots$ & .043 & $\cdot 360$ \\
\hline North Lakhimpur - &.. & $\ldots$ & .050 & 462 \\
\hline Dibrugarh &.. & $\ldots$ & .078 & 480 \\
\hline Doom Dooma & $\ldots$ & $\ldots$ & .078 & $\cdot 608$ \\
\hline Sibsagar and Nazira & $\ldots$ & $\ldots$ & .043 & 343 \\
\hline Jorhât & $\ldots$ & $\ldots$ & .039 & 469 \\
\hline Golaghât & .. & $\ldots$ & $\cdot 050$ & 417 \\
\hline Nowgung" & $\ldots$ & $\ldots$ & '040 & 430 \\
\hline Mangaldai† & $\ldots$ & $\ldots$ & $\cdot 120$ & $\cdot 878$ \\
\hline
\end{tabular}

These figures show several interesting points. The gardens whose soil was analysed were chosen as typical of the districts, and so one may, I think, rely on the substantial relative accuracy of the figures. They indicate (I) that the land producing the highest yield of high class tea are those in which the Phosphoric Acid is in large proportion combined with a large percentage of Organic Matter and Nitrogen; (2) that the cause of the permanently high quality and large yield of the Upper Assam districts may be found in the composition of the soil, as well as in the ideal tea climate they possess. Of course in considering questions of quality one cannot eliminate the difference in styles of plucking, but taking this as far as possible into consideration, there still remains the undoubted fact to explain that a flavour and a pungency is produced in Upper Assam it is impossible to obtain elsewhere, and this is intimately connected with the presence of a high concentration of Phosphoric Acid combined with an ample quantity of Organic Matter. + It has been pointed out for Ceylon teas

- Omitting Koliabar, where the conditions are somewhat unique.

† The case of Mangaldai appears, as would be expected, as an exception. Here the climate is distinctly inferior to the Upper Assam districts, the plucking is decidedly coarser, and no attempt is made to obtain very fine teas. The figures given are chiefly obtained from the rich, all but virgin, grass lands under the Himalayas. 
by Mr. John Hughes, who visited that island for the tea planters some years ago, that tea of highest value usually contained the largest quantity of Phosphoric Acid. The following table (taken from his figures in the "Tropical Agriculturist," I900) shows this. Taking Ceylon Broken Orange Pekoes he found-

\begin{tabular}{c|c|c|c|c|c|c}
\hline PrICE. & $1 / 4 \frac{1}{2}$ & $1 / 2 \frac{3}{4}$ & $1 / 2 \frac{1}{2}$ & $7 \frac{1}{2}$ & $6 \frac{1}{2}$ & $6 \frac{1}{6}$ \\
\hline Phosphoric Acid. & .87 & .92 & .87 & .60 & 71 & .58 \\
\hline
\end{tabular}

If Phosphoric Acid is greater in the tea, it stands to reason it must be present in the soil, other things being equal, in greater quantity in an available form. Mr. Bamber (los. cut.) rather doubts the connection between quality and this soil constituent, and gives a very interesting diagram showing how these ingredients vary in soils producing varying quality teas. But I hardly think that too much stress should be laid on these figures, and he himself indicates an opinion that a determination of the amount of actually available Phosphoric Acid might give a different result. I have determined this available Phosphoric Acid for a number of typical Assam soils, and the following are the results :-

\begin{tabular}{|c|c|c|c|c|c|}
\hline \multicolumn{4}{|c|}{ District. } & \multirow{2}{*}{$\frac{\text { QUALITY. }}{\text { Medium }}$} & \multirow{2}{*}{$\begin{array}{c}\text { Available Phosphoric Acid } \\
\text { in soil. Parts per 100,000. } \\
22^{\circ} 69\end{array}$} \\
\hline Tezpur Bank & (Virgin) & .. & $\ldots$ & & \\
\hline Dejoo & , & $\ldots$ & .. & High medium & $7 \cdot 62$ \\
\hline Noakachari & , & $\ldots$ & $\ldots$ & ", & $5 \cdot 84$ \\
\hline Cinnamara & $"$ & $\ldots$ & -. & , & $5^{\prime 24}$ \\
\hline Panitola & $"$ & $\ldots$ & $\ldots$ & High & $10 \cdot 10$ \\
\hline
\end{tabular}

These figures bear out in a remarkable manner those previously given, and render the relation of Phosphoric Acid in the soil to quality of tea practically a certain one.

\section{EXHAUSTION OF PHOSPHORIC ACID.}

The exhaustion of this constituent is further very considerable when tea is long grown on the same land, and the loss of the pristine quality of a garden is probably largely due to this cause, combined always, of course, with the simultaneous loss of Organic 
Matter. The following table gives the loss, in a considerable period, of both available and total (calculated on the non-sandy part of the soil) Phosphoric Acid, the former in parts per 100,000, the latter in percentages.

\begin{tabular}{|c|c|c|c|c|c|c|c|c|}
\hline \multirow{2}{*}{\multicolumn{2}{|c|}{ GARDEN. }} & \multirow{2}{*}{ AGE OF TEA. } & \multicolumn{3}{|c|}{$\begin{array}{l}\text { TOTAL PHOSPHORIC ACID } \\
\text { IN "SOIL LESS SAND." }\end{array}$} & \multicolumn{3}{|c|}{$\begin{array}{l}\text { Available Phosphoric } \\
\text { ACID. }\end{array}$} \\
\hline & & & $\begin{array}{l}\text { Virgin } \\
\text { Land. }\end{array}$ & $\begin{array}{c}\text { Old Tea } \\
\text { Land. }\end{array}$ & $\%$ Loss. & $\begin{array}{l}\text { Virgin } \\
\text { Land. }\end{array}$ & $\begin{array}{c}\text { Old Teal } \\
\text { Land. }\end{array}$ & $\%$ Loss. \\
\hline Sonajuli & $\ldots$ & Io years. & $\cdot 34$ & 30 & $11 \cdot 8$ & $2 \cdot 69$ & $2 \cdot 94$ & ...... \\
\hline Dikorai & $\cdots$ & 35 years. & 45 & $\cdot 43$ & $4^{\circ} 4$ & $\cdots \cdots$ & $\cdots \cdots$ & $\cdots$ \\
\hline Dejoo & $\ldots$ & $35-40$ years. & $\cdot 39$ & .23 & $4 I^{\circ} 0$ & $7 \cdot 62$ & $3 \cdot 80$ & $50 \cdot 1$ \\
\hline Panitola & $\ldots$ & $26-28$ years. & 47 & $\cdot 36$ & 23.4 & 10.10 & $6 \cdot 96$ & $3 r \cdot r$ \\
\hline Noakachari & $\ldots$ & $30-40$ years. & $\cdot 51$ & $4 \mathrm{I}$ & $19 \cdot 6$ & $5 \cdot 84$ & $5 \cdot 39$ & $7 \cdot 7$ \\
\hline Cinnamara & $\cdots$ & 40 years & 48 & $\cdot 48$ & ...... & $5^{\circ} 24$ & 4.74 & $9 \cdot 5$ \\
\hline
\end{tabular}

CAUSE OF RELATION OF PHOSPHORIC ACID TO QUALITY.

But why does Phosphoric Acid play such a preponderating part in the production of high quality teas? Researches pursued in connection with other plants give us the clue to the reason. In all cases wherever the production of new tissue in plants is most active, there Phosphoric Acid plays a principal part. No albumens, no cells, and hence no tissue can be formed in its absence. Now as those parts of the plant used in tea manufacture are those in which the production of new cells is extremely vigorous and energetic, so is this constituent of more importance for the perfect production of the crop than with ordinary agricultural products. There is another reason also. It has recently been shown that the acidity of plant juices depends on the amount of Phosphoric Acid in the soil. Now the younger leaves and hence those which make the best tea are more acid than the older ones, and so one is, I think, entitled to assume that a certain proportion of acidity is necessary in the leaf for making the best tea, and this is rendered more certain by the presence of much Phosphoric Acid in the soil. The following table shows the acidity, and also the percentage of Phosphoric Acid calculated on the dry matter, in the unopened bud, in the first two leaves and in the stalk of a flushing shoot taken from a hybrid bush in Darjeeling in August I90I, and it will be 
seen that their value as tea varies with the amount of acidity present.

\begin{tabular}{|c|c|c|c|c|}
\hline & & & $\begin{array}{l}\text { ACIDITY CALCULATED AS } \\
\text { CITRIC ACID PER CENT. }\end{array}$ & PhOSPHORIC ACID. \\
\hline Unopened leaf & $\cdots$ & $\cdots$ & $I^{\circ} 64$ & $1 \cdot 35$ \\
\hline First open leaf & $\cdots$ & $\ldots$ & $1 \cdot 15$ & $1 \cdot 19$ \\
\hline Second open leaf & $\ldots$ & $\cdots$ & 92 & $\mathrm{I} \cdot \mathrm{OI}$ \\
\hline Stalk & $\ldots$ & .. & 72 & $1 \cdot 06$ \\
\hline
\end{tabular}

To summarize therefore with regard to Phosphoric Acid. It is an essential constituent of the soil in tea culture and one on which great demands are made. It is present in greater quantity in those districts, and those gardens renowned for quality, and hence may be considered a factor of the greatest importance in its production, especially as it is known to be fundamentally concerned in the production of new cells, and also in increasing the acidity of the plant sap.

POTASH.

The constituent next of importance to the tea plant is without doubt the Potash, but this occurs probably in sufficient quantity in most parts of Assam. Its function in the plant is most important, and there is little doubt that it plays a fundamental part in the production of tannin (the essential element in the pungency of tea), as well as in the formation of albumens and the production of new cells and new growth. In the latter function it runs parallel with the Phosphoric Acid, and the latter would be quite paralysed were not a sufficiency of Potash present. Mr. John Hughes (loc. cit. supr.) considers that the Potash is overwhelmingly important in the production of good tea, and states that for a number of good teas'which he examined, the price very fairly corresponded with the sum of the soluble Potash and the Phosphoric Acid taken together in the tea, To decide whether this is so or not, demands a much larger series of analyses than we have at present.

It is somewhat difficult to estimate the richness of a soil in Potash from the analysis. The amount may reach very high proportions if the clay is increased, without the Potash being in any greater available quantity. Perhaps the best way of getting at the 
relative available richness of two soils in this material is to take the proportion of the Potash to the clay present, and this clay may very fairly be measured by the Oxide of Iron and the Alumina taken together. Under these circumstances the Potash should not be less than three per cent. of the Oxide of Iron and Alumina. The follow ing table shows for several gardens the percentage of total Potash, and the proportion it bears to the clay measured as above.

\begin{tabular}{|c|c|c|c|}
\hline \multirow[b]{2}{*}{ Number. } & \multirow[b]{2}{*}{$\begin{array}{l}\text { Yield per acre and } \\
\text { class of Tea. }\end{array}$} & \multirow[b]{2}{*}{ Potash in Soil. } & Potash. \\
\hline & & & $\begin{array}{l}\text { Oxide of Iron } \\
\text { and Alumina. }\end{array}$ \\
\hline I & $8-10 \mathrm{mds} .$, medium quality ... & $\cdot 35$ & $4 \cdot 37$ \\
\hline 2 & 6 mds, high medium quality ... & $\cdot 19$ & 4.48 \\
\hline 3 & Small yield, high quality & 38 & 4.37 \\
\hline 4 & $6-8$ mds. high quality & 50 & $5 \cdot 28$ \\
\hline 5 & $8-10$ mds. do. & $4 \mathrm{I}$ & $4 \cdot 17$ \\
\hline 6 & 7-8 mds. do. & 29 & 437 \\
\hline 7 & small yield, medium quality ... & 10 & 2.91 \\
\hline 8 & 5 mds. & 32 & 3.16 \\
\hline
\end{tabular}

Any direct connection of either the yield or the quality with the figures is not evident, and this is probably because there is a large excess of Potash in almost all the Assam soils I have examined. In fact there are only about three in the sixty or seventy soils in which Potash has been determined in which it is markedly deficient.

But as stated above, not by any means all the Potash in the soil is immediately available. The following table shows the amount actually available in the virgin and in the old tea soils of several gardens. They show, if nothing else, the drain on this ingredient which takes place in the growing of tea, and the necessity sooner or later of Potash manures. The day when this will be required is, however, I fancy, still far off in most cases.

\begin{tabular}{|c|c|c|c|c|c|c|c|c|}
\hline \multirow{2}{*}{ GARDEN. } & & \multirow{2}{*}{ Age of Tea. } & \multicolumn{3}{|c|}{$\begin{array}{c}\text { Total Potash in Soil. } \\
\text { Per cent. }\end{array}$} & \multicolumn{3}{|c|}{$\begin{array}{c}\text { Available Potash in Soil. } \\
\text { Per cent. }\end{array}$} \\
\hline & & & $\begin{array}{l}\text { Virgin } \\
\text { Land. }\end{array}$ & $\begin{array}{l}\text { Old Tea } \\
\text { Land. }\end{array}$ & $\%$ Loss & $\begin{array}{l}\text { Virgin } \\
\text { Land. }\end{array}$ & $\begin{array}{l}\text { Old Tea } \\
\text { Land. }\end{array}$ & $\%$ Loss \\
\hline $\begin{array}{l}\text { Sonajuli } \\
\text { Dikorai } \\
\text { Dijoo } \\
\text { Panitola } \\
\text { Noakachari } \\
\text { Cinnamara }\end{array}$ & $\begin{array}{l}\ldots \\
\cdots \\
\ldots \\
\ldots\end{array}$ & $\begin{array}{l}10 \text { years. } \\
35 \text { years, } \\
35-40 \text { years. } \\
26-28 \text { years. } \\
30-40 \text { years. } \\
40 \text { years. }\end{array}$ & $\begin{array}{l}\cdot 35 \\
\cdot 19 \\
\cdot 24 \\
\cdot 38 \\
\cdot 09 \\
\cdot 13\end{array}$ & $\begin{array}{l}33 \\
.16 \\
19 \\
\cdot 31 \\
.09 \\
10\end{array}$ & $\begin{array}{l}5.7 \\
15.8 \\
20.8 \\
18.4 \\
.9 \\
23.1\end{array}$ & $\begin{array}{l}.021 \\
\ldots \\
016 \\
014 \\
.009 \\
009\end{array}$ & $\begin{array}{l}.015 \\
\ldots \\
008 \\
.007 \\
.007 \\
006\end{array}$ & $\begin{array}{l}28 \cdot 6 \\
\ddot{30} \cdot 0 \\
50 \cdot 0 \\
22 \cdot 2 \\
33 \cdot 3\end{array}$ \\
\hline
\end{tabular}


The only question is as to what connection this falling off of the Potash has with the falling off of the quality, and to this one cannot at present give a satisfactory reply. It is a matter which demands investigation by experimental culture on the spot.

\section{LIME IN ASSAM SOILS.}

In past time much has been made of the exceedingly small proportion of Lime in Assam Tea soils. Scarcely an analysis has been made by English chemists, as a result of which this material has not been mentioned as a necessary constituent of any manure. The basis for these remarks is the richness in Lime of most European soils, and the apparent necessity of its presence in fairly large quantities for most agricultural crops, especially where a large amount of leaf formation is desired. As a general rule among agricultural crops, the more leaf surface developed the more Lime is required, and as a confirmation of this it is found that the ash of tea is fairly rich in this constituent. Prima facie, therefore, it would appear that a rather large quantity of Lime would be required in the soil for successful tea culture. The facts however are all the other way. Lime is contained in very small amount in nearly all Assam soils, -even the best,-and more than this, the plant seems to resent any attempt to unduly increase it. If a heap of Lime has stood for some time on a particular spot, the tea never flourishes there, I am told. "Busti" soils always contain more Lime than the surrounding land and will not grow tea well, but this fact may or may not be a result of the excess of Lime. Nor does continued growth of tea apparently exhaust the Lime, either total or available, to an extent at all comparable with the exhaustion of the Phosphoric Acid and Potash. The following table shows this :-

\begin{tabular}{|c|c|c|c|c|c|c|c|c|}
\hline \multirow{2}{*}{ GARDEN. } & & \multirow{2}{*}{ Age of Tea. } & \multicolumn{3}{|c|}{ Total Lime in Soil. } & \multicolumn{3}{|c|}{ Available Lime in Soil. } \\
\hline & & & $\begin{array}{l}\text { Virgin } \\
\text { Land. }\end{array}$ & $\begin{array}{l}\text { Old Tea } \\
\text { Land. }\end{array}$ & $\%$ Loss & $\begin{array}{l}\text { Virgin } \\
\text { Land. }\end{array}$ & $\begin{array}{l}\text { Old Tea } \\
\text { Lard. }\end{array}$ & $\%$ Loss \\
\hline $\begin{array}{l}\text { Sonajuli } \\
\text { Dikorai } \\
\text { Dejoo } \\
\text { Panitola } \\
\text { Noakachari } \\
\text { Cinnamara }\end{array}$ & $\begin{array}{l}\ddot{.} \\
\ddot{*} \\
\ddot{*} \\
\cdots\end{array}$ & $\begin{array}{l}10 \text { years. } \\
35 \text { years. } \\
35-40 \text { years. } \\
26-28 \text { years. } \\
30-40 \text { years. } \\
40 \text { years. }\end{array}$ & $\begin{array}{l}04 \\
04 \\
\cdot 11 \\
09 \\
06 \\
06 \\
04\end{array}$ & $\begin{array}{l}\cdot 09 \\
\cdot 04 \\
02 \\
05 \\
04 \\
04 \\
04\end{array}$ & $\begin{array}{c}\ldots \\
8 \ddot{8} \cdot 8 \\
44 \cdot 4 \\
33 \cdot 3 \\
\ldots\end{array}$ & $\begin{array}{l}.019 \\
\ldots \\
.086 \\
.023 \\
.020 \\
.013\end{array}$ & $\begin{array}{l}.064 \\
\ldots \\
012 \\
0117 \\
018 \\
018 \\
015\end{array}$ & $\begin{array}{l}\ldots \\
\ldots 6 \\
86 \cdot 0 \\
26 \cdot 1 \\
10 \cdot 0 \\
\ldots\end{array}$ \\
\hline
\end{tabular}


These results are wholly irregular, but they do not seem to indicate nearly the demand on the Lime which would have been expected. In fact, small as the percentage usually is in Assam soil, I think there is hardly any case where Lime manuring is necessary because the soil is exhausted of this constituent. It may be applied for other reasons, as for instance, to improve the physical condition of the land (see page 16 ), or it may be put on to eradicate blight, or it may even be put on to correct the acidity of soils (though acidity is unknown in Assam, except in peat bheels), but otherwise the necessary changes will take place in the soil, and the plant be sufficiently fed without any intentional addition of Lime as a manure. Only about $4 \mathrm{lbs}$. per acre per annum is needed by the plant, and this is always abundantly present.

\section{EFFECT OF LIME ON QUALITY.}

At one time Lime was supposed to have a beneficial effect on quality. Mr. Bamber however showed that the gardens and districts giving the best tea had by no means necessarily the most Lime in their soil, and it has recently been pointed out that the teas which sell at the highest prices generally contain the least Lime. The small quantity in the soil of the best gardens is shown in the following table, all being places yielding very high class tea.

\begin{tabular}{c|c||c|c||c|c}
\hline \hline No. & Percentage of Lime. & No. & Percentage of Lime. & No. & Percentage of Lime. \\
\cline { 2 - 4 } 1. & .09 & 3. & II & 5. & .06 \\
2. & .16 & 4. & .08 & 6. & .10 \\
\hline
\end{tabular}

When it is considered that English soils rarely contain less than 0.2 per cent. of Lime, and that most of the Ceylon tea soils contain more than this, the independence of quality of the amount of Lime may, I think, be considered proved.

\section{EFFECT OF OXIDE OF IRON.}

Such are the more important ingredients of the tea plant obtained from the soil. There remain however several others to which great powers and influence on the quality of the tea have been attributed. Oxide of Iron is perhaps the most important of these. The red colour, due to iron, of the best tea soils is evident to everyone. Again and again it is noticed. Jorhat soil is a red sand, 
Tezpore has a bank of red loam, and the Doom Dooma ridge is a deep red sand. But the amount, on analysis, of the Oxide of Iron does not here seem to be really greater than in those gardens where for one cause or other the soil has not the rich red colour. It is merely in a different state of combination, which may or may not indicate a readier availability for the plant, but which does mean a thoroughly aerated soil.

I thought that if the total iron had no appreciable effect on the quality of the tea, the amount available for the plant might be some guide to the value of the soil for this purpose. This seemed likely to be the case, for a trace of iron has a great part to play in forming rich dark-coloured leaves. The following analysis seems to give support to this idea, and it is distinctly a line to be followed out in the future. The exhaustion during the growth of tea has in every case been considerable, and this may in some measure account for the reputed falling off in the quality of many old gardens. In the cases cited, however, there still seems an ample margin of readily available iron for many years to come.

\begin{tabular}{|c|c|c|c|c|c|}
\hline \multirow{2}{*}{ GARDENS, } & & \multirow{2}{*}{ Age of Tea. } & \multicolumn{2}{|c|}{$\begin{array}{l}\text { Available OXIDE OF Iron in } \\
\text { SOIL PER CENT. }\end{array}$} & \multirow{2}{*}{$\begin{array}{l}\text { Percentâge } \\
\text { L } \sim \text { ss. }\end{array}$} \\
\hline & & & Virgin Land. & Old Tea Land. & \\
\hline $\begin{array}{l}\text { Sonajuli } \\
\text { Dejoo } \\
\text { Noakachari } \\
\text { Cinnamara } \\
\text { Panitola }\end{array}$ & \begin{tabular}{l|}
$\ldots$ \\
$\ldots$ \\
$\ldots$ \\
$\ldots$ \\
$\ldots$
\end{tabular} & $\begin{array}{ll}\text { 10 years } & \ldots \\
35-40 \text { years } & \ldots \\
30-40 \text { years } & \ldots \\
40 \text { years } & \ldots \\
26-28 \text { years } & \ldots\end{array}$ & $\begin{array}{l}436 \\
\cdot 420 \\
\cdot 269 \\
\cdot 172 \\
\cdot 327\end{array}$ & $\begin{array}{l}\cdot 277 \\
\cdot 345 \\
\cdot 230 \\
\cdot 152 \\
\cdot 307\end{array}$ & $\begin{array}{r}36.4 \\
17.9 \\
14.5 \\
11.6 \\
6.1\end{array}$ \\
\hline
\end{tabular}

\section{LOWEK OXIDE OF IRON.}

$\mathrm{Mr}$. Bamber enunciated last year a theory that the quality of tea was directly connected with the amount of lower Oxide of Iron in a soil, an ingredient which is, however, hardly ever present except in very minute quantity. As far as Ceylon soils were concerned, the amount of the lower oxide found was a fairly satisfactory measure of the quality of the tea produced upon the land. I cannot say that this theory fits in at all with Assam conditions. The lower oxide does not seem to have any constant relationship either to flavour, pungency or strength, and I am inclined to regard its percentage as depending ( 1 ) on the quantity of Organic Matter; (2) on the 
condition of the Organic Matter. Virgin grass lands seem to contain a good deal; virgin forest much less; grazed land very little, and its apparent influence is probably only the influence of the organic matter in the soil. The following are the amounts found in a number of Assam soils :-

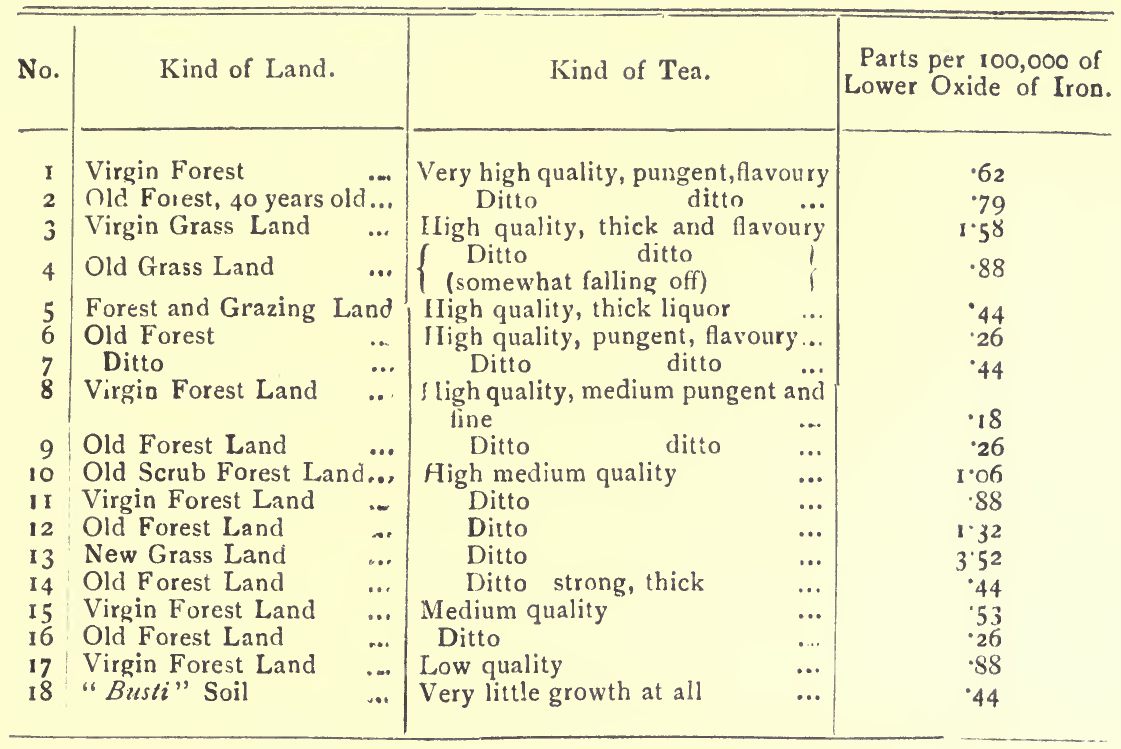

No regularity can be observed among these figures. Some of the highest quality gardens are as low in percentage of lower Oxide of Iron as any of the examples given,- and on the other hand the high medium gardens give as high a quantity as any. One cannot therefore base any argument as to the quality of tea produced applicable to Assam on their percentage of the lower Oxide of Iron.

\section{MANGANESE IN SOIL.}

An attempt has been made to draw a connection between the amount of Manganese in the soil and the quality of the tea. Mr. Bamber seems to indicate that an addition of Manganese to the soil caused the leaf to colour better and give a brighter liquor. I therefore determined the amount of available Manganese in a number of virgin and old soils, but the figures, which follow, are so extremely irregular that one is driven to the conclusion that either it has no connection with the quality of the tea, or else it is present in ample 
quantity in all the soils examined. The latter seems the most likely supposition.

\begin{tabular}{|c|c|c|c|c|c|}
\hline \multirow{2}{*}{ Garden. } & & \multirow{2}{*}{\multicolumn{2}{|c|}{ Age of Tea. }} & \multicolumn{2}{|c|}{$\begin{array}{l}\text { PERCENTAGE OF OXIDE OF } \\
\text { MANGANESE. }\end{array}$} \\
\hline & & & & Virgin Land. & Old Tea Land. \\
\hline Sonajuli & ... & Io years & $\ldots$ & 009 & .013 \\
\hline Dejoo ... & $\cdots$ & $35-40$ years & $\ldots$ & 015 & .031 \\
\hline Panitola ... & ... & $26-28$ years & $\ldots$ & .018 & $\cdot 007$ \\
\hline Noakachari & $\ldots$ & $30-40$ years & $\ldots$ & OII & .002 \\
\hline Cinnamara & $\ldots$ & 40 years & $\ldots$ & .004 & .004 \\
\hline
\end{tabular}

BALANCE AMONG SOIL CONSTITUENTS.

But finally, what seems of greater importance for the luxuriant growth of high quality tea than the presence in large quantity of any particular constituent, is that the constituents of the soil should be well balanced-that is, that it should contain enough organic matter and nitrogen to satisfy the utmost needs of the plant (say not less than 0.8 per cent. of nitrogen calculated on the soil less the sand), and then a sufficient quantity of other constituents to prevent the plant having any trouble in obtaining them, If there is a large quantity of readily available nitrogen - with the necessary organic, matter-and not sufficient readily available Phosphoric Acid, etc., there will probably result a rank growth giving sappy wood, and leaf without the special qualities of high class tea. If, on the other hand, the nitrogen is too small in amount and the other constituents in excess, a high quality tea will be produced,-but only little of it. And further if both nitrogen and phosphoric acid are low, then neither luxuriance nor quality are obtained, and the garden is worn out-becomes the prey to blight after blight-fills with vacancies and probably ultimately disappears or is abandoned. Such are the washed teelas found occasionally in Assam, but more often in Cachar, and which are now all but given up.

SUMMARY.

In summary, therefore, tea requires for its successful cultivation a considerable quantity of organic matter and nitrogen in the 
soil-the best results being only obtained when more than 35 per cent. of the non-sandy portions of the soil consist of organic matter, and 0.8 per cent. of nitrogen. Provided this is present, tea can be cultivated with success in presence of a minimum quantity* of other constituents, notably Phosphoric Acid and Potash, but to obtain high quality tea these latter materials must exist in the soil in larger amount, and other things being equal, the larger the quantity of phosphoric acid (in presence of sufficient nitrogen) the better will be the tea. Potash runs parallel with phosphoric acid, but is probably present in ample quantity in Assam soils. In short, much nitrogen with little phosphoric acid will produce rank growth with medium tea only-much nitrogen with much phosphoric acid will give luxuriant growth and high quality tea-little nitrogen with much phosphoric acid will give high quality tea, but comparatively littl eof it-and if there is a deficiency in both, tea can never be profitable. Other constituents beside the three named may possibly have an intimate connection with the quality of the tea. Lime probably has little or none-and is in any case present in ample quantity everywhere. Iron-available Iron-may have some influence and apparently decreases in old soils, but this requires further investigation, and Iron, at any rate, does not apparently need to be applied as manure. Manganese--whatever its value, which needs to be proved yet by thorough experiment on a garden-is, I believe, generally present in abundance in an available form in Assam. The deficiencies, and the increasing deficiencies, of the soils of many of the tea gardens in the Brahmaputra Valley render manuring a necessity in the future. To the methods by which the necessary replacement of the materials indicated above as affecting the yield and quality of tea, the next chapter will be devoted.

- One might tabulate these results and say that in general terms if on analysis a soil presents-

1. Less than 35 per cent of Organic Matter on the non-sandy portion of the soil it

2. Less than 0.8 per cent. of Nitrogen $\}$ needs these constituents as manure.

3. Less than 0.25 per cent. of Phosphoric Acid, calculated in the same way, it needs phosphates, and if high quality tea is to be produced 0.4 per cent. should be present.

4. Potash in amount less than $3^{\circ} \circ$ per cent. of the Oxide of Iron and Alumina, taken together, it needs Potash manures. 


\section{CHAPTER IV.}

\section{MANURES FOR TEA IN A.SSAM.}

Once it has been established that material exhaustion of land takes place by growing a crop, there remain only two alternatives before the cultivator - that of manuring the land already in cultivation, and that of abandoning the old plots and putting out fresh land. The latter has been the plan usually adopted in new countries, and it has generally been difficult to make the old agriculturists see that manuring would ever be needed. This has been precisely repeated in the case of tea. And in some few cases the position is probably correct. There are some deep rich alluvial sands which may probably be cultivated under tea for very many years without any fertilisation being needed-but these are very few in number, and I doubt whether there are more than one or two pieces of tea land in Assam about which it could be said. But a system of abandonment an'd extension cannot go on indefinitely on account of the exhaustion of suitable land,-a point which has been reached already in certain cases,-nor can such a system proceed for long because of its expense and because it means the removal of the best yielding land on a garden further and further from the factory. The only alternative is manuring in one form or another, and this will have to be the policy of the future.

\section{OBJECTIONS TO MANIJRING.}

Two objections are at once raised. "Manuring can never payit costs too much" is the first of these--and to this it can be replied summarily that "manuring must pay, or the land must become a wilderness, and the population it supports abandon it or starve." Agriculture all over the world emphasises the fact that except in very favoured places no agriculture can be carried on on the same spot year after year without the application of manure.

The second objection taken is that once manures are used it becomes a necessity to use them continually. To a certain extent this is true and necessarily so. Land which has once commenced to deteriorate will continue to do so unless by repeated applications it is kept up to the mark. And the reason which compels manuring in the first instance compels its continuance at intervals for ever afterwards. This however can be reduced to a minimum of frequency and of cost by judicious selection of manures,-leaving those as far as possible on one side whose action s purely temporary such 
as Nitrate of Soda, or which themselves have a tendency to impoverish the soil for the future as, for instance, Sulphate of Ammonia. To argue that because future manuring will be necessary, therefore a garden is to be allowed at present to deteriorate beyond recall, is a policy so shortsighted that had it not been put before me on many many occasions, I should not have attempted to discuss.

GENERAL PRINCIPLES OF MANURING.

As a general policy, Firstly it is by no means wise to await manifest deterioration before going to manuring. A slight but continuous decrease in yield is a warning that the land is less capable of producing than it was. Collar-pruning is then often adopted and results in a temporary spurt after which the bushes only become worse again than they were before. Really what was wanted was not collar-pruning, but manure. I fancy that in nearly all parts of Assam, after about the tenth year of a garden some means should at least be used to retain and increase the food material in the soil, and after the fifteenth there are few cases where manure is not absolutely required, if some loss in yield and often in quality is not to be anticipated. In some unsuitable lands put out in tea even recently, manure is required almost as soon as the tea commences to grow, but these are exceptional, and ought really never to arise.

Secondly.--The nucleus of whatever manuring is done must be found on the spot. Everything not profitably saleable that the garden produces should be returned to the land. Every morsel of cattle manure, of wood ashes, of pruning ashes, of tea refuse not sold, of sweepings of coolie lines, of road sweepings, of jungle cut round the tea, \&c., \&c., should be put on the tea if a really economical manurial policy is to be carried out. If all these were collected and composted with soil during the whole season and then put on the land, much less manure would be required from outside. To have such products and allow them to rot about the place, unless for some trenchant reason, is wasteful in the extreme.

Thirdly_As little should be bought outside the district as possible. Artificial manures should be reduced to the lowest quantity especially in view of the enormous cost of their importation. There are occasions in which it may be necessary to use them, but the less they are needed the better. Assam, as a province, is extremely rich, and while there is so much unoccupied land, it seems almost inconceivable that nearly all the materials required for fertilising the 
tea cannot be produced on the spot, and it should be the aim to obtain all that is possible in this way.

Fourthly.-If artificial manures be required, it should be regarded as essential just to supply the constituents which are deficientand no more. Complete mixed manures for a new province like Assam, as sold ready made under the name of "Tea manure," are not only generally very dear for what they contain, but also contain several constituents of no value under the special circumstances.

Fifthly,-Manures of lasting character should be chosen rather than those which, while more powerful for a short time, are soon used up. Of the latter class are Nitrate of Soda, or Nitrate of Potash, and Sulphate of Ammonia, and in general those easily soluble manures which are apt in large measure to be soon washed out of the land if not immediately taken up by the tea.

\section{SOIL CONSTITUENTS REMOVED BY CROPS.}

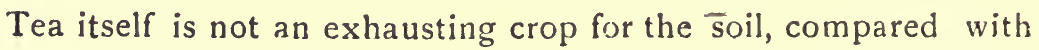
many others. It is rarely that more than ten maunds of tea are taken away from the garden, the ashes of the prunings should be returned to the soil, so that the nitrogen in the prunings when these are burnt is the only manurial matter which forms a dead loss. Now ten maunds of tea roughly contains-

$\begin{array}{lllrl}\text { Nitrogen } & \ldots & \ldots & 36 & \mathrm{lbs} . \\ \text { Phosphoric Acid } & \ldots & \ldots & 8 & " \\ \text { Potash } & \ldots & \ldots & 20 & " \\ \text { Lime } & \ldots & \ldots & 4 & "\end{array}$

Compare this with the quantity of these constituents removed by other crops of which some are given below.

\begin{tabular}{|c|c|c|c|c|c|}
\hline & & $\begin{array}{l}\text { Wheat } \\
40 \text { bushels. }\end{array}$ & $\begin{array}{l}\text { Sugar Beets } \\
18.19 \text { tons. }\end{array}$ & $\begin{array}{l}\text { Cotton } \\
1 \frac{1}{2} \text { tons. }\end{array}$ & $\begin{array}{l}\text { Tobacco } \\
720 \text { lbs. }\end{array}$ \\
\hline Nitrogen & $\cdots$ & $48 \mathrm{lbs}$. & $121 \mathrm{lbs}$. & $58 \frac{1}{2} 1 b s$ & $28 \frac{3}{4}$ lbs. \\
\hline Phosphoric Acid & $\ldots$ & 24, & $72 "$ & $45 "$ & $6 \frac{3}{4} \quad 1$ \\
\hline Potash ... & ... & $16 "$ & 304, & $70 \frac{1}{2} n$ & $41 \frac{3}{4}$ \\
\hline Lime $\quad \ldots$ & ... & $1 \mathrm{lb}$. & 32, & 88, & $51 \frac{8}{4} \quad "$ \\
\hline
\end{tabular}

Even if the above quantity of Nitrogen be doubled to represent the loss in burning the prunings, it will still be far and away below 
the amount needed for many crops, and the quantity of other constituents removed is much less than with most agricultural products. Tca does not therefore make very excessive demands on the soil, and both from a consideration of these figures, and from analyses of old and new tea soils one may, I think, say that for Assam at any rate only Nitrogenous and Phosphatic Manures will usually be needed at present, and only the latter will be required from purely artificial sources.

TOP-DRESSING SOIL MANURE.

But let us first consider the manures locally available. The first and most important of these, both for the extent to which it has been used, and for the extension which its use is likely to take in the future, is top-dressing soil material. It is not in many climates and countries that the extremely rich deposits which can be used are available, and their presence arises from the low character of the land, from the fact that the excessive rainfall causes it to be cut up in every direction, and from the extreme rankness of the vegetation which causes the low uncultivable tracts thus produced to be immediately covered with plants, which by constant growth and decay give a topsoil of exceeding richness. On the other hand, it must be remembered that after all, it is a very clumsy method of manuring, as it often involves the removal of roo tons of soil to get 5 tons of valuable material, and that it is only in a country where labour is extremely cheap that it could even be thought of. The success which has followed its application has tended to make it somewhat of a fetish, and I have seen many hundred tons of material put on the land which, except for some slight mechanical improvement of the soil to which it was applied, could have little or no manurial value. When it is remembered that the usual dressing of 6 inches deep (equal to 2 to $2 \frac{1}{2}$ inches when settled down) means the application of 400 tons of material per acre, it will be seen how extremely wasteful it is of labour, strength and money if the material be not of the best. It has also been objected that "bheel soiling" lowers the quality of the tea obtaincl. In this connection it must be remembered that there are various kinds of top-dressing,-real peat bheel might lower quality, but even this question is still sub judice, while it would be difficult to conceive that forest surface soil could do so. It is quite possible that the supposed lowering of quality may be quite as much due to the sappy growth after cutting down,-for the time of hard pruning was usually chosen for top-dressing,-as to the top-dressing itself. 
PEAT BHEEL SOIL AS TOP-DRESSING.

The various kinds of top-dressing have however very different properties and are of very different value. Best of all, as producing luxuriance, is the real peat theel soil which only occurs occasionally in Assam. A real peat is formed by the decay of many generations of rank growing plants, the principal part of this decay occurring under water. Where this has occurred, naturally drainage-and hence wastage of material-has been at a minimum, especially as under these conditions practically no nitrates are formed. It implies long years of formation, for the particular deposit termed peat is of very slow formation. These deposits occur snmetimes on the surface, sometimes at some depth under the soil, especially in the Tezpur and Nowgong districts. The Nitrogen and Organic Matter in these is usually very high, as the following analyses both from the Tezpur District show :-

Organic Matter, \&c.

I.............. 30.29 per cent. ...

Nitrogen.

$2 \ldots \ldots \ldots . . . . .2[78$

... 60 per cent.

... 68 ,

Another bheel soil of the same character from Chittagong, which came into my hands, is even richer.

$3 \ldots \ldots . . . \ldots . . . .50 .85$ per cent. ...

... II 5 per cent.

These peats are eminently valuable, and wherever found should be undoubtedly used for manure, as they will assuredly pay for putting on the land. It has been said, as noted above, that they lower the quality of the tea. I have recently had the opportunity through the kindness of Mr. M. Chamney of the British Assam Tea Company's gardens at Tezpur. of comparing the quality of tea produced by two similarly light-pruned plots lying side by side on the Tezpur bank, one of which was treated with the very rich bheel material marked 2 above, at the rate of 100 tons to the acre, while the other received none at all. The top-dressing was carried out in February, March and April, 1901, and the yield of the plots has been as follows (up to September 26th), in 1900 and 1901 , weighed as green leaf-

\begin{tabular}{|c|c|c|c|}
\hline top-dressed in $I$ & 1900 & $\ldots$ & $48 I$ \\
\hline (34 acres) & I9O I & $\therefore$ & 543 \\
\hline $\left.\begin{array}{c}\text { Plot unmanured in either } \\
\text { year }\left(35^{\prime} 7 \text { acres }\right)\end{array}\right\}$ & $\begin{array}{l}1900 \\
1901\end{array}$ & $\begin{array}{l}\cdots \\
\ldots\end{array}$ & $\begin{array}{l}458 \frac{1}{2} \\
358 \frac{3}{4}\end{array}$ \\
\hline
\end{tabular}

The increase in yield is therefore enormous. Messrs. W. S. Cresswell \& Co. of Calcutta, who were good enough to report on the quality of these teas, say that in each case the plots treated with top-dressing give a tea with a slightly brighter liquor than 
that obtained from the unmanured section, but in other respects not differing in value.

This experiment, the only one carried through under exact conditions which is on record, affords decided evidence that such top-dressing does not cause a loss of quality : the impression is, however, so strong among planters thai deterioration is produced by this means that during the coming year I hope to test the question further. At present we have no reason. to suppose that the leaf is poorer after top-dressing with bheel soil than before. Material so rich as this should, however, never be applied in greater quantity than $100-120$ tons to the acre, or an entirely different state of affairs might result.

\section{ASSAM BLACK SUBSOIL.}

Often in the same districts as these peat bheels, and in many other places besides, there exists a black sub-soil which at first sight seems to possess the character of peat. I have noticed it in the Tezpur and Bishnauth districts, on the bank of the river at Behalli, in the Dehing Valley, and at several places in the Jorhat district, and have been many times asked whether it will be useful for topdressing. It consists of a very finely divided, greasy, slimy material, containing no vegetable remains, which, when damp, cuts like cheese and which contracts very much on drying. It will write on a white surface like graphite. Wherever this material occurs near the surface the tea is invariably not luxuriant, and I have never seen it penetrated by the roots of the tea bush. By itself it therefore is certainly not suitable for tea. On the other hand, it is rich in plant food, as the following analyses show :-

\begin{tabular}{|c|c|c|c|c|c|}
\hline & & & $\mathrm{I}$. & 2. & 3. \\
\hline - Organic Matter, \&c. & . & $\ldots$ & $7 \cdot 49$ & $8 \cdot 58$ & $9 \cdot 59$ \\
\hline Oxide of Iron ... & .. &.. & 5.90 & 466 & $7 \cdot 45$ \\
\hline Alunina & $\therefore$ & $\ldots$ & 560 & $6 \cdot 39$ & 379 \\
\hline Lime & .. & $\cdots$ & 35 & 21 & 67 \\
\hline Magresia & .. & $\cdots$ & $1 \cdot 07$ & $1 \cdot 19$ & 52 \\
\hline Polash & $\cdots$ & $\cdots$ & 52 & $6_{3}$ & $\cdot 33$ \\
\hline Soda & .. & $\ldots$ & $\cdot 45$ & $\cdot 26$ & 27 \\
\hline Phosphoric Acid & .. & $\cdots$ & 15 & 14 & $\therefore$ int \\
\hline Sulphuric Acid & $\cdots$ & $\cdots$ & · 18 & .02 & ${ }^{\circ} 02$ \\
\hline \multirow[t]{2}{*}{ Insoluble Silicates (Sand) } & $\cdots$ & $\cdots$ & $79 \cdot 10$ & 77.92 & $77 \cdot 25$ \\
\hline & & & $100 \cdot 00$ & $100 \cdot 00$ & $100 \cdot 00$ \\
\hline "Containing Nitrogen & .. & .. & $x_{5}$ & $\cdot 21$ & $\cdot 6$ \\
\hline
\end{tabular}


Other samples, in which only the Organic Matter and Nitrogen were determined, gave in percentages -

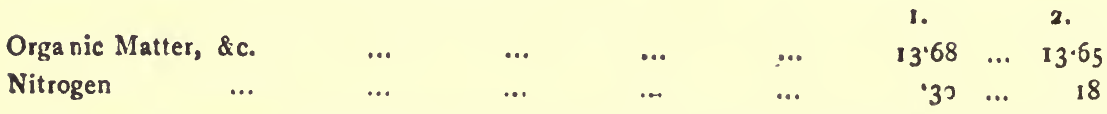

This material, which will, I think, be everywhere recognised from the above description, is of very doubtful value as a manure. On no account should it be put on soil which is already somewhat stiff, as it will tend to puddle the surface. Further, it contains always a certain quantity of Sulphur as Sulphides-which forms Sulphuretted Hydrogen (a plant poison) under certain conditions. In the first of the above samples this Sulphur amounted to 22 per cent., equal to 42 per cent. of Iron Pyrites, and when moistened smelt distinctly of the above-named Sulphuretted Hydrogen. This however would soon pass off on exposure to the air; and it is well worth while to try this material on a small scale, on light land only, as it is quite possible that it may turn out very valuable, and in some places it occurs in inexhaustible quantities. In such a case it would be wise to keep it, so far as possibie, from actually touching the stems of the bushes when first placed on the land.

\section{HULLAH SOIL AS MANURE.}

The most common material applied as top-dressing is however hullah soil-a material as variable in composition as can well be imagined. In some cases where rank vegetation has existed for many years it approaches bheel soil in character: in others it is little else than sand from the bed of a running stream.

For a hullah soil to be really valuable, it should, I think, fulfil the following conditions:-

(1). It should carry a rank vegetation, - wild cardamoms are often a feature of suitable situations.

(2). It should be black in colour, at any rate when wetted, and contain plant refuse-rootlets, \&c.

(3). It should not be taken from running water.

(4). In cases where the soil to which it is to be applied is heavy or close in texture, it should at least be of a lighter character than that on which it is to be placed. 
If it answers to these characters, it may fairly be assumed that the material is good enough to safely apply to most of the land in Assam. Such are some of the soils in which the following determinations of Nitrogen and Organic Matter have been made :-

\begin{tabular}{|c|c|c|c|}
\hline \multicolumn{2}{|l|}{ Garden. } & Organic Matter, \&c. & Nitrogen. \\
\hline & & per cent. & per cent. \\
\hline Cinnamara $\quad \ldots$ & $\ldots$ & $6 \cdot 05$ & .25 \\
\hline Sangsua $\quad\left(6^{\prime \prime}\right.$ deep) & .. & $8 \cdot 62$ & .23 \\
\hline Samaguri (6" deep) & $\ldots$ & $9 \cdot 73$ & $\cdot 30$ \\
\hline Gotoonga ( $7^{\prime \prime}$ deep) & $\cdots$ & $8 \cdot 40$ & 23 \\
\hline Suntok & $\ldots$ & $7 \cdot 45$ & $\cdot 15$ \\
\hline
\end{tabular}

In this connection there is one practice which, from an economical point of view, one cannot condemn too strongly. This is that of top-dressing from a hullah, and then again using the material of the same hullah for top-dressing again three or four years later. In the meanwhile there has not been sufficient time for a new layer of vegetable soil to form, and the practice merely consists of putting on little more than a layer of subsoil of little manurial value, and certainly not worth the thirty to forty rupees per acre that the application would cost. The following are the partial analyses of some of these hullahs, which it was suggested to use for top.dressing, but which had been used three or four years before :-

\begin{tabular}{c|c|c|c}
\hline Number. & District. & Organic Matter, \&c. & Nitrogen \\
\hline & & Per cent. & Per cent. \\
Tezpur. & $4 \cdot 89$ & $\cdot 06$ \\
Jorhat & $4 \cdot 23$ & $\cdot 13$ \\
do. & 4.00 & $\cdot 09$ \\
& do. & 4.03 & $\cdot 12$ \\
\hline
\end{tabular}

In each of the above cases the soil was poorer than that on which it was intended to put it -and so money spent on this busi. ness would have been almost entirely lost. Even under the most favourable conditions, such as those of the Brahmaputra Company, where the hullahs are fed annually with rich river silt, as well as the 
refuse of an exceedingly rank vegetation, it is considered that the same hullah cẩnot furnish top-dressing material again before ten years have elapsed-and this estimate is much too low for the average garden. In certain cases, however, practical experience seems to indicate that mere subsoil from hullahs may be of some service. This hás"apparently been the case on some of the Assam Company's gardens. At present the only explanation is that it has some beneficial effect on the texture of the land, but if so, it can only be in rare cases that it will repay the cost of application.

FOREST SURFACE SOIL AS MANURE.

In the absence of peat or good hullah soil, the surface of the forest has often been used, and, provided it has not to be carried more than a few yards, this has been distinctly an economical success. Only about the top six inches is usually however valuable, and the depth at which the removal should stop can generally be seen by a change of colour in the land. This material is useful exactly in proportion to its richness in Organic Matter and Nitrogen, and no more. Its effect on the texture of the soil to which it is applied can be practically neglected. If, therefore, it is richer in the above constituents, as it presumably is, than the soil to which it is to be applied, it is useful, but an analysis of both will be necessary (in regard to these constituents) before one can say whether it will be profitable or not. Thus the material used at Salonah, Nowgong, taken from the surface of "Korkani" Jungle, contained 9.53 per cent. of Organic Matter and is per cent. of Nitrogen, the soil on which it was put contained 5.13 and 08 per cent, respectively, hence the material did very great good. Another forest surface soil which came into my hands from Golaghat contained 497 per cent. Organic Matter and 13 per cent. of Nitrogen. As the soil was a light one, it would probably be of advantage, but it will not usually pay, even on light land, to put on material containing a much less amount of valuable matter than this.

In these cases it becomes a very grave question as to whether other less cumbrous methods would not give better results. The method is costly, from 30 to 100 rupees per acre being spent on one application, but the usual justification seems to be that this is expended" in labour, and the labour must in any case be paid. Therefore, as the process of putting it on the land comes in the 
slack months, the expense is not entirely an out-of-pocket one, but represents money, a large part of which would have to be expended in any case. This, 1 am afraid, opens up an aspect of the question which I am hardly competent to discuss; but would it not be possible for coolies to be more profitably employed? In certain cases, at any rate, would it not be feasible to plant up some of the: waste land of the grant with a crop in the cold weather which would yield an equal amount of manure, and a valuable product as well? Such a crop would be mustard-which would entirely be produced with comparatively little labcur in the slack time of the year-and would give a valuable manure cake, and also a large quantity of oil needed by the employees of the garden (see page 88). I throw this out merely as a suggestion, but it certainly seems hardly the most profitable and economical method of manuring to remove say 200 tons of material per acre, cnly 5 per cent. of which is in any way valuable to the tea plant.

GARDEN SUBSOIL AS MANURE.

There remains to consider one type of top-dressing which one cannot condemn sufficiently as unprofitable, namely, that of putting on ordinary garden subsoil as manure. In several cases canals have been cut through the garden at the sacrifice of one or two rows of tea, and then the material down to 4 feet deep put on the surrounding land. This can be justifiable only in the special case where excessive wash has taken place, the bushes are standing right out of the ground, and it is essential to replace the soil lost,-anything being better than nothing for the purpose. In other cases, however, such a process is absolutely devoid of advantage, save very occasionally to improve the texture of the land. In some cases the application of subsoil has even resulted in material injury to the bush-and I cannot recommend it on economic grounds in any but those places where the subsoil is itself a black peaty material. To show the average extreme poverty of the subsoil, the following figures are given :-

\begin{tabular}{c|c|c|c|c}
\hline \multirow{2}{*}{ No } & \multicolumn{2}{|c|}{ Percentage in Subsoil of } & \multicolumn{2}{c}{ Percentage in Soil of } \\
\cline { 2 - 5 } & $\begin{array}{c}\text { Organic } \\
\text { Matter, \&c. }\end{array}$ & Nitrogen. & $\begin{array}{c}\text { Organic } \\
\text { Matter, \&c. }\end{array}$ & Nitrogen. \\
\hline 1 & 4.94 & .07 & 469 & .69 \\
2 & 3.75 & 09 & 4.81 & 13 \\
3 & $\ldots . .$. & 07 & 3.59 & 09 \\
\hline
\end{tabular}


In every case the subsoil to be applied as manure is poorer than the soil on which it is to be placed. Can it therefore be worth applying aș manure? It might perhaps be answered that these subsoils may contain stores of mineral food-apart from the abovenamed constituents-and that these are rendered useful to the plant by putting the material on the surface. This may be the case to a small extent, but from my analysis of the Assam subsoils, they are never so rich as to make it worth while applying it to the tea at an enormous cost. A top-dressing soil should therefore be analysed in respect of nitrogen and organic matter before application. The whole process only takes a very few days, and it would save the absurd waste of labour which has taken place recently. Any sample sent should be accompanied by a description (sandy, heavy, red clay, \&c., \&c.) of the soil to which it is intended to apply the material. and thus a vast amount of waste expense would be saved.

SUMMARY AS TO TOP-DRESSING SOIL AS MANURE.

In summary, therefore: relative to material for top-dressing, peat will always increase the luxuriance of tea, but there exist some doubts whether the quality is not deteriorated by it : hullah soil is the most variable material possible, but to be valuable should be ( 1 ) black; (2) covered with rank vegetation; (3) not from running water ; (4) lighter in texture than the land to which it is to be applied. Once scraped, a hullah cannot usually be profitably again used for topdressing purposes, even under the most favourable conditions, for ten years. Forest jungle soil may occasionally be profitably applied, but no general rule can be laid down, and garden subsoil is only worth using either to replace the soil taken away by wash, or to improve the texture of the land. It is emphatically advisable that a partial analysis should be made of any material suggested for top-dressing before this latter is applied.

\section{CATTLE MANURE.}

Next in importance to top-dressing soil as a fertilising agency in Assam is cattle manure. Nothing is more astonishing to an outsider visiting Assam tea gardens, than the little use which is made of this material. Always present, generally in enormous quantity, it is indeed rare to find any place where any systematic attempt is made to utilise it. On the average garden of 500 acres there are usually at least five hundred cattle, and each of these may be estimated to produce at least 2 tons of dung per annum, or, 
allowing 25 per cent. to be inevitably lost during the grazing in the day time, about 750 tons per annum for the property. Now ten tons per acre is a very fair dressing, and hence with care from 50 to 75 acres could be treated per annum, or the whole garden, at the least, once in ten years.

Such a proceeding, simple though it appears, involves care in the collection and preservation of the dung which is rarely seen at present. First in its collection. The most feasible and satisfactory way of collecting the manure is to have the whole of the cattle driven at night into an enclosed space or yard, part of which might be roughly covered over or not, as most convenient, and from which they were allowed to go to graze during the day. Adjoining such a yard should be the manure pit, and it would seem hardly too much work for a man to remove and put in the pit daily the dung voided by the cattle during the night time. Such a yard is in operation at some of the gardens I have visited and is a great success, as the coolies have the satisfaction of knowing their cattle safe, and yet the manure is retained and saved without much trouble for the garden. If another man were retained to sweep up all material from the coolie lines daily and put in the manure pit, another source of dung,-goats, fowls, \&c., - would not be lost. As to the preservation of the manure, the pit, which I suggest should be a necessary accessory to every garden, may be formed by digging several feet into the ground, and covering over the hole thus made with the roughest of thatch roofs, say 12 feet from the ground at the lower eaves. Into this every piece of dung, wheresoever picked up, would be placed, and so gradually rot during the season, and be ready for application after pruning is done in the cold weather just before the first spring hoeing. Without such a method of covering up the dung from the weather an enormous loss takes place from washing out of the valuable matter by the rain, and although a large loss is unavoidable in keeping manure under the best conditions, yet there is no reason for making this $\operatorname{los}_{\mathrm{S}}$ greater than it really is. In some recent experiments in Canada, where the rainfall is much less than here, when the loss of manurial matter in exposed and protected manure was compared, it was found that while the exposed lost $540 \mathrm{lbs}$, of Organic Matter, the protected only lost 288 lbs.; while the exposed lost 14 lbs. of Nitrogen, the covered only lost $8 \mathrm{lbs}$; while the uncovered lost 4 lbs. of 
Phosphoric Acid, the covered lost none, and while the open manure lost $22 \mathrm{lbs}$. of Potash, the Potash in the protected remained absolutely intact. In India the loss, as I said above, would probably have been far greater proportionately in the manure left open to the weather. As a conclusion to the above quoted experiment, it is pointed out that the best conditions of rotting necessitate (a) protection from rain, sun and wind ; $(b)$ a watertight floor ; $(c)$ that the mas; of manure should be kept as compact as possible-and there is little doubt that the nearer one gets to these conditions, the more valuable the cattle manure will become.

At present I see no simple way of retaining the urine, but if this could be done a great point would be gained, as the urine contains the most valuable and also the most easily assimilable part of the material voided by the cattle.

But is Assam manure worth all this trouble? Is its composition such as to make it worth while to adopt all these means of retaining it ? The following figures show the composition of dung from Indian cows grazing just as Assam cattle do, and where the urine is not retained (Dr. Leather, Agric. Ledger, 1897, No. 8) :-

\begin{tabular}{llc|c|c|c|c}
\hline & & 1 & 2. & 3 & 4. \\
Moisture & $\ldots$ & $\ldots$ & 76.05 & 78.84 & 75.61 & 73.95 \\
Organic Matter & $\ldots$ & $\ldots$ & 14.90 & 1343 & 1469 & 1595 \\
Siliceous Matter & $\ldots$ & $\ldots$ & 7.4 & 6.67 & 8.46 & 824 \\
Phosphoric Acid & $\ldots$ & $\ldots$ & .182 & .167 & .192 & .126 \\
Nitrogen.. & $\ldots$ & $\ldots$ & 273 & 237 & .269 & 251 \\
\hline
\end{tabular}

A certain amount of drying would take place during the rotting. of the manure, and hence there would be far less moisture in the finally rotted product than appears from these analyses, but an application of ten tons of even such moist material as that shown would mean the addition of $1 \frac{1 / 2}{2}$ tons of Organic Matter, of $56 \mathrm{lbs}$. of Nitrogen, and of 30 to $40 \mathrm{lbs}$. of Phosphoric Acid to the resuurces of each acre of land, an amount by no means to be despised, especially when it is gained at merely the cost of collection.

It hạs been again and again suggested that this manure deteriorates the quality of the tea, even when applied in reasonable quantity. 
I think it may be said that there is absolutely no evidence of this being the case, and such reasonable quantity would be not much more than 10 tons per acre. Of course if an enormous quantity were added, one could not guarantee that an unnatural growth would not be produced 'as has, indeed, been shown to be the case with many fruit trees), but the amount I have named could, I am sure, be applied with perfect safety.

Cattle manure will suit almost any Assam soil, but it is specially indicated on those which are heavier than the average, and its addition would much benefit such lańd. Very light sand also, especially such as lies over clay would also derive very great advantage from the application. The manure as stated above, should be applied, when well rotted, before the early spring hoe; and immediately buried by the hoeing. Its effect should be visible in May and continue throughout the season.

One objection has been raised against the use of cattle manure - that it encourages the orange beetle in the garden. I have been, however, unable to trace any connection, and fancy that the prevalence of jungle and especially of ula grass has more to do with the presence of the beetle than the manure application.

\section{FILLING IN VACANCIES.}

In one matter I regard cattle manure as all but indispensable, namely the filling in of vacancies. There still remain men who deny that it is profitable to fill in the vacant parts of old tea. In some cases I own it would be better to uproot and replant, but where this is not necessary, vacancy filling should be regarded as an essential, and a garden with a large percentage of unoccupied soil should be its own condemnation. For it has now been definitely proved by numerous examples that land can be filled in with perfect success if only care be taken. It is decidedly not sufficient to take a seedling from the nursery, plant it as one would in a fresh clearance, and expect success. It would be a wonder if a plant put out thus did prove a good one. But that such plants cannot be made to flourish where old tea is flourishing has, I think, by many planters, been shown to be a fallacy.

A mature tea plant is worth about 6 annas in Assam. A planter very successful in filling in vacancies informed me that each plant filled in cost him 2 annas at the time of planting, and he did not expect 
success without spending this amount. His method was as follows : A hol 2 feet deep and 18 inches wide is dug and the soil removed The bottom is then filled with jungle soil and a 2-year old plant with a very large block of earth attached is put in hard, pressed down hard round it, the remainder of the hole filled with cattle manure and the whole well compacted by treading down. Then straw is put round the plant to prevent the direct rays of the sun striking the plant's own soil. One year after planting (3 years from seed) the new bush is pruned at 6 inches from the ground (not more), and in order to avoid injury from plucking when not ready to pluck, it is generally arranged, if possible, that the plot should be heavy pruned as a whole when these infillings are cut down. The method has been a splendid success, and I can recommend none better. The only point is that jungle soil is not always obtainable, but a substitute could well be made during the previous season by making a compost with soil and cattle manure on the plot itself. To do this the cattle manure should be taken on to a vacant place, if possible under shade, on the plot to be treated, and made into a layer 4 inches thick, and then covered with 6 inches of ordinary garden soil; on top of this another 4 inches of manure should be placed and then soil as before alternating layers thus until enough has been produced for the purpose. This will unite into a rich black mass by the following cold weather, and may be used instead of jungle soil with equal confidence of success.

\section{SUMMARY re CATTLE MANURE.}

As a whole then cattle manure is capable of being used far more than it has been, and, properly collected and preserved, should form on most Assam gardens the nucleus of the manure required. It is valuable for all kinds of land, but especially for those with stiff soil, and for the extremely light sands. It should be applied in the spring and immediately hoed in. For filling in vacancies it is almost indispensable.

\section{GREEN MANURING.}

Only second in importance to cattle manure, and probably likely to take enormous extension in the future, is green manuring or the growing of green crops amung the tea, to be hoed in entirely so that by their decay in the soil, the land may be improved and food added to the soil. It is long since they were first recommend. ed, but in spite of very successful experiments their use has not 


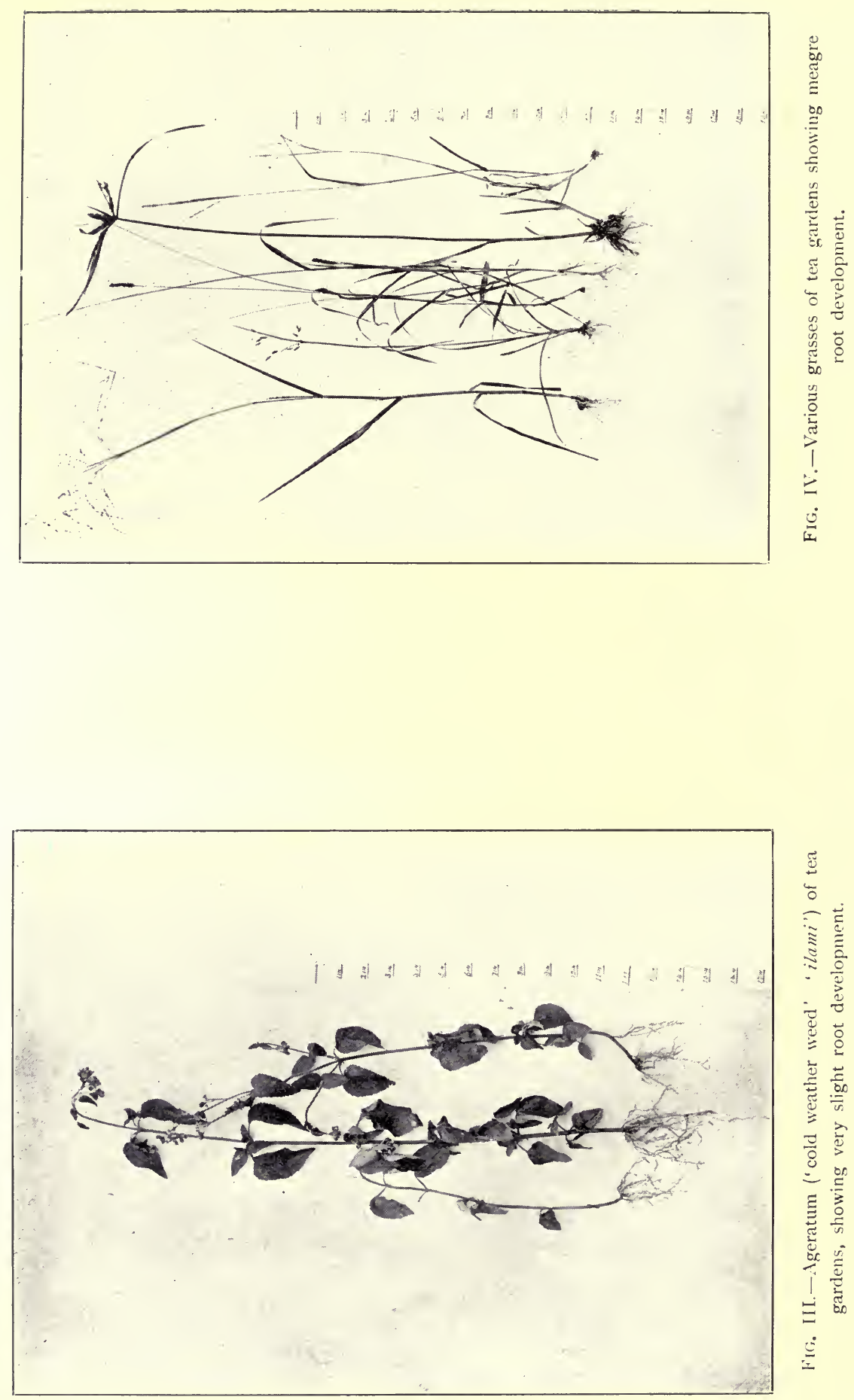
hitherto been at all general. Mr. Bamber in 1893 indicated several plants which might be useful for this purpose, and in his book on the Pests and Blights of the Tea plant, Dr. Watt repeatedly insists on the value of the method, and points out the plant which has hitherto been most successfully employed, the Mati Kalai(Phaseolus aconitifolius).

A plant to be used as a green manure should fulfil the following conditions :-

(I) It should be one which develops rapidly, so as to occupy the land as short a time as possible.

(2) It should give - the largest mass of green vegetation possible, for hoeing in.

(3) It should be as deep rooting a plant as possible.

(4) It ought to be sufficiently hardy to itself flourish under fairly unfavourable conditions of climate and soil.

(5) It ought, also, to return more to the land than it has extracted for its own growth.

(6) It should be grown at a time when it may retain manurial constituents in the soil, which would otherwise be washed out.

(7) It should easily rot when hoed into the land.

(8) It ought to be grown without in any way interfering with the tea or with the plucking of it.

The conditions (1) (2) and (3) at once condemn the grasses for green manuring. Neither rice, grass, wheat, maize, nor buckwheat are the most suitable plants for they all possess very shallow roots (see Fig. III) and except for maize, the amount of vegetable matter to be hoed in is small in proportion to the land covered by the crop. Maize might, however, be valuable in some hill districts. In some measure the same objection applies to a very large proportion of the weeds of tea gardens. The Ageratum, known as cold weather weed in Assam or "ilami" in the Dooars, and which forms perhaps the most common weed in tea culture, though succulent in the extreme, yet possesses a most meagre root development (see Fig. IV) so that though usually a sign of well cultivated land it could hardly be recommended for special planting as a green manure. The same may be said of most other weeds which are not objection. able in themselves. 
In fact I can hardly say that I believe in the theory of a garden being allowed to become weedy for the sake of the green manure these weeds supply. When a miscellaneous collection of plants like the usual crop of weeds are allowed to grow in a garden, some may be valuable, some may be neither valuable nor harmful, and some may very likely be distinctly injurious inasmuch as they may form refuges for the pests and blights of the tea, and further they, at some seasons, abstract water from the soil that the plants need. Perhaps there is not much objection to a few weeds in September and October, but even then, as first suggested to me by Mr. Henderson of Salonah, it is surely far better to have a definite crop known to be valuable on the ground than a mixture of useless, and it may be, injurious plants.

It will, I think, be found that the plants which answer most of the conditions laid down only belong to two classes: the mustards on the one hand, and leguminous plants on the other. The former answer every condition admirably, except that of returning more to the land than they have extracted, but the latter answer this as well as all the others. This condition does not exclude the use of the mustards in Assam for green manuring though they have been hardly found to be profitable in other countries. Land however which grows leguminous crops too often is apt to become "sick" of them, and under these circumstances mustard might replace them with great advantage.

\section{LEGUMINOUS PLANTS AS GREEN MANURES.}

To the leguminous crops, however, one has to turn to supply the really most valuable green manures, and this because they return to the soil more Nitrogen than they take from it, owing to the growth of a bacterium on the root which fixes the Nitrogen of the air and passes it on to the plant,-a bacterium which seems exclusively to grow on the roôts of this order of plants, on whose roots it forms nodules nearly always visible to the naked eye.

The only plant of this order hitherto used to any great extent in Assam is Mati Kalai (Phaseolus aconitifoluus) and its growth has been very successful. It has been most systematically tried perhaps by Mr. Hutchison of Dooria, Golaghat, and in a recent letter to me on this subject he says :-

I have sown kalai in various months with varied success, as good growth is much dependent on moisture, and not too hot and dry a time. April is a gond month for sowing 
provided you take advantage of a wet period, and it is not followed by a hot dry April sun just after the seedlings are a few inches high, or the whole crop may be ruined. The same remarks apply to May. Both these months are good for sowing kalai in low pruned tea, as it is beneficial in keeping off or lessening the effects of blight. In June the growth is very rank, and I don't think so beneficial.

The best time of all, 1 think, is September. During October the kalai can be hoed in, and a deep hoe given for the cold weather. I also believe there is $I \frac{1}{2}$ to 2 per cent. more Nitrogen in the root nodules during the time the plant is forming seed in Octuber. The result is very perceptible at the commencement of the following season; although the bushes are having a rest, the roots $I$ believe are active during the cold weather, and during the first flush the bushes have a healthy oily green cclour, so that in walking over a plot you can pick out the line treated with kalai from the line not so treated

As regards the actual increase in outturn I have never set apart a plot to test the increase in pounds, but a healthy plant is more capable, I take it, of giving more quantity and better quality than an unhealthy one. " " " I am planting now (August 1901) 70 acres with seed for deep hoeing in October.

When first suggested, it was put on to the land at the same time as is done in local native cultivation, that is to say in November. The result was a very small plant which quickly went to flower and seed, and which when hoed in did little good, and I doubt not, in many cases, considerable harm. This was cnly to be expected as it contradicted all principles of green manuring-only a small amount of vegetable matter was produced, and this was growing and abstracting moisture from the soil just at the time when it was most important to preserve it. If on the other hand it be sown from April to August a rank growing plant is produced, which gives much vegetable matter, occupies the land when there is always or nearly always excess of moisture, and fulfils every condition required.

In successful culture it has usually been applied in April and May, and certainly has in several cases been very successful. Mr. Wylde at Bamgaon, Tezpur, estimated the increase in yield in 1900 of about three quarters of a maund per acre on the plots treated, and the cost was practically nil. At Cinnamara it has now been applied for several seasons to sections of the garden, and one of the principal advantages there noticed was that green fly did not appear to attack the tea all the time the Mati Kalai was on the ground. During the present year it has been used on several gardens in Nowgong with much benefit to the condition of the soil, and also to the health of the bushes.

On evidence in hand at present therefore, I am inclined to think that we have in the Mati Kalai an exceedingly valuable green manuring crop. It may be planted at any time from April to August, though 
1 myself prefer April and May, and is hoed in about six weeks after, when it forms a mass of green foliage at least two feet high. Some planters have had difficulty in growing this crop owing to the extreme poverty of the land. Mr. Buckingham particularly notes in a letter to me the difficulty of getting the crop to grow on poor land. In this case it would be wise to put on a slight dressing-say one ton per acre-of farmyard manure before sowing the seed of the Mati Kalai, when probably a very luxuriant growth will occur. Another trouble seems to have been the difficulty of hoeing in the crop when grown, but this is overcome by giving an extra deep hoe for the time of year, when the crop goes in very satisfactorily. To quote Mr. Hutchison again :-

Its application is comparatively cheap and easy. During its growth you can dispense with one round of the hoe, which about pays for the kalai. In fact if you hoe the kalai in 6 weeks after sowing, the extra deep hoe then given will do for another 6 weeks. Thus we have one hoe in three months and benefit derived. These remarks apply more to the sowings in the early part of the year.

The cost of application is very small. Mati Kalai seed rarely costs more than five rupees per maund, and half a maund is about sufficient for one acre. The seed is broadcasted after rain and left. It is said, however, to possess deeper roots if covered up at the time of sowing. The plant is not appreciably injured by the coolies walking among it for plucking purposes.

There are two or three cases in which such a green manuring crop as we are discussing seems particularly useful. The first of these is in connection with uprooting and replanting. After uprooting the land should be ploughed and at the earliest opportunity Mati Kalai seed put in-say in May. This crop will then be hoed or ploughed in by the end of June. A second crop is sown in August and hoed in at the commencement of October, and the land is ready for planting again the following cold weather. If replanting be then carried out with liberal use of farmyard or cattle manure, I have very little fear of failure of plant. Of course two year old plant should be used, and allowed to grow a year after planting before being pruned to 6 inches. Mati Kalai is also useful on land which has been cleared and is not yet planted. Such land deteriorates very quickly if left bare, but a crop of Mati Kalai* in the rains, will keep a large amount of the valuable material in the soil which would otherwise escape.

- Sensitive plant (Mimosa pudica) has also been recommended under these circum. stances. 
There are probably other crops which would answer for green manuring quite as well as Mati Kalai." Dr. Watt mentions several. The sensitive plant (Mimosa pudica) he points out would be valuable, but for its thorns; and there would be no objection to planting it on old nurseries and "busti" sites. He also names Crotalaria striata, Desmodium polycarpum, and Uraria crinita among others. The first of these three has been strongly recommended by $\mathrm{Mr}$. Bamber to the Ceylon planters, but Mr. Buckingham's experiments with the plant have not up to date been very promising (see page 85 ). In addition to these, Mr. Hulbert has used French Beans as a green manure on the Assam Company's gardens, but no apparent good effect was produced and the treatment has been discontinued. I hope, at an early date, to have facilities for making a careful trial of these various plants, as well as some of the Lupins which have proved such a brilliant success elsewhere for green manuring.

In all that precedes it has been assumed that the green manuring crop was an occasional crop on any particular plot. I think, however, that there seem distinct arguments in favour of making it an annual and regular matter on many soils, and having a green crop on the land during the greater part of the rains. The object secured by this means would be-

(1) The prevention of a great amount of nitrates being washed out of the soil, because they would be used up by either the tea or the green manuring crop as soon as formed.

(2) The avoidance of much destructive wash.

(3) The reduction in the number of hoeings, although at the same time each hoe would be deeper.

Under such a system we might have the following scheme :-

(a) Sow Mati Kalai in May with the spring rains on the top of a recent hoeing.

(b) Hoe in the crop about the end of June.

(c) Hoe an ordinary hoe in August, and on top of this.

(d) Put in a crop of mustard (or even Mati Kalai again if the land will stand it) to be hoed in at the commencement of October.

This would, under such a scheme, be applied, with modification as to time and to crop, to a large part of the cultivated area each

- I have recently noticed the enormons number of root nodules possessed by Sesbania argyptica. It would hence very likely be an extremely valuable plant for this purpose. 
year. I am sure it is worth experiment. It would avoid two hoeings per annum, and although two of these given would have to be deeper than is usual, yet the total labour would probably be less than before, and a large amount of valuable matter, otherwise washed out would be retained in the soil.

\section{SUMMARY re GREEN MANURING.}

Summing up therefore, green manuring has already proved a success where it has been tried, but the crops used up-to-date with success have only been mustard and Mati Kalai. The latter is usually the best, and has been used the most. It (1) gives more healthy bushes; (2) increases the crop; (3) improves the texture of heavy scil ; (4) is said to keep off green fly while it occupies the ground; and (5) acts as a direct manure by fixing the nitrogen of the air. It is best sown at the rate of half a maund per acre either in May or at the end of August, and in each case should be hoed in after about six weeks. Other crops have been suggested for green manuring but have, as yet, received no adequate trial. Finally there seem distinct arguments in favour of regularly having the ground covered with a green manuring crop during a great part of nearly every rains, and thus making it a normal part of tea culture instead of a special occasional means of manuring.

\section{LEGUMINOUS TREES AMONG THE TEA.}

In connection with this subject of green manuring, that of the use of leguminous and other trees among the tea must be considered, and the question of their value or otherwise has formed one of the vexed questions of tea culture for many years. I cannot do better perhaps than reprint Mr. Hooper's summary of the history of the use of the sau tree (Albizzia stipulata) for the purpose of fertilising tea gardens. (Vide Dr. Watt's Pests and Blights of the Tea Plant 1898) He writes :-

"Several years ago Colonel Hannay (io Dibrugarh, Assam) called attention to the value of the sau tree, and gave it the name of the tea fertilising tree. * * To Mr. J. Bucking. ham belongs the henour of having prominently drawn attention to the value of the sau tree. Several experiments were made by him which went to prove that sau possessed peculiar properties in bringing round exhausted soils and causing the bushes to flush vigorously, while imparting a vitality of which old tea was deficient. On the 2nd October, 1884 , Mr. Buckingham published, for the benefit of the Indian Tea Association, a little pamphlet on this subject, which gave his own experience and that of several planters regarding the sau tree. Shade is not usually the cause of an increase in yield, and is in fact condemned by the generality of planters, as it tends to make the bush throw out long stalky shoots, and thus to produce poor and woody flushes; such, however, can hardly 
be said to be the case where sau is employed. The tea bushes under that tree have been reported by those who believe in it to yield a considerably higher amount in a given area than in any other part of the garden, under similar conditions of soil and age of bush. It has been observed that tea grown under sau enjoys a considerable immunity from blights and pests while the surrounding trees are suffering badly.

"The action of the sau was attributed by some to the beneficial shade which it casts over the plants; others considered that it was the manure furnished by the dead leaves; a few thought that the advantage of interplanting the trees was the fact that the roots went to a greater depth that the tea roots, and drained the superabundant moisture from the surface soil while, on the other hand, they brought up from the subsoil food naterial for the tea plants. Mr. Buckingham remarks:-I do not wish to contend that sau is capable of improving tea plants where the soil contains elements which in some instances nature has abundantly supplied for the support of the bush, but I do assert that the vitality of the tea bush is limited, probably in a great measure depending on the character of the soil, and unless we restore some of these essential parts we are yearly, I may say weekly, abstracting, the tea planter in a few more years may be surrounded by tea which the very best cultiva. tion and the most scientific pruning can never bring round.

"The immediate benefit which Albizzia confers upon the soil and the tea plants where it grows is not due to some chemical ingredient imparted to the soil, as was once supposed, but to the presence of tubercles which are attached to the rovis. The discovery " of these tubercular bodies on the roots of the sau tree was made by Dr. Watt during his tour in Assam in 1895."

It will thus be seen that the sau tree (Albizzia stupulata) was the first tree which was supposed to have fertilising properties. Others have been since used with nearly as much, if not with equal, success. But all of them have belonged to the same family of legumin. osæ, and all have had nodules on the roots which fix the nitrogen of the air. Such are the medeloa (Dalbergia Assamica), the koroi (Albizzia odoratussima), and still other species of Albizzia have been used, as well as Erythrina indica.

The advantages claimed for these trees are as follows :-

I. They give a slight shade to the tea which is itself an advantage, The value of shade, however, has been very much doubted, but probably this is only another instance of general conclusions drawn from particular districts being quite fallacious in others. In the lower part of the Brahmaputra valley, except where mosquito blight is abundant, slight shade will, I think, be found of distinct advantage. This will probably be especially the case in Nowgong. And it will be of advantage here because it will to a certain extent prevent evaporation from the soil by the exceedingly hot sun in a district rather deficient in rainfall. On

* I believe the nodules or tubercles on the roots of the sau tree were observed long ago by. Mr. Bamber, but he did not publish his observations. 
the other hand I hardly think that the shade itself will be a sufficient cause to warrant the planting of the above trees in Dibrugarh, Sibsagar, or North Lakhimpur. It might be noticed, in passing, that Mr. Bamber has expressed himself recently in favour of slight shade for tea in Ceylon.

2. The continual dropping of leaves, flowers, \&c., from the trees are a distinct manurial gain to the soil round about, as the material of which they are formed is obtained from a different layer of soil from that in which the tea bush feeds. Mr. Bamber has laid stress on their utility in this respect in connection with the Grevillea tree (Report on Ceylon Tea Soils I900). He writes-

"One of the means by which lime has been preserved in Ceylon soils has been the general growth of grevilleas (Grevillea robusta) as shade or for wind belts. As a rule the roots of the grevillea descend into the soil to considerable depths, - - - bringing up stores of plant food, including a large proportion of lime, which the tea plant could not have reached. This plant food after being utilised in building up the grevillea, is largely returned to the soil on the fall of the leaf."

On the other hand, the quantity of leaf falling from one tree could hardly be greater than fifteen pounds, and with these planted at 40 feet apart, the total quantity of leaf per acre would be 180 pounds or thereabouts. It is difficult to see what great effect this quantity of material could have on the land; as it amounts to little more than $1 \frac{1}{2}$ cwts. per acre of what is confessedly only a poor material. In some experiments made at Amgoorie, Mr. Buckingham found the leaves, spread in the land, produce no visible effect, and this would agree with expectation. I think that the amount of manurial matter added through the leaves in a single season is hardly worth consideration.

3. The penetration of the soil by the roots makes the soil more porous, and hence in better condition for tea culture. This is no doubt the case, and for this reason alone these trees are highly to be recommended in heavy soils, as they quickly improve the texture considerably.

4. The nodules on the roots contain bacteria which fix the nitrogen of the air, and thus enrich the soil in this most desirable constituent. Under these circumstances it would have been thought that near the trees, or at any rate near the roots, the soil would be decidedly richer. Mr. Buckingham has been kind enough to supply me with samples of soil taken from these positions, but I 
have as yet been unable to find any marked improvement in that taken from near the roots. The following are the figures of my analyses*:-

\begin{tabular}{|c|c|c|c|c|}
\hline & \multicolumn{2}{|c|}{ Surface Snil. } & \multicolumn{2}{|c|}{ SOIL IO INCHES DERP. } \\
\hline & Nitrogen & Organic Matter. & Nitrogen. & Organic Matter. \\
\hline Near roots of "Sau" tree & · 106 & $4 \cdot 25$ & $\cdot 089$ & $3 \cdot 82$ \\
\hline Away from root of "Sau" tree... & $\cdot 100$ & $4 \cdot 13$ & .09 I & $4 \cdot 30$ \\
\hline Near root of " Medeloa" tree ... & $\cdot 085$ & $3 \cdot 92$ & 113 & $5 \cdot 26$ \\
\hline Away from root of "Merleloa" tree & $\cdot 105$ & $4 \cdot 46$ & .093 & $4 \cdot 29$ \\
\hline
\end{tabular}

The numbers are wholly irregular, and no result can be deduced from them. Nevertheless, in spite of this, there is little doubt that the marked benefit resulting from these trees is due largely, if not entirely, to their fixation of atmospheric nitrogen, which they pass on, in part, for the use of the tea bush. Whether the fact that it cannot be detected in the soil indicates that it leaves the leguminous plant in such a soluble form as to be washed quickly from the soil, or whether the tea plant is fed only by contact with the Albizzia or other root, and the nitrogenous body never exudes into the soil, we do not know at present. The benefit is, however, undoubted, and can only rationally in chief part be attributed to the fixation of nitrogen by the roots.

\section{OBJECTIONS TO TREES IN TEA GARDENS.}

Several objections have been raised against these trees in tea gardens. The first and most common is that they induce a long stalky growth and hence give a lower quality of tea than would otherwise be obtained. This objection is just, as I have been informed in a very large number of cases, but depends, I think, on the trees being planted too thickly. On Mr. Buckingham's garden they are planted 40 feet apart throughout the best part of the tea, and this is quite close enough, and probably 60 feet would be better. That a proper proportion of sau trees is not injurious to quality may be regarded as certain. Badulipar, the garden producing about the best tea in the Golaghat district, is largely covered with them, at sixty feet apart, I believe. But this objection may be entirely

- Mr. Buckingham has, while this report has been in the press, supplied me with samples of the soil round the fine rootlets of these trees. The determination of the amount of nitrogen in these has given results just as inconclusive as those here set out, 
removed by cutting down the trees to a moderate size as they grow up, and so preventing them ever casting an appreciable amount of shade. They may even be entirely cut down after three year's growth, if only a new lot are growing up to replace them. It has again and again been found that their beneficial action remains after the tree has been removed. Such was found to be markedly the case on the Seleng garden of the Jhanzie Co., and I am likewise informed that this continuance of benefit after removal of the trees has been noticed on the Moran Tea Company's gardens. It would therefore appear to be good policy to have a regular rotation of trees, none more than three years old, at 15 feet apart in the rows, the various lots being newly planted seedlings, one year old plants, two year old plants, and three year old plants ready for removal. At any rate this would be a simple method of obtaining the benefit of the sau tree in situations where shade would be harmful.

A second objection is that these trees, as well as any shade, encourage various pests and blights of wich the chief are mosquito, faggot worms and similar caterpillars, and blister blight (Exobasidium vexaus). With regard to faggot worms I have never been able to trace a connection. If mosquitoes are systematically caught, as they ought to be in an affected district, these should cause little more trouble under trees of this character than elsewhere. But all these pests would be prevented from benefiting by the shade, if only the trees were cut down in rotation as above suggested.

\section{SELECTION OF TREES TO BE USED.}

Among the trees recommended I think there is little to choose between the sau (Albizzia stipulata) and the medeloa (Dalbergia assamica). The "koroi" (Albizzia odoratissima) is distinctly inferior to these two, as its form is quite different and not nearly so suitable. Personally, from what I have seen, I prefer the sau itself, because the foliage gives a slighter shade than the medeloa, but really both are so equally valuable that there should be no hesitation in putting in either. Other trees than the leguminosæ cannot be recommended as a rule, as they have practically no manurial value. The Silver Oak (Grevillea robusta) has been shown to do no harm to tea, ${ }^{*}$ and makes a good windbelt, but I have never seen any benefit accrue from its presence. Several other local trees have no harmful effect, but nevertheless do no good, and their shade

- I have been recently informed by Mr. C. J. Dunlop, of Monobarie, that tea is apt to die out round the decaying stumps of Grevillea. This is a serious objection to these trees. 
is usually objectionable. Others should at all costs be removed. Such are the India rubber tree (Ficus elastaca), the Simul, the Nahor (Mesua ferrea) (unless this last is preserved for show at the cost of the tea bushes) and several others.

\section{LEGUMINOUS BUSHES FOR PLANTING AMONG TEA.}

I have often been asked by those who object to shade whether there is any bush which would answer the purpose of the sau tree, and yet not have the supposed harmful effect of a large tree. In this connection Mr. Buckingham, who has experimented on the subject, has supplied me with the following note :-

"You ask if I have ever experimented with leguminous plants as manurial agents for tea, which have, instead of the tree form like Sau or Medeloa, a bush shape, so that the manurial benefit of the sau may be obtained without the shaae, as you are constantly asked whether the effect cannot be obtained without the shade.

"To say nothing of 'Kalai,' I have experimented with the following leguminous plants that are of the bush type.

(I) Crotalaria striata.

(2) Tephrosia candida.

(3) Desmodium polycarpum.

"The first named is an annual growing very much like a lupin and possessing a con. siderable number of nitrogenous tubercles on the roots. This I experimented on in young tea, and I must confess that I could not see that the results were in any way remarkable. The plants were allowed to grow to their full height, about five feet, and then hoed in and also some were hoed in when a couple of feet high.

"I next tried the Tephrosici candida and I am still carrying on my experiments with this bush. The advantage of this plant is that it is a perennial, has a goodly number of root tubercles, and will grow in almost any soil. My plan is to let it grow some three or four feet high, and then prune it down to about a foot; some three prunings can be done in the year. This leguminous plant will grow in almost any soil. I have seen it come on well in hard barren land, where certainly Sau, Medeloa, Erythrina indica, Crotalaria striata, and others would die out in a month. I am pleased with the result accruing from this plant, and intend this cold weather (1900-1901) to sow the seed over, I hope, from fifty to sixty acres of the garden in spots where the soil is hard and stiff, and the tea poor.

"In small patches I have already planted, I certainly notice an improvement in the tea which I attribute not only to the nitrogen assimilated by the bacteria, but also to the enrichment of the soil by leaves, contributing to the amount of organic matter and acting eventually as plant food.

"With regard to No. 3, the Desmodium polycarpum, this plant is a trailer - * - and does not grow over a foot high. The roots possess a larger number of tubercles than I have seen in any other leguminous plant ${ }^{*} \cdot \bullet^{-}$- I have not perhaps given the plant the attention it deserves, as it is of such a straggling nature, that the hoers were always cutting it out. My opinion is that to be of any practical use, it should be allowed to run wild in poor tea for a year or so, and the land not touched with the hoe ; any other jungle growing might be hand weeded. No. 2 (Tephrosia candida), however, is the shrub I should call particular attention to for the present. 
This plant (No. 2) recommended by Mr. Buckingham and locally named the "bogga medeloa" is still in the experimental stage. It is being tried, to my knowledge, at several places, and is, I think, well worth trying among the tea in districts like Bishnauth which have had mosquito to such an extent as to render it inadvisable to plant the sau or Medeloa trees.

\section{ADHATODA VASICA.}

One other plant has been several times highly recommended for planting among tea,- - the Adhatoda Vasica, -on the expectation that it acted as a manure. This plant does not belong to the Leguminosæ and, so far as we know, does not fix nitrogen, and I have failed to note any improvement in the bushes round about it. The leaves are, however, very rich in nitrogen, and their dropping may be of some value,-if not of much. At the same time while I do not think it worth while to plant among the tea, yet the leaves form such a valuable insecticide (giving off alkaline vapours on crushing) that it would be worth while to grow a few square yards, as recommended by Dr. Watt, by putting in cuttings one foot apart on any waste land, when a supply would be obtained for use against some of the pests of the gardens.

\section{BONES AS MANURE.}

Such are the manures actually produced or producible on the tea gardens themselves. To them might be added the wood ashes which, on all gardens burning wood, are produced in enormous quantity. I will however deal with those later. (Page 98.) But there are locally produced other manures which ought to be put to the utmost use. The first of these to Bones, which in certain districts, notably on the grass plains of the north bank, could easily be collected in large quantities for use. At present I believe there is an export of bones from the Brahmaputra valley, and a certain import of the same bones crushed for use on tea gardens, If bones are valuable they should never be allowed to leave the province and be re-imported, but rather be bought in the collecting districts by the planter and crushed on the spot-by means of a small Devil Disintegrator, the cost of which would be recovered, if much bones were used, in the first season. One planter has come under my notice who buys up local bones and crushes them in this manner, and is eminently satisfied with the result. 
But are bones of great advantage as a manure? On the basis of their composition they should be eminently so. The analysis of a typical Indian bone meal is as follows :-

$\begin{array}{llllr}\text { Moisture } & \ldots & \ldots & \ldots & 7.50 \\ \text { Nitrogen } & \ldots & \ldots & \ldots & 4.05 \\ \text { Phosphoric Acid } & \ldots & \ldots & 23.25 \\ \text { Equal to Phosphate of Lime } & \ldots & 50.68\end{array}$

But the actual value of the application in this form has everywhere proved much less than would be anticipated on the basis of the analysis. In fact according to recent experiments in Germany,* the Phosphate of Lime, though it forms half of the weight of manure, may be almost ignored in determining its manurial worth, and the whole value calculated at little more than that of the nitrogen and organic matter. This being so, the benefit accruing from the application of bone meal or steamed bones is much less than has hitherto been assumed. In fact I doubt whether bone meal is ever worth importing to Assam in this form at a price at Calcutta higher than Rs. 2 per maund, at which it at present stands.

On the spot bones are, however, very valuable, and worth probably on the garden in Assam, about one rupee per maund before crushing. Their limitations must, however, be recognised. They are an exceedingly slow manure. In the first year no benefit will be seen, only possibly some advantage in the second. In a recently published report on one of the Darjeeling Tea Gardens $t$ it is stated that the beneficial effect of bone meal applied in 1897 was visible in 1900 . In fact it may be said that bone meal is an excellent manure to apply to a good garden in order to keep it from deteriorating, but is not sufficiently active alone to bring back a garden already deteriorated into good condition.

It has been said that borie meal causes the production of seed, but of this I have not been able to obtain any evidence.

Bone meal may be relied upon not to affect the quality of the tea. It should be applied at the rate of 5 to $10 \mathrm{cwts}$. per acre, ground so as to pass through a sieve of $\frac{8}{16}$ inch holes at least, though even more finely ground bones are preferable, and would be best applied buried round the bushes in a small trench made for the purpose a foot away from the stem at the end of the rains while the ground is still moist. For a consideration of the use and value of dissolved bones see page 94 .

- "On the effects of bone meal as a source of phosphoric acid to crops" by Maercker and Steffek. Berlin. 1895.

† Kurseong and Darjeeling Tea Co., rgor. 
OIL CAKE AS MANURE.

Another valuable manure which is to a certain, and can be to a greater extent produced locally, is oil cake. The local production is limited almost entirely in Assam to that from mustard seed, and the imported almost entirely to castor cake. In his book $\mathrm{Mr}$. Bamber mentions various other of these materials which might be used, including margosa cake, cocoanut cake, poppy cake, niger cake, cotton cake, sesamum cake, mahua cake, and linseed cake. But in order that a manure of this type should be valuable it must either be produced locally, or else be so rich as to pay the expense of transit to the place where it is to be used. Of all this list the only ones which could in any way be worth while importing would be cotton cake and linseed cake. Both of these are fairly rich in manurial matter, and together with the cake obtained from castor form the only ones which it would pay to carry to Assam, and which are obtainable in sufficient quantity. I had at one time some hopes of mahua cake (from Bassia latifolia) but the analysis I made showed it to be not worth the cost of importation."

Local supplies should, however, here again, form the chief source from which the manure is derived. Mustard is grown in large quantities practically throughout the province for the production of oil. In some cases the seeds are exported direct to Calcutta as such; in many others, they are pressed locally by native presses. I wish to insist here on the necessity of increasing, so far as is possible, this local pressing of mustard seed, in order that the oil may be saved for local consumption and the manure for the tea. Why for instance should a small bonus over and above the price obtainable in the market not be offered for all mustard seed brought to the factory, when the oil would be expressed and sold to the coolies on the garden (where the demand is always great), and the cake applied as manure? Or alternatively there seems no objection to encouraging the growth of native local presses, by giving a slightly higher price for the cake? Or even, as was suggested to me by one of the leading Assam planters, why not grow mustard on some of the waste land attached to the grant, and press the crop, which should amount to twenty bushels per acre, at the factory, by means of an oil press which is not very expensive? This would only require labour in November-and when

- The sample $I$ had, contained only Nitrogen $3^{\circ 1}$ per cent. Phosphoric Acid 1.44 per cent. and Lime ' 20 per cent. 
the seed was ripe in March-two periods at which labour can be to a certain extent spared. One cannot go into the details of such a scheme, but there are few grants where twenty acres could not be given up for this purpose, and on this land ought to be produced about 400 bushels or 300 maunds of seed, giving 200 maunds of cake, or sufficient to give a moderate dressing to twenty acres. Such land would be allowed to revert to jungle after gathering the crop, and the herbage grown up in the meantime would be ploughed in before again sowing the next November; or better still, the same land might only be used once in say three years for mustard growing, being allowed to revert to jungle in the meantime. The oil produced would, by sale on the garden, almost recoup the cost of the crop, and the tea would be manured almost for nothing. At any rate to send out of the province for oil cake, when so much land (not suitable for tea, but quite suitable for mustard) exists even on the tea grants, seems hardly econumical.

But is oil cake of value for tea? Luckily on this question we have definite figures of recently carried out experiments. The first here reported was carried out at the Harchurah garden of the Borelli Tea Company by Mr. J. C. H. Mitchell. Taking three very even one-acre plots similarly pruned in the previous year-

No. I was left without manure.

No. 2 was treated with $151 / 2$ maunds castor cake and $151 / 2$ maunds bone meal per acre.

No. 3 was treated with $151 / 2$ maunds castor cake only.

The soil was on the Tezpur bank. The following table gives the results for 1899 and 1900 :-

\begin{tabular}{|c|c|c|c|c|c|c|}
\hline & & & \multicolumn{2}{|l|}{ PLOT I. } & Plot 2. & Piot 3. \\
\hline Total Tea in 1899 & $\ldots$ & $\ldots$ & $3 \mathrm{Mds} .38 \%$ & Srs. & $5 \mathrm{Mds} .261 / 2 \mathrm{Srs}$. & $6 \mathrm{Mds} .24 \mathrm{1} / 2 \mathrm{Srs}$ \\
\hline Do. in 1900 & $\cdots$ & $\cdots$ & $4,, 16$ & $"$ & $5,, 263 / 4$, & $6 \quad, \quad 93 \frac{1}{4} \quad$, \\
\hline Increase in 1899 & $\cdots$ & $\ldots$ & $\ldots \ldots$ & & I Md. $281 / 4$, & $2,, 261 / 4$, \\
\hline Do. 1900 & $\cdots$ & $\cdots$ & $\cdots \cdots$ & & $1,103 / 4$, & $1 \mathrm{Md} .33 \mathrm{3} / 4$ \\
\hline Total increase in th & o years & $\ldots$ & $\cdots \cdots$ & & 2 Mds. 39 & 4 Mds. 20 Sis. \\
\hline Percentage increase & in 2 years & & $\cdots \cdots$ & & $26 \cdot 2$ & $35^{\circ}$ \\
\hline Total cost of Manu & & $\cdots$ & $\cdots \cdots$ & & Ks. $76-0-0$ & lis. $44 \cdot 9 \cdot 0$ \\
\hline Cust per lb. of incr & eased Crop & $\ldots$ & $\ldots .$. & & 5 annas I pie & 2 annas. \\
\hline
\end{tabular}


The mixture of bone meal and castor cake was therefore somewhat profitable on the first two years' yield, and further it left the bushes much more healthy than it found them, but the castor cake alone gave an immediately profitable return.

A similar experiment was carried out in 1900 on the Bindukuri garden of the Bengal United Tea Company, on the low flat land between the Tezpur bank and the river. The soil by analysis was shown (see page 109) to be more or less exhausted.

Plot I was again unmanured.

Plot 2 received 15 mds. 9 seers of castor cake.

Plot 3 received 15 mds. 20 seers castor cake and 5 maunds of bone meal.

Tabulating the results as before, we have:-

\begin{tabular}{|c|c|c|c|c|}
\hline & & PLOT I. & PLOT 2. & PLOT 3. \\
\hline Total Tea in $1900 \quad \ldots$ & $\ldots$ & Io Mds. $17 \mathrm{Srs}$. & I 2 Mds. I4 Srs. & $12 \mathrm{Mds}$ 3o Srs. \\
\hline Increase in 1900 & $\ldots$ & -..... & I Md. 37 , & $2, " 13$, \\
\hline Percentage increase in 1900 & $\ldots$ & $\ldots \ldots$ & I 8.53 per cent. & $2 I^{\prime} 2$ per cent. \\
\hline Total cost of Manure & $\cdots$ & $\cdots \cdots$ & Rs. $69-\mathrm{I} \cdot 6$ & Rs, $82-14-9$ \\
\hline Cost per lb. of increaser: Crop & $\cdots$ & $\cdots \cdots$ & 7 annas 2 pie & 7 annas 2 pie. \\
\hline
\end{tabular}

These figures only refer to one year's crop. It is probable that the effect will be felt for at least two years further, and, if so, the whole increase for those two years will be obtained at no out of pocket cost whatever. The manager ( $\mathrm{Mr}$. C. B. Taylor) reported at the end of 1900 that "the strong growth and healthy condition of the manured section is remarkable, and there is very little doubt that these sections will give increased yields next year, and probably the year after."

It may therefore be taken that oil cake, whether applied as castor cake as in the above instance, or as mustard* cake or other locally produced material increases the crop to an extent which, even with castor cake costing nearly 3 rupees per maund on the garden,

- Very great benefit has resulted from an application of mustard cake, locally obtained, in an experiment which is being ccnducted for me by Mr. IW. N. Edwards of Majulighur. The complete figures for the season are not however to hand, but I understand the increased yield for this season alone will pay more than for the cost of the cake. 
would form a profitable application. Its effect on quality certainly was not a deteriorating one, and I look on castor or mustard cakes as the manures for tea, obtainable from sources outside the gardens themselves, which have the greatest future before them. They supply all the constituents which the tea bush needs, and if imported should be bought on a guaranteed analysis, not to contain, in the case of castor cake, less than 5.5 per cent. Nitrogen and 4 per cent. Phosphate of Lime; in the case of mustard cake, less than $4^{\circ} 5$ per cent. Nitrogen and 5 per cent. Phosphate of Lime; in the case of cotton cake, less than 4 par cent. Nitrogen and 5 per cent. Phosphate of Lime; and finally, in the case of linseed cake, less than 4.5 per cent. Nitrogen and 5 per cent. Phosphate of Lime. The following are some analyses made recently of good quality oil cakes used in Assam last winter. Of the item marked "alkalies, \&c." about half in each case will consist of Potash.

\begin{tabular}{|c|c|c|c|c|c|c|}
\hline & & & $\begin{array}{l}\text { Castor Cake } \\
\text { Imported. }\end{array}$ & $\begin{array}{l}\text { Mustard Cake } \\
\text { Local (Dibru- } \\
\text { garh). }\end{array}$ & $\begin{array}{l}\text { Mustard Cake } \\
\text { Local (Bish. } \\
\text { nauth). }\end{array}$ & $\begin{array}{l}\text { Mustard Cake } \\
\text { Local (Now- } \\
\text { gong). }\end{array}$ \\
\hline Moisture & .. & ... & $7 \cdot 67$ & $8 \cdot 44$ & $9 \cdot 04$ & $19 \cdot 33$ \\
\hline " Organis Matter & $\ldots$ & .. & $82 \cdot 78$ & $82 \cdot 92$ & $80^{\circ} 90$ & $72 \cdot 39$ \\
\hline Lime $\quad$. & $\cdots$ & $\cdots$ & $\cdot 83$ & $\cdot 90$ & $\cdot 8 \mathbf{1}$ & $\cdot 9 \mathrm{I}$ \\
\hline + Phosphoric Acid & $\cdots \cdot$ & $\cdots$ & 307 & $2 \cdot 97$ & $2 \cdot 81$ & $2 \cdot 66$ \\
\hline Alkalies, \&c. & $\cdots$ & $\cdots$ & $3 \cdot 31$ & 2.93 & 3.05 & 3.41 \\
\hline \multirow[t]{2}{*}{ Sand } & \multirow[t]{2}{*}{$\cdots$} & \multirow[t]{2}{*}{$\cdots$} & $2 \cdot 34$ & 1.84 & 3.39 & $1 \cdot 30$ \\
\hline & & & $100 \cdot 00$ & 100.00 & $100 \cdot 00$ & $100 \mathrm{co}$ \\
\hline * Containing Nitrogen & .. & .. & 6.46 & $5 \times 7$ & $4 \cdot 6 x$ & 4.78 \\
\hline I Equal to Phosphate 0 & of Lime & .• & $6 \cdot 70$ & 6.48 & $6 \cdot 13$ & 5.80 \\
\hline
\end{tabular}

Oil cake is best applied before the first hoeing, in spring (when it is mixed with the soil by that hoeing), at the rate of 10 to 15 maunds per acre. It may roughly be said that mustard cake is fourfifths as valuable as castor cake, and linseed cake slightly more valuable than the former. The best way to apply it is in a trench round each bush a foot away from the stem, but broad-casting and then hoeing in is almost as good.

Some things, however, castor or other oil cake cannot do. It cannot, for instance, bring back a washed slope, consisting 
of little else than sand, to a highly fertile condition. In such a case it is a question for bheel soil or cattle manure, and practically nothing else will answer. Further, it will not make tea luxuriant on a stiff clay. Here the condition of the soil is at fault, and must be remedied prior to any manuring by means of the methods given in Chapter II. But with exceptions like this, oil cake bids fair to be the most important of manures, outside actual garden sources, in the future.

ARTIFICIAL AND CHEMICAL MANURES.

A part from the fertilisers I have so far dealt with, we are limited to imported chemical manures. These have, of course, the immense advantage that they are far more concentrated than the locally produced materials can ever hope to be, are susceptible of much more exact application, and can be imported to fill any particular $\mathrm{defect}$ in the soil without adding a large amount of unnecessary material. Nevertheless, I cannot consider that at present they can have, except for phosphates, any but a very subsidiary position in Assam-an almost virgin land teeming with waste products not produced from tea land, but well capable of replacing much of the loss caused by tea culture. We will, however, consider briefly some of those most likely to be useful.

\section{NITROGENOUS FERTILISERS.}

And first for Nitrogenous fertilisers. The artificial manures, specially supplying Nitrogen, are almost limited to the Nitrates of Soda and Potash, and to Sulphate of Ammonia. The first is imported from South America, the second is a local Indian product, while the third is a necessary bye-product in a. well conducted gas works. They all three have a fundamental objection, that in a rainy climate they are quickly washed out of the soil. Last year Nitrate of Soda was used on several of the Assam Company's gardens, and the general result showed that six weeks after application, the effect of the manure began to disappear, and the treated plots were soon reduced almost, if not entirely, to the level of the untreated plots. A contradictory result was obtained by $\mathrm{Mr}$. F. H. Edwards at Heeleaka, where the improvement was manifested right through the season, and the bushes appeared better at the end. In this case, however, I fancy that for some reason or other,-not the exhaustion of the soil,--the roots had ceased developing, and the Nitrate of 
Soda gave the necessary stimulus to make them start again. In such cases Nitrate of Soda may be of value, but they are comparatively rare. As a rule, it will give an abnormal growth for two or three months, and then, if the soil be poor previously, there is a tendency for the bush to fall back to its previous position, unless in the meantime manuring with oilcake has been carried out. There is another reason against its use. It is an extremely soluble salt, and the soil does not retain it in the slightest. A few inches of rain after application would wash nearly all the application into the drains in a day or two. At any rate, if applied at all, it should be used in very small quantity, say five per cent. of an application containing some more permanently useful manure like oilcake. As an application before collar-pruning, or even heavy-pruning, it is absolutely out of place.

Nitrate of Potash is very similar in its action. It has the valuable Potash, instead of the all but useless Soda, but as Potash is not usually required in Assam, this is not usually of very material advantage.

The third typical Nitrogenous manure is Sulphate of Ammonia, and it contains more nitrogen than any other manure which could be used. I cannot advise it in practically any case in Assam, although it has, in time past, been very extensively advised as a con. stituent of mixtures. It would appear to be objectionable because :-

(I) It causes incidentally the removal of a large amount of other valuable constituents from the soil, the chief being the Lime and the Potash. In order to ascertain to what extent this might go on, I shook two typical Assam tea soils with a one per cent. solution of Sulphate of Ammonia for two days, allowed to settle, and analysed the liquid. There were extracted in the two cases as follows, calculated on the air dry soil :-

$$
\text { Soil No. I. }
$$

$\begin{array}{lllllll}\text { Lime } & \ldots & 037 & \text { per cent. } & \ldots & 018 & \text { per cent. } \\ \text { Potash } & \ldots & .052 & \text {. } & & \end{array}$

That is to say, one application of Sulphate of Ammonia might remove more Potash than the tea bush would do in ten years, and a large quantity of Lime. Now the latter is present in very small quantity in Assam soils, and though it could be replaced, yet there are other means of manuring tea which have not this objection, and do not necessitate a further expensive and really unnecessary application. 
(2) It is easily washed out of the soil, almost as easily as Nitrate of Soda, and is hence not suited for a rainy climate-where the rains form the cropping season.

(3) It has only a very temporary action on the bush, and after the year of application the soil is poorer than it originally was.

In 1900 an extensive correspondence took place as to its use for tea in Ceylon. Sir John Lawes, perhaps the greatest authority in the world on manuring, wrote:- "My objection to Sulphate of Ammonia does not arise because it is a highly nitrogenous and soluble manure, but because it removes Lime from the soil, and I understand that the Ceylon soils are poor in Lime." If it is to be condemned in Ceylon because the soils are poor in lime, it is much more so in Assam, where the soils are poorer.

There are grave suspicions that large quantities of these soluble concentrated nitrogenous manures injure the quality of the tea, but this requires confirmation. I cannot, however, think, for the reasons above given, that any of them should be used, except rarely, and then only in combination in small quantity with permanent feeding manures, as a slight stimulant to bushes which, for an unknown reason, have become stationary and refuse to yield, and in these cases I should much prefer the Nitrates of Soda and Potash to Sulphate of Ammonia.

\section{PHOSPHATIC MANURES.}

We come now to Phosphatic Manures, that is to say, to those which have the closest relation of any to quality in tea. Though bones, as such, hardly act at all as a source of Phosphates for the plants, yet they may be prepared in such a way that they do this very effectively. The Phosphate in bones is present as Tribasic Phosphate of Lime, which the plants are almost unable to take up. If, however, Sulphuric Acid be added to the bones, a different Phosphate is produced-the Mono-Phosphate of Lime-which the plants are perfectly capable of assimilating. Under this form the manure is known in commerce as dissolved or vitriolized bones, and would probably be very useful, both as a source of Nitrogen and of Phosphates. Actual field experiments are not however to hand, and any attempt to utilise them would be more or less of an experiment,an experiment however very likely to yield successful results. If 
put on, they should be used at the rate of 5 to $8 \mathrm{cwt}$. per acre, and put in a trench round the bushes at about one foot from the trunk. They should he guaranteed to contain 2 to $2 \frac{1}{2}$ per cent. of Nitrogen and 12 per cent. of soluble Phosphate of Lime. Superphosphate of Lime, prepared from mineral phosphate deposits, now chiefly in Carolina and Florida, will also supply phosphates to the plants. It is obtained from these sources in a precisely similar fashion to that in which the last named manure is prepared from bones. Alone it should not usually be applied, but mixed with oilcake it forms a very effective manure, or indeed it might be added along with cattle manure to soil deficient in Phosphates.

The objection to all these manures made by treatment of some raw product with Sulphuric Acid, is that it is apt to exhaust the Lime already rather deficient in the soil, and hence, though one could recommend small quantities in mixtures, they are not materials to be added in large quantity.

\section{BASIC SLAG.}

The Phosphatic Manure which has been the most successful up to date is probably Basic Slag, and in Ceylon its use has had a very great extension. It has practically only been on the market ten years, being a bye-product of the manufacture of steel by the Basic Bessemer Process, and consists, it is supposed, of a TetraBasic Phosphate of Lime, together with Iron compounds. It varies very much in value, and should always be bought on a guarantee of at least the equivalent of 35 to 40 per cent. of Phosphate of Lime, and a fineness of 70 to 80 per cent. (that is to say, this percentage will pass through a sieve of 10,000 meshes to the square inch). As it contains an excess of lime, it cannot be mixed with or stored with most other manures, and further, it is of little or no value applied alone. The greatest success in Ceylon has been obtained by burying light prunings in trenches with this manure, when the rotting material thus buried becomes quickly interlaced with a mass of the feeding rootlets of tea. I have seen one of these trenches opened after six months, when the prunings had fairly well rotted, and found this to be the case.

\section{BURIAL OF PRUNINGS.}

This, however, raises the whole question of the advisability of burying prunings, a practice which, on the recommendation of 
Mr. Bamber, is in vogue in almost all the best tea culture in Ceylon. Dr. Watt is emphatically opposed to it on account of its little manuial value, apart from the ash (which can be returned to the land in any case), and because he believes it to be a means of spreading blights. He writes :-

"But for the use of such expressions as "fancy" and "unaccountable" applied to a question of this nature, I should have regardel the burying of prunings as one that had only to be mentioned in order to secure that the practice would in future be rigorously prohibited. Even admitting that there is a slight manurial advantage by so doing, some of the most serious maladies to which tea is subject are thereby distributed all over the garden. It will pay the planter ten times over to incur the expense of purchasing chemical manure, that will give to the soil as much, if not more, Nitrogen and other materials than are contained in the prunings. By burying them he risks the perpetuation and extension of many insect and fungoid pests that harbour on the shoots when the periods of their inactivity occur In a garden, * I pulled out of the ground many projecting twigs of partially buried prunings, and showed ** * that they contained, in their active condition, the spore bearing structures of red rust. These prunings had been buried in the autumn, and had thus continued for months to distribute the disease. Red Rust had made its appearance in the garden a few years previously, and had been spreading to an alarming extent, and no wonder, since, year after year, by burying the prunings the malady had been carried from affected to healthy bushes."

Dr. Watt then goes on to instance the spread of thread blight and of other enemies of the tea bush by the same means, and finally recommends that everything should be burnt-advice which has been very largely adopted, more especially in Upper Assam, since his day.

There is no doubt that this advice is far and away the safest in every case. It may be perhaps that more spores of grey blight are blown about and alight on other bushes by carrying off the plot to burn than by sweeping them immediately into a trench and covering up, but such cases are isolated in the extreme-and under all conditions the burning of prunings is $f_{a r}$ and away the safest way, always making a point of returning the ashes to the land. This returning the ashes to the land is always a difficulty. On one of the best managed gardens in Upper Assam last year, I found the ashes from several acres spread over a strip a few yards wide. If this is done serious depletion of the land takes place, and it surely is comparatively little trouble to see that the ashes are effectively distributed over the land from which they were taken. Burning, therefore, is the ideal way of disposing of prunings, especially if the Nitrogen thus dissipated be returned to the land by means of a leguminous green manuring crop the following spring. In heavy pruning this green manuring should always be carried out, as 
the amount of Nitrogen removed by the pruning is considerable. Burning should in every case be resorted to to get rid of prunings if blights are prevalent in the garden. The most dangerous in this connection are red rust and thread blight,-but one does not know how many others are carried by means of their burial. To leave prunings lying about in a garden with these blights on them is suicidal, and to bury them is dangerous. If the garden is, however, free from blight there does not seem any absolute reason against burying the light prunings-ant these only-provided the following conditions are adhered to :-

(1) They must be buried deep. At least six inches of soil should be left on top of them, so that they will not be turned up by the hoe.

(2) They should be buried immediately on pruning or as soon after as possible. In Ceylon trenches are dug to receive the prunings before the bushes are touched at all, and the prunings are put into them practically at once. Once dried up much of the manurial value has gone, or is rendered less available.

(3) They should be buried with something which will destroy any latent germs or spores of fungi which are upon them. The best materials for this are Lime and Basic Slag, which not only cause the blight spores to be destroyed but also the prunings to rot more quickly. The usual way of applying the Basic Slag, which is preferable, is to dust it over the buried prunings from a tin in which holes have been made, and immediately cover up the hole. In this way 4 to $5 \mathrm{cwts}$. would be applied per acre, and in Ceylon the method-coupled with a more complete manure on the surface the following spring-has been said to be eminently successful.

If conveniently situated, the burial of jungle-provided it does not contain thread blight-would be advantageous on heavy soils. It should be put in in trenches, and lime or basic slag added as suggested in the cases in which burial of prunings is admissible.

BASIC SLAG IN COMBINATION WITH GREEN MANURING.

The abovecourse can only be recommended in blight-free gardens, and in general, the method which follows would probably be a better way of applying Basic Slag. Instead of burying this with prunings, broadcast it on the surface, either at the autumn deep hoe (which is preferable) or with the first spring hoe, and then follow with a crop of matikalai in May, to be hoed in in June, The green manuring 
crop is rendered more vigorous by the Basic Slag, absorbs a large portion of its Phosphoric Acid, and when it decays passes it on to the bush. This method was carried out last spring in several gardens on my recommendation. It is too early yet to judge its ultimate effect (as at the rate of $8 \mathrm{cwt}$. per acre it would last for several years, and several green manuring crops), but I think there is distirct promise of this combination proving a very effective manure. I should recommend its trial with much more confidence as a quality manure, than either the dissolved bones or the superphosphate previously mentioned. It must again be insisted however that alone Basic Slag is almost useless, as it has no faculty of diffusing itself in the soil, and hence the roots have no chance to come in contact with it.

WOOD ASHES.

Another phosphatic manure of great value now often largely wasted, but produced on the great majority of gardens is wood ash. This is of course usually put on the land, but only when three quarters of the virtue have gone. It it is advisable to put cattle manure under cover, it is ten times more so to protect wood ashes from the rain. May I suggest that the wood ashes produced should be put on the covered manure heap, which I hope henceforth will be a necessity on every garden. It was formerly be supposed that any alkali, such as wood ashes are, would increase the evolution of ammonia from a dung heap and hence bring about deterioration of the cattle manure under such conditions, but that idea has now been abandoned and probably manure keeps better somewhat alkaline than otherwise. It would then be applied with the cattle manure. Alone it would be valuable (1) before green manuring at the rate of $5 \mathrm{cwt}$. per acre; (2) for burying with prunings (if this be done), or (3) as a mixture with oilcake, but it is of little use in any case if it has stood exposed to the rain for months.

Wood ashes form not only a phosphatic manure, but also even more essentially a source of Potash. The analysis of samples of fresh ashes, and ashes exposed to the rain, will give the following figures. Of course, they vary much for every tree and wood.

Fresh Ashes.

Washed Ashes.

$\begin{array}{llrlr}\text { Moisture } & \ldots & 12^{\circ} 0 & \ldots & 12^{\circ} \circ \\ \text { Potash } & \ldots & 5 \cdot 5 & \ldots & 1{ }^{\circ} \\ \text { Phosphoric Acid } & \ldots & 1 \cdot 9 & \ldots & 1 \cdot 7 \\ \text { Lime } & \ldots & 34^{\prime} 1 & \ldots & 35^{\circ} \mathrm{S}\end{array}$




\section{POTASH MANURES.}

As a source of Potash however, they should be used in an exactly similar manner to that just described.

Potash manures, I have said, will be rarely specially required for tea in Assam. If analysis of the soil indicates that Potash is deficient and wood ashes are not available in sufficient quantity, the only two manures which would be worth carrying to Assam are the Sulphate of Potash (containing 50 per cent. of Potash) and the Muriate of Potash, containing a little more. They may form components of mixtures, but should never be applied alone to the bushes.

\section{LIME AS MANURE.}

We now come to the use of lime. As stated in the previous chapter, I consider that very little of the Assam soil is in need of lime, or is likely to be for a good many years, if manures like Sulphate of Ammonia be avoided, although at present it contains far less of this constituent than the average agricultural soil. Lime has its functions, however, and should not be totally neglected.

I. It is often useful to apply lime to a garden affected with fungous and insect blights, not so much as a manure (though this may in the future be found to be of advantage in connection with blights), but as a means of destroying the insects, caterpillars, and fungous spores in the soil round the bushes. For this purpose it should be freshly slaked-if possible, slaked just before use. Slaked lime bought and imported ready slaked is of little value for the purpose, as usually fifty per cent. has reverted to the state of Carbonate of Lime, and is useless.

2. It forms a good substitute for Basic. Slag as an addition when burying prunings, and has the same effect in increasing the rapidity of rotting, but not the advantage of adding Phosphoric Acid.

3. It is useful also in keeping cattle manure. By adding a layer of lime to a manure heap occasionally, a sort of compost is formed, the manure rots more quickly, and the lime becomes entirely incorporated with the manure.

Further than this lime seems to possess no immediate use in manuring tea in Assam.

\section{OTHER MANURES.}

Various other more or less rare salts have been suggested as additions to tea. Sulphate of Iron and Sulphate of Manganese have 
been suggested as manures for quality in Ceylon. As at present they are expensive-in the latter case very expensive-and of no present proved value I cannot recommend them.

We therefore limit the possibly profitable manure in Assam for the present to the following :-

I. Bheel Soil and Top-dressing material of all kinds.

2. Cattle Manure.

3. Green Manuring.

4. Fertilising Trees and Bushes.

5. Bones.

6. Oil cakes-chiefly those of castor and mustard.

These are all more or less complete manures. Of those useful for special constituents we have-

7. Nitrate of Soda, or Potash in rare cases for nitrogen.

8. Superphosphate from Bones or from Mineral Phosphate for phosphoric acid.

9. Basic Slag for phosphoric acid and lime.

10. Wood Ashes for phosphoric acid and potash.

II. Sulphate or Muriate of Potash in rare cases for potash.

12. Lime.

I have already, under each heading, pointed out the utility of each of these, but it remains now to submit certain general considerations on the methods in which it should be carried out.

I. I am strongly of opinion that manuring should always be carried out the year before heavy pruning a plot. Thus, if a section is to be cut down in December 1902, it should be manured with whatever it needs in the winter of 190I-1902. This is on the prin. ciple that before a serious operation is undertaken, the general health of the bush should be as great as possible, and the manure should be so incorporated with the soil, that without undue stimulation the bush recovers from the serious cutting.

2. In 1898 , Dr. Watt hinted in several places that rotation of crops in some form or other was imperatively needed in tea gardens. In this, I am at one with him, and would add that there is equal need of rotation of manuring, and would suggest here 
some rotations which might be profitably carried out. As far as manuring is concerned, I do not think that a period of more than seven years should go by on any plot of established tea without at least one application of manure. Ten years might occasionally pass on some lands and some gardens, but this is I fancy quite the limit. Take for instance a garden of 500 acres, soil light and fairly deep, top-dressing soil easily available and cattle manure well kept. Such a garden would be divided into seven sections, of seventy acres each, and a method of dealing with it might be :-

IST Section.-Ist year.-Bheel Soil-light dressing-not more than 4 inches thick when put on.

2nd year.-Crop of mustard in May and June to be hoed in as green manure.

3ric year-Nothing in growing season. Basic Slag (8 cwt. per acre) in November.

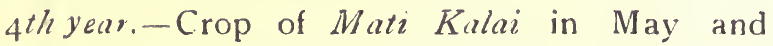
June to be hoed in as green manure.

5 th year-Nothing.

6th year.-Dressing of 7 tons per acre of Cattle Manure, in March.

7th year-- Nothing.

When the first 70 acres received the bheel soil, the second would be having the second year's treatment, so that every year's would see one section under some kind of treatment coupled with rotation of crop. The total expense outside the garden for the seven years would be thus limited to the $8 \mathrm{cwt}$. per acre of Basic Slag in the $4^{\text {th }}$ year - which would probably not be needed in the next seven year's series on the same plot. Of course endless variations could be introduced. If bheel soil were not available, a dressing of Io cwt. per acre of castor or $12 \mathrm{cwt}$. per acre of mustard cake would more or less replace it - and cost no more, but in most cases rather less. The Basic Slag might be replaced by Lime, or a smaller dressing, say $4 \mathrm{cwt}$. per acre might be put on and added to each rotation instead of once in 14 years. The cattle manure might be found not to be needed-or finally the Basic Slag might be 
altogether omitted and superphosphate ( 2 cwt. per acre) be added with the farmyard manure. The cost roughly would be as follows :-

I Bheel Soiling

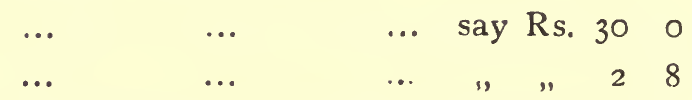

2 Mustard Seed

(The hoeing in would be paid for by missing a regular hoe.)

3 Basic Slag $8 \mathrm{cwt} . \quad \ldots \quad \ldots \quad \ldots \quad \ldots$ say Rs. $30 \quad 0$

4 Mati Kalai seed ... $\quad$.. $\quad \ldots \quad, \quad, \quad 2 \quad 0$

6 Cattle Manure, including carting and application

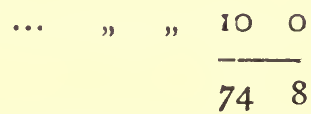

or a cost of Io rupees ro annas per annum for the first seven years, and 6 rupees 8 annas per annum for the second seven years. Even if an increase of tea were kept going of thirty pounds per annum, this expense would be doubly wiped out, for the treatment suggested would certainly not lower the quality.

The rotation suggested might be extended to ten years on some gardens, as I said above, by the introduction of a year without treatment after the first, fourth, and sixth years, and so the cost would be recuced to $71 / 2$ rupees for the first period, and $41 / 2$ rupees per acre for the second. I have placed the bheel soiling at 30 rupees per acre, a rather low figure perhaps, but the dressing I suggest, is only a light one. If the material were very good, even a less dressing would suffice, if there was any prospect of a repetition at the end of seven years.

Another rotation based on entirely different lines, say for a heavy soil might be-

IST SECTION-Ist year.-Deep trench, the soil between alternate rows (see page 21 ) and put in the trenches 2 tons cattle manure per acre, another three tons being applied on the surface of the plot.

2nd year.-Grow Mati Kalai over the whole plot in May, and hoe in in June.

3rd year.-Nothing.

4th year. - Deep trench the other rows, and add jungle in the trenches with Basic Slag $4 \mathrm{cwt}$. per acre. 
5th year. - Grow Mustard over the whole plot in May, and hoe in in June.

6 th year-Nothing.

7 th year.-Grow Mati Kalaz as in the 2 nd year.

In the next rotation of seven years, the section would be deep trenched in the corresponding years across the former lines of trenching between the other rows. The cost of such a system would be-

Rs. A.

\begin{tabular}{llllll} 
I & Deep Trenching, say & $\ldots$ & $\ldots$ & 8 & 0 \\
2 & Cattle Manure, 5 tons, say $\ldots$ & $\ldots$ & 7 & 0 \\
3 & Mati Kalai seed, say & $\ldots$ & $\ldots$ & 2 & 0 \\
4 & Deep Trenching, say & $\ldots$ & $\ldots$ & 8 & 0 \\
5 & Carrying Jungle, say & $\ldots$ & $\ldots$ & 5 & 0 \\
6 & Basic Slag, 4 cwt, say & $\ldots$ & $\ldots$ & 1 5 & 0 \\
7 & Mustard seed, say & $\ldots$ & $\ldots$ & 2 & 8 \\
8 & Mati Kalai seed, say & $\ldots$ & $\ldots$ & 2 & 0 \\
& & Total & $\ldots$ & 49 & 8 \\
\hline
\end{tabular}

or a cost of 7 rupees I anna per acre per annum, and all except that or Basic Slag, and the various seeds would be paid for labour, which would in any case have to be employed. Oilcake can always replace cattle manure, at the rate of $2 \mathrm{cwt}$. of the former to one ton of the latter, but with a stiff soil the improvement of condition with the cattle dung renders it preferable.

I am confident that rotations of this character, the above being only offered as suggestions in which the cost of the operations would vary in every district, will have to be regular things in the future. They, to a certain extent, prevent the land getting so one-sidedly exhausted as it would by growing tea constantly, and above all, would, I believe, retain the quality of the tea. For this last reason specially, $\mathfrak{l}$ have introduced a phosphatic manure in each example given. The whole, however, in each instance, should be based on an analysis of the garden soil, the value of any artificial manures bought should be checked by analysis, and a most rigorous control instituted in every part of the system. 


\section{CHAPTER V.}

\section{CHARACTER OF SOIL IN THE ASSAM DISTRICTS.}

[ In this chapter I have tried to describe, classify, and indicate the best method of manuring the tea soils of each district in the Brahmaputra Valley. Such an attempt must necessarily be very imperfect, as my acquaintance with the districts themselves is only a short one, and I have not been able to analyse the soils of any but comparatively few sup. posed typicil gardens. The incompleteness may be wiped out by further studies : for any errors which may be present I must plead in excuse the short opportunity I have had for study, and ask for lenient judgment.- H.H.M.]

The whole of the tea culture in the Assam Valley lies in the alluvial tract, which fills the space between the Himalayas on the North, and the hills, variously termed Naga, Mikir, Jaintia and Khasia on the South. Though it is all alluvial, yet it differs very much in character in the different parts, and even within a few miles of each other points may be found the soils of which are totally distinct. The lower part of the valley contains a large number of isolated hills, and in fact the main range of the Khasias approaches the river at Gauhati. Even above this, however, an isolated hill or two crops up, generally composed of rock of a gneissic character and red in colour. These isolated hills occur right up to Tezpur and Silghat, where they appear to form outposts of the Mikir hills, and even at Bishnauth and at Nigriting. The existence of such hills would probably point to the fact that, at a long ago period, what is now the lower part of the valley, had a general higher level than what is now the higher.

The geological history of the formation of the valley is little known. Though officers of the Geological Survey of India have worked in the hills round the valley itself, since 1865 practically nothing has been done in connection with the mass of alluvium which forms the cultivated area. In that year, Mr. Medlicott, a then officer of the Survey, wrote of the valley as a whole as follows :-

"I scarcely like to touch upon the very interesting and important, but most intricate, question of alluvium without having time or data to discuss it as it deserves. On first reading Mr. Ferguson's most valuable paper on the delta of the Ganges, it struck me as prima facie anomalous, and requiring explanation, that the deposits of the Brahmaputra should be so backward as compared with those of the Ganges. Its volume is stated to be equal to that of the Ganges, and the amount of silt it carries is immensely greater. The valley of Assam above Dhubri is insignificant compared with that of the Ganges above Rajmahal; over a large portion of it, moreover, rock seems to be near the surface. Yet the alluvial formation of Assam is far more backward than that of the Gangetic plain. Even supposing that most of the deeper deposits of the Dinagepore region, and even of the delta, were the work of the Brahmaputra, the actual relations of the rivers must have been long 
since established, and still the work of the Brahmaputra, in the delta, *** is altogether in arrears as compared with that of the Ganges. "* The difficulty for which I would seek an explanation is expressed by the question, why is it, remembering the silt power of the Brahmaputra, that at present the elevation of the river at Gauhati with 350 miles to run, is apparently lower than the Ganges at Rajmahal within 250 miles of the ocean? Mr. Ferguson correctly described Assam as in a semi-habitable state. From the Bramahkoond to Dhubri it is under the dominion of the waters. It is in the condition of a delta without the power of vertical growth which a delta must possess. -.. As evidence of how these quasi-deltaic conditions obtain, how completely this stationary point of formation has been attained, I may notice a remarkable feature of the Dehing. This large stream drains the southeast terminal corner of the valley, as the Erahmaputra proper does that of the northeast. After leaving the gorge of the h:lls, it flows for several miles over a zone of bhabur, the flat slope formed by the coarser torrented debris. On about the middle of this slope. the river being still at strong torrent, it divides into two approximately equal streams : one flows tolerably direct to the Brahmaputra above Sadya, the other flows along the base of the southern hills, through the rocky gorge of the Tippum range at Jaipur and joins the Brahmaputrd more than a hundred miles helow Sadya. That a river should form itself into two is necessary proof that it is constructing, not destroying, and that for many years such a bifurcation is maintained, shows that there can be no chose of levels between the two courses."

I have quoted this passage in extenso from the Memoirs of the Geological Survey of India for 1865, where it forms the last paper of any importance on the Geology of the Assam valley alluvial deposits to date, because it shows how little is known of the origin and progress of these deposits. Of their present state as to increase or decrease, of the conditions which have made the general level of the country relative to the river higher between Gauhati and Silghat than it is in the Subansiri and Dehing valleys, of the cause of the production of the curious ridges running from the hills towards the river in the Jorhat and Golaghat districts, or of the isolated plateaux surrounded by low land in Tezpur, Bishnauth and Sibsagar, we know little or nothing. One can but wish that in the near future, for the sake of general knowledge, if not for the sake of the tea, these problems may be tackled by a trained geologist.

TYPES OF SOIL.

The soil however of the valley, more or less capable of growing tea, inay perhaps, except in the Dibrugarh district, which seems to present the most complicated portion of the valley, be divided into five classes of very different value for purposes of this culture. These may be said to consist of (1) a bed of alluvial micaceous sand skirting the base of the Himalayas in Kamrup, Mangaldai, and, I think, Tezpur and part of Bishnauth; (2) the soil of the plateaux rising suddenly out of the lower plains in Tezpur ("Tezpur bank"), Bishnauth, and probably Sibsagar: (3) a heavy soil composed chiefly 
of very fine silt, probably deposited in calm water, of which a large amount of Nowgong consist, and which forms occasional ridges in Jorhat, Sibsagar and Dibrugarh; (4) a series of sandy ridges running more or less across the line of the valley and repeated again and again from Doom Dooma in the upper end of the district down through Sibsagar (in small quantity), Jorhat, and Golaghat down to the line of the Mikir Hills; and (5) a series of low hills skirting the base of the Naga Hills proper throughout the greater part of the Sibsagar district. These various ridges and kinds of soil will be noticed, so far as I know them, in dealing with the individual districts, which I will take in the order, slightly modified, in which I visited them in November and December, 1900 , and January of the present year.

\section{MANGALDAI DISTRICT.}

Mangaldai, the tea district lowest in the valley on the north bank of the Brahmaputra, is found to consist of two absolutely distinct sections,-distinct in character of soil, in level, and in suitability for tea. One of these is on a bank of sand near the hills; the other is on land only slightly raised above the rice level and much nearer the river.

The former of these consists principally of grass land, and is composed of micaceous sand, light grey in colour, which, having borne grass jungle annually burnt over for many years, usually possesses a very rich surface soil, eminently suitable for tea. Like most grass lands, the exceeding richness of the surface does not extend to a great depth, but the following analysis of the soil to I 5 inches deep of several gardens, show how very good the surface soil of the virgin land must be.

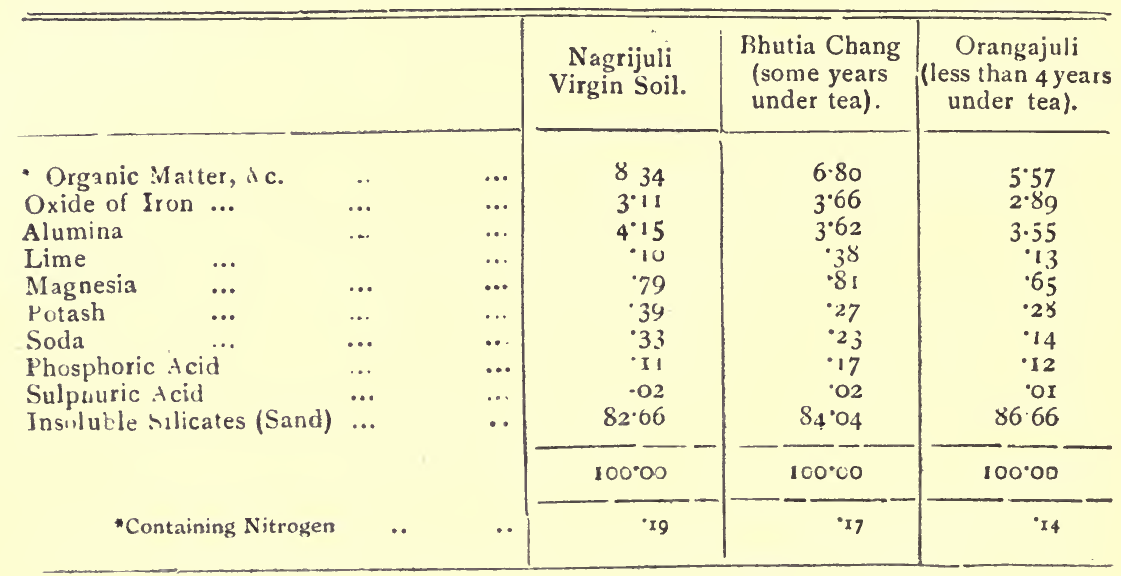


All these are excellent soils, as is well shown by the analysis of the non-sandy portion of the soils. These gave -

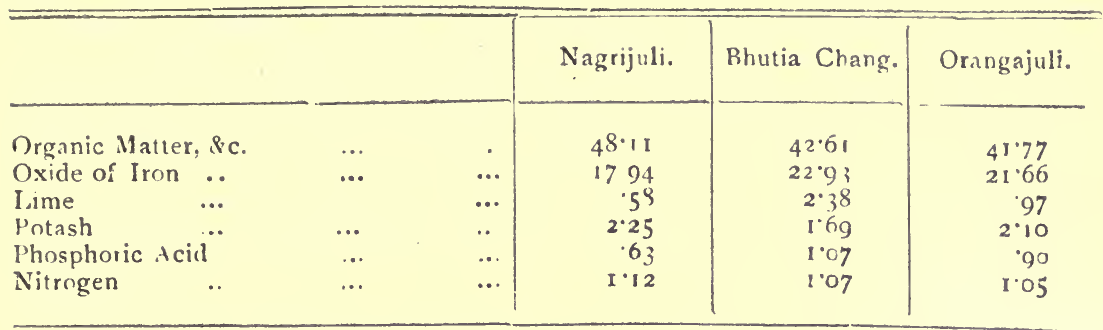

In parts of these lands there are ridges of gravel, but now the water level is in some cases over one hundred feet below the surface. This is caused by the rivers sinking underneath this bank of sand at the foot of the hills, and proceeding underneath until its southern edge is reached. On these soils, I fancy, artificial drainage will only be needed in special cases-the soil is generally so porous that the water disappears practically at once. This bank would be one of the places where irrigation,-if it was possible, and would pay anywhere,owing to the extreme porosity of the soil, and the great depth at which water is found, would be of advantage.

Exhaustion will take place first in the Organic Matter and Nitrogen, and it would be advisable to grow crops of Mati Kalni or other leguminous plant at intervals after the tea has been ten years on the ground. On this land "sau" trees would be of great advantage. Ultimately the most effective manure here will be the rich surface soil from the surrounding grass jungle (where this exists), or in its default cattle manure, or oil cake. Soluble Nitrogenous manures cannot be at all recommended, and phosphates of any sort will not be required for many years. If the climate will allow (and I fear it will not) of close plucking, high quality teas should be here producible.

There is, I understand, a deposit of red soil, as well as the above grey material, in this district, but $I$ have not been able to examine it.

Of a totally different character is the soil which is met with on the tea gardens which lie nearer the river. Here one gets land very slightly above the level of the adjoining country, and composed of a soil much finer in texture than those I have just been describing. Furthermore it is not very deep, and at a depth varying from 8 to 15 feet there is found, in places at any rate, a subsoil water charged with 
Sulphuretted Hydrogen, which is a plant poison. The ultimate depth of root development is limited by the highest point to which this water rises, and so on this land drains are a necessity, and should be narrow, and in a hot district like Mangaldai, banked up at the sides. Owing to the lack of depth of the soils, exhaustion is apt to quickly take place, but with manure, luxuriant bushes can, I am confident, be kept up. The following is the analysis of an old tea soil at Singrimari, still fairly flourishing, but occasionally manured.

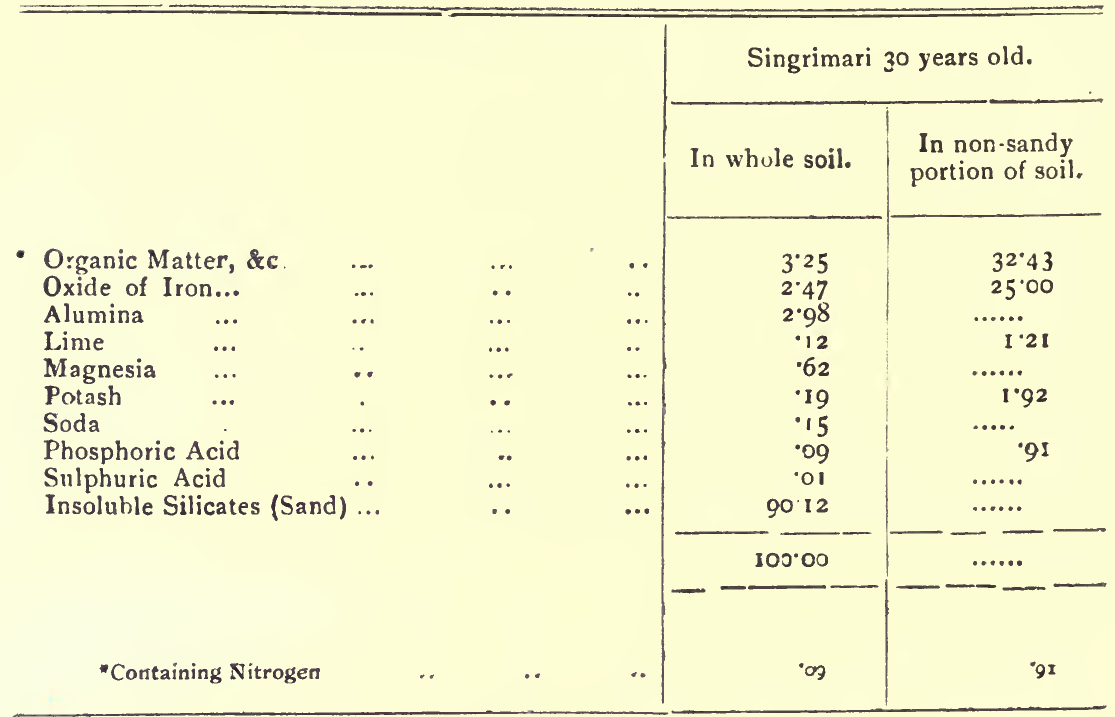

Manuring will be early needed on these gardens. The soil which the above analysis represents urgently needs nitrogenous and organic matter,-and little else. This would be best supplied by green manuring with a leguminous crop, and I would urge this, together with the burial of jungle, or of any refuse which can be obtained, including village manure. Such treatment would also improve the condition of the land, which is urgently necessary.

TEZPUR DISTRICT.

The Tezpur district is composed of three entirely different sections. The first of these lies between the river and the so-called Tezpur bank, and the land consists of a whitish grey soil (when dry) overlying a sandy clay. Most of this land has been undoubtedly under cultivation before, if not immediately before, being devoted to tea. It is pure alluvium, and the worst feature is the shallowness 
of the friable soil on the surface, and the comparatively high waterlevel which necessitates on all this land the most careful and thorough drainage. This shallowness of the soil leads to the prevalence of "red spider " and "red rust." The former is now kept in hand on most of the gardens ty means of sulphur, which is dusted on in the spring, and has been shown to be exceedingly effective, and to cost here only five rupees per acre. Red Rust is perháps : greater enemy than Red Spider, and on most of these gardens demands attention by the methods suggested in my pamphlet on the subject (August 1901). The methods suggested there for deepening the soil would all pay, I am confident, on this section.

Owing to the comparative shallowness of the useful soil exhaustion takes place comparatively quickly, and hence manure is generally necessary on all land here, which has been under tea for more than a few years. The wonderful increase in yield given by castor cake in 1900* (at the rate of $15 \mathrm{I} / 2$ maunds per acre) show how the tea responds to the application of nitrogenous manures and, in fact, I could recommend nothing more likely to be useful here than an occasional dose of oil cake, either mustard or castor, at the rate of 10 to 15 maunds per acre mixed with 3 maurds per acre of mineral superphosphate and followed by a green manuring crop in May and June of the following year.

The following are analyses of somewhat exhausted soils, both having given tea for over twenty years and needing manuring in this manner in the district:-

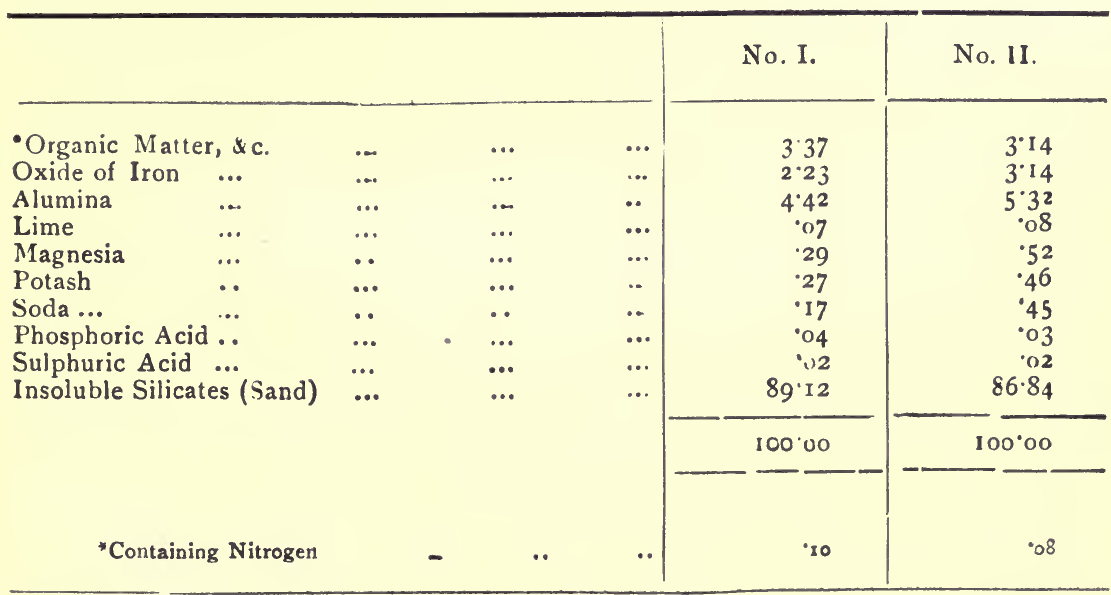

* See page go. 
or if we calculate on the non-sandy portion of the soil, we have:-

\begin{tabular}{|c|c|c|c|c|c|}
\hline & & & & No. I. & No. II. \\
\hline Organic Matter, \& & $\ldots$ & .. & $\ldots$ & $30 \cdot 97$ & 23.87 \\
\hline Dxide of Iron .. & . & $\ldots$ & $\ldots$ & $20 \cdot 50$ & 23.87 \\
\hline Lime ... & $\ldots$ & $\ldots$ & $\ldots$ & $\cdot 64$ & $6 i$ \\
\hline Potash & $\ldots$ & $\ldots$ & .. & $2 \cdot 48$ & 3.49 \\
\hline Phosphuric Acid. & $\ldots$ & $\ldots$ &.. & 37 & .23 \\
\hline Nitrogen & .. & .. & $\ldots$ & 92 & $6 \mathrm{I}$ \\
\hline
\end{tabular}

THE TEZPUR BANK.

A few miles from the river a sudden rise of eighteen to twenty feet occurs in the land, and one rises on to one of the banks of red soil of the Assam Valley, whose existence is as yet unexplained. Mr. Medlicott, in the paper previously quoted, says of them :-

"Although so little developed, these deposits are here the representatives of what has been called the 'older alluvium' so extensively found in the Ganges Valley. It were of great importance that some definite opinion should be formed regarding these recent formatiuns, as at present grave dotibt rests upon them, obstructing, if not vitiating our speculations. It is still a general opinion that this older alluvium is of marine formation. The more rational views of fluviatile rock formation *** are to a great extent adopted within the range of the actual river courses, but those associated deposits are still looked upon as of a different order. The fact against their belonging to the actual form of conditions is their higher raised position, apparently quite out of reach of the formative action of ra:n and rivers."

Whatever the origin and cause of the existence of these banks, there occur several in the Assam Valley, none as striking as that at Tezpur, but all apparently of a similar character. Formed of a red loam, somewhat finer in texture than the average of the valley soils, and hence somewhat hard when in bulk, they seem, in the virgin condition to be largely covered with magnificent forests of which the Nahor (Mesua ferrea) is perhaps the prevailing tree in many places. These banks seem to he formed of even soil throughout, right down to the level of the patta land round about them. Occasionally they become slightly sandier and somewhat gravelly, but usually there are practically no stones. In the Tezpore bank, there runs a section of whitish compact sand, varying in width from a hundred feet to perhaps a quarter mile, from North West to South East, much inferior for tea culture. The deep red tint of the soil of these banks is usually only taken where the soil has been exposed to the air, and the subsoil taken below the cultivation depth is often merely a brown tint. 
The whole of the bank at Tezpur seems admirably suited when first opened out for the growth of tea. It needs fairly thorough cultivation right from the commencement, but with this gives pro. bably bushes as luxuriant as any other part of the valley. It would be a mistake however to call it a rich soil. The constituents are admirably balanced when the soil is virgin, but after about ten years of the intensive cropping in vogue here, need manuring if the land is not to become much less valuable. The change in the composition of the soil in ten years is shown in the following analyses of samples from Sonajuli :-

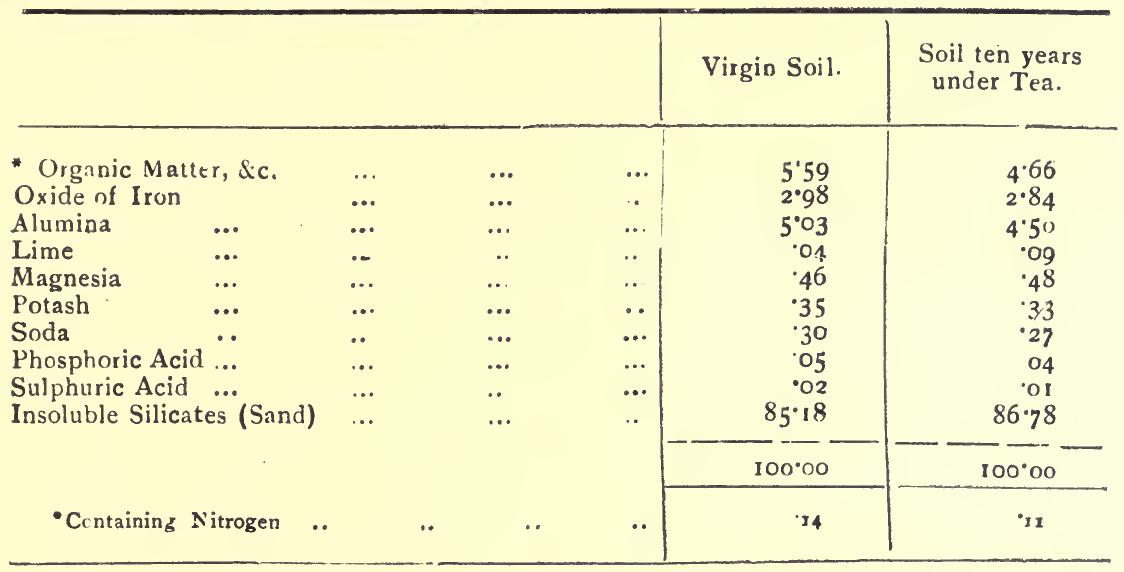

or calculated, as before, on the non-sandy part of the soil :-

\begin{tabular}{|c|c|c|c|c|c|}
\hline & & & & Virgin Soil. & $\begin{array}{c}\text { Soil ten years } \\
\text { under Tea. }\end{array}$ \\
\hline 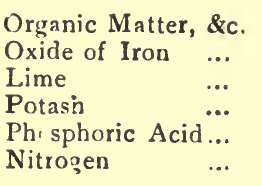 & $\begin{array}{l}\cdots \\
\cdots \\
\cdots \\
\cdots \\
\cdots\end{array}$ & $\begin{array}{l}\cdots \\
\cdots \\
\cdots \\
\cdots\end{array}$ & $\begin{array}{l}\ldots \\
\ldots \\
\cdots \\
\cdots \\
\cdots \\
\cdots\end{array}$ & $\begin{array}{r}37 \cdot 72 \\
20 \cdot 10 \\
\cdot 27 \\
2 \cdot 36 \\
\cdot 34 \\
\cdot 94\end{array}$ & $\begin{array}{r}35 \cdot 26 \\
21 \cdot 49 \\
\cdot 68 \\
2 \cdot 50 \\
\cdot 30 \\
.83\end{array}$ \\
\hline
\end{tabular}

there being a loss during the ten years (as shown in a preceding chapter) of 16.6 per cent. of Organic Matter, $2 \mathrm{I}^{\prime} 4$ per cent. of Nitrogen, and II'8 per cent. in the Phosphoric Acid, the whole soil being thus much impoverished in the constituents most needed by the tea plant.

Very fortunately, round and in this bank there exist, apparently, very rich deposits of peat and other bheel soil material. Close to Addabari, for instance, in what is apparently the old bed of the 
Borelli river, there is a deposit unexcelled in Assam, so far as I know, for richness as a manure, and one sample sent to me from Sonajuli was almost as rich. They both contained over 20 per cent. of Organic Matter, and 6o per cent. of Nitrogen. In such positions as these deposits occur, and where they are available, there need be no anxiety about the manuring of the land. In other positions this is precisely a place for oilcake and superphosphate. 'This manure put on the land at the rate of say 12 maunds mustard cake and 3 maunds of superphosphate, and applied in the spring with the early spring hoeing, would answer for three years, if in addition two green manuring crops were grown in the meantime of Mati Kalai. Without these green manuring crops, the amount of nitrogen supplied would be insufficient; with them it would be enough.

Near the east side of the bank, the soil is apparently not quite so good as on the West. The following is an aralysis of this section :-

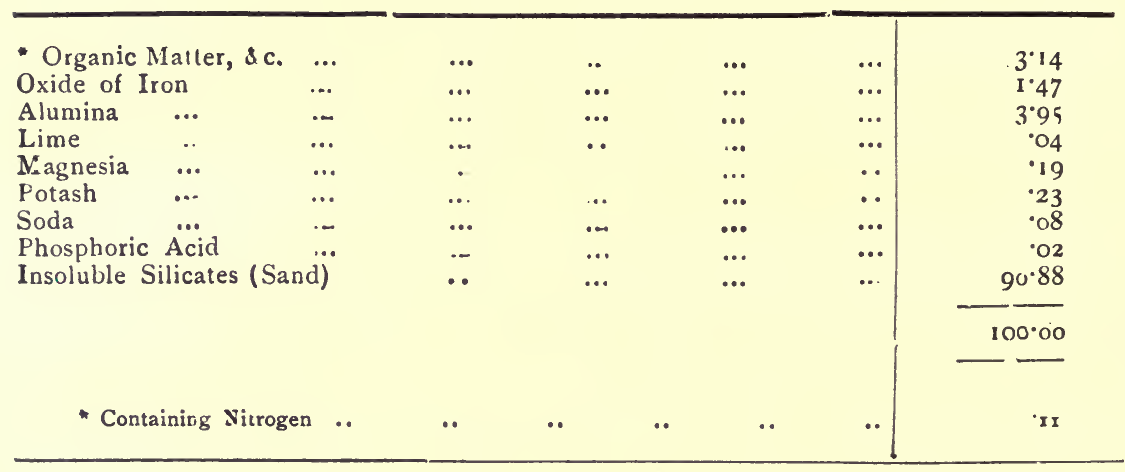

Such soil as this is in urgent need of manuring in one of the ways above suggested.

SANDY SOIL AT TEZPUR.

Between the Tezpur Bank and the Himalayas lies a tract of sandy land, largely, if not entirely, formed of the valley of the Borelli river, on which some of the earliest tea in the district was planted. The subsoil here is sand, and in a few cases gravel, and provided the water level in the soil is sufficiently far from the surface, and the fertility of the soil is kept up, the land does excellently. Below the sand or gravel, as the case may be, there 
is usually found a blue clay, and where this approaches anywhere near the surface, the limited root range causes the soil to be exhausted comparatively early.

The best manure for these gardens will be cattle manure followed by green manuring, the former being applied in spring, at about 5 to io tons per acre. "Sau" trees will be here of great advantage, and should undoubtedly be planted among the tea. Basic Slag followed by a green manuring crop (see page 97) will also be an alternative, but in any case the gardens in this section will rapidly deteriorate unless manured.

\section{BISHNAUTH DISTRICT.}

To the east of the Borelli river lies the Bishnauth district, which resembles that of Tezpur in the various types of soil found there. There is here, for instance, a bank of red soil, apparently originally forming one with that of Tezpur. It seems, however, decidedly heavier and more clayey than the latter, but there lie on it several of the best gardens in the district.

The following is the analysis of a soil on this bank, perhaps, however, a little more clayey than the average :-

-Organic Matter, etc.

Oxide of Iron

Alumina $\quad$...

Lime

Magnesia $\quad \ldots$

Potash

Soda

Phnsphoric Acid

Sulphuric dcid

Insoluble Silica tes (Sand)

$\begin{array}{lcc} & & \\ \ldots & \ldots & \\ \ldots & \ldots & \ldots \\ \ldots & \ldots & \ldots \\ \ldots & \ldots & . \\ \ldots & \ldots & \ldots \\ \ldots & \ldots & \cdots \\ \ldots & \ldots & \ldots \\ \ldots & \cdots & \cdots \\ & \cdots & \cdots\end{array}$

- Containing Nitrogen ..

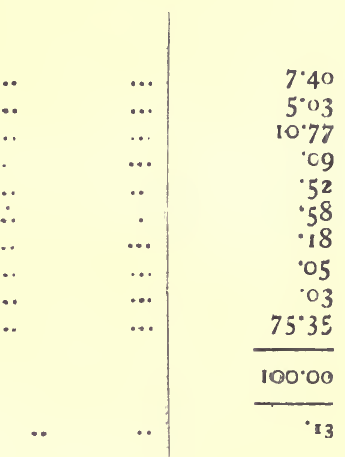

That is to say, there is roughly double as much clay as in the samples analysed from the Tezpur bank in the apparently very similar Sonajuli soil. The agricuitural result of this will be to emphasize (1) the lasting character of the soil, provided organic matter and phosphoric acid be kept present in sufficient quantity; (2) the necessity of thorough and frequent cultivation, or else the soil 
will puddle in the rains and dry hard when they cease; (3) the value and necessity of a thorough deep hoe in the early part of the cold and dry weather, which keeps the lower subsoil moist, and causes valuable weathering of the upper layer. One cannot exaggerate the value of a good deep hoe, when long dry weather is expected on such a soil as this. On sandy land the matter would assume a totally different aspect, but here it is essential.

It would be wise to have the several parts of this Bishnauth bank, which are ten years old and over-treated, in rotation with topdressing soil, or in its absence with mustard cake (10-12 maunds per acre), followed two years afterwards by mati kalai as a green manure, the mustard cake being again applied six years after the first application, and the rotation being so continued. This is land on which the system of trenching recommended on page $2 \mathrm{I}$ would probably be very successful.

Below the bank of red soil there lies a little tea on land very similar to that nearest the river at Tezpur. It should be dealt with by similar methods.

The belt of sandy soil so evident between the Tezpur bank and the Himalayas is also in existence north of the bank at Bishnauth, but in the best cases it is, I fancy, much deeper in the latter case. Dikorai, one of the best gardens in the Bishnauth Tea Co., lies upon it, and there the soil gave the following analyses, No. I being virgin and No. II having been many years under tea.

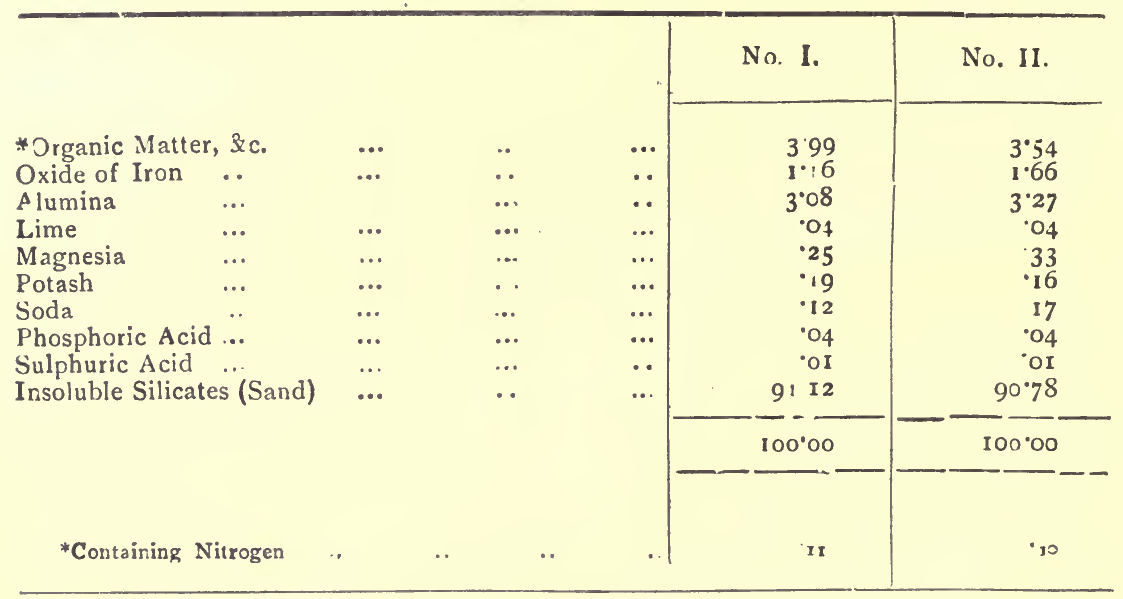


or-calculating on the non-sandy part of the soil, we have :-

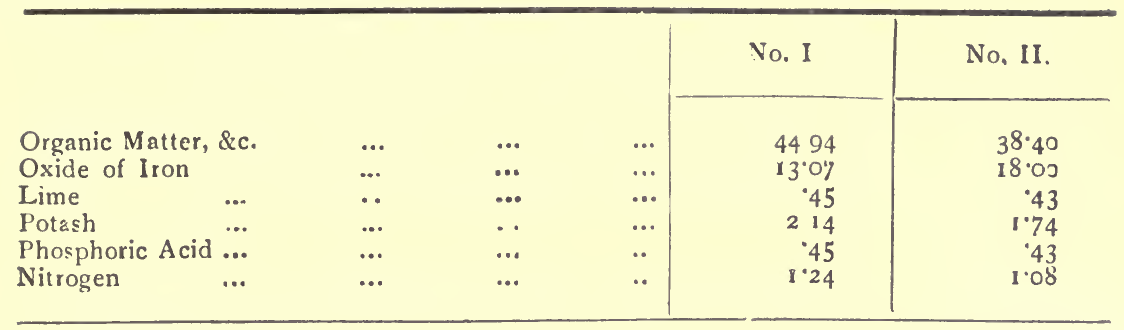

The exhaustion is evident in every constituent of importance, and to replace these losses, which, considering the age of the tea, are very small, the best methods would be those suggested in the very similar land at Tezpur, viz., cattle manure followed by green manuring, together with the planting of sau trees. In this case the sau trees should be cut down when three years old, as this land is, in the Bishnauth district, badly affected with mosquito, and hence shade would hardly be advisable. The "bogga inedeloa" (Tephrosia candida) is distinctly a bush which may have very great advantages under these special conditions. Basic Slag before a green manuring crop, just as recommended at Tezpur, would probably well pay for application.

East of the Bishnauth bank there lies a strip of korkani forest, and beyond this a huge grass plain. In the forest strip several gardens are found on a sandy soil, excellent in character, but not very deep, and requiring manuring at a comparatively early stage of their tea history. The subsoil, at a depth varying from $\delta$ to 20 feet, consists of clay, and this depth represents hence the depth of useful material. Probably the following nine-year course rotation would be the best that could be adopted :-

Ist year- io tons cattle manure the year before heavy pruning, and follow in spring with mati kalai as green manure.

2nd year-Nothing.

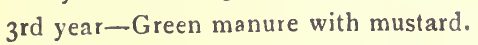

4 th year-Nothing.

5 th year-Oilcake $10 \mathrm{cwt}$. per acre, and green manure with mati kalai (all in spring).

6 th year - Nothing.

7 th year-Green manure with mustard.

8 th year-Nothing.

$9^{\text {th }}$ year-Nothing.

Ioth year-Cattle manure as in Ist year, \&c.

In this scheme the only thing to be imported would be the oilcake, and even this might be obtained locally. 
To the east of this strip of what was formerly korkani forest, as stated above, there lies a huge grass plain containing a considerable number of gardens. In common with much grass land it is not usually very deep, though exceptions do occur, and the soil is generally very light. The methods recommended for manuring the sandy forest gardens in the same district would be applicable here.

\section{NOKTH LAKHIMPUR DISTRICT.}

East of the Bishnauth district there lies that of North Lakhimpur, almost all of which is situated in the wedge of land between the Subansiri river and the Himalayas. The country as a whole is here exceptionally low and swampy, and it is only in tracts above the general level that tea can be planted out. In fact even in some of the existing gardens there is need of large works in order to keep out the water.

In the district, however, there appear to be three types of land.* The first of these, embracing Hoolmarie, Anniesbari, Doolahat and Merbheel, is composed of a good friable soil overlying a stiffer subsoil, the whole requiring deep thorough subsoil draining and heavy cultivation to yield luxuriant tea, and yet forming really a rich alluvial deposit. The soil of Anniestari, which has heen 20 to 25 years under tea, analysed as follows :-

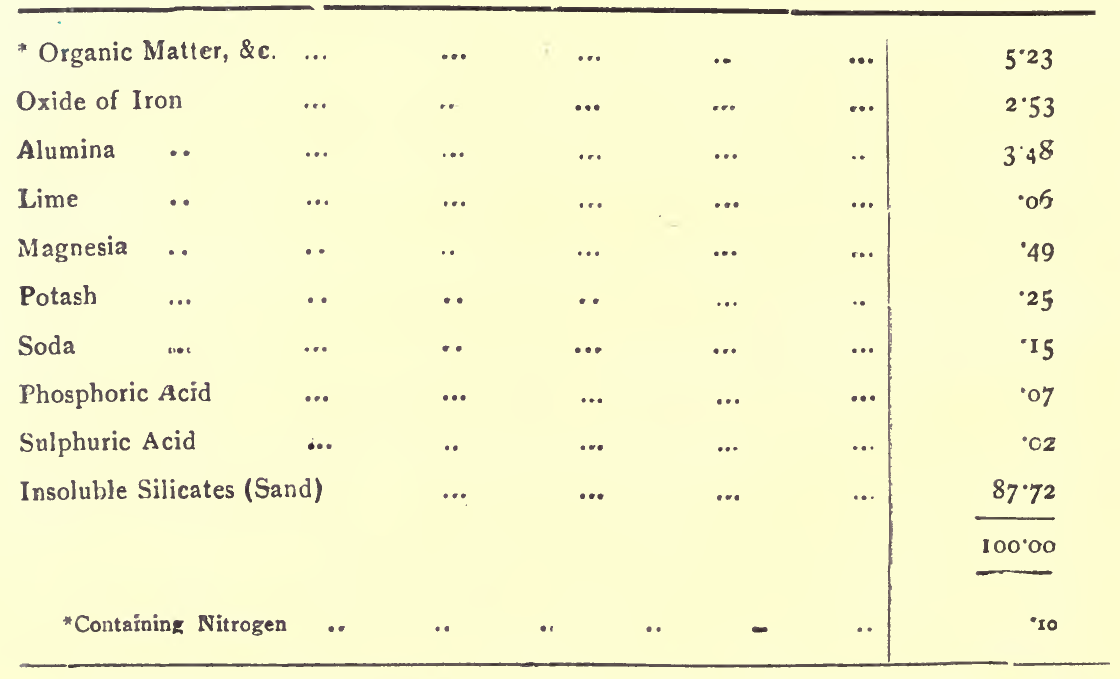

* I am much indebted to Mr. W. A. Hudson of the Dejoo Tea Co. for information as to these parts of this district which I was not able to see-H. H. M. 
or calculated on the non-sandy part of the soil-

Organic Matter, \&c. Oxide of Iron

Lime

Potash

Phosphoric Acid

Nitrogen

$\begin{array}{ll}\ldots & \ldots \\ \ldots & \ldots \\ \ldots & \ldots \\ \ldots & \ldots \\ \ldots & \ldots \\ \ldots & \ldots\end{array}$

$\ldots$
$\cdots$
$\cdots$
$\cdots$
$\cdots$

$42^{\circ} 6$ I $20 \cdot 61$ 49 $2 \circ 4$ $\cdot 57$ $\cdot 81$

Land such as this hardly wants manuring at present. Deep and thorough cultivation should produce as good tea as the land can give for the time being, but ultimately nitrogenous manures will be required in the first place. In any case, even at present, a green manuring crop would be found to be of very great value.

The second section of the North Lakhimpur district embraces chiefly the sandy land gardens,-Lilabari, and, I believe, Pathalipam and Bordeobam. In these sections it is difficult to prevent drains falling in owing to the sandiness of the soil, but nevertheless they are capable of growing excellent tea. The following analyses of Lilabari soil, the first a virgin soil (in Nahor forest) deeper than the average of the garden, and the second a soil which has been fifteen years under tea, illustrate the composition.

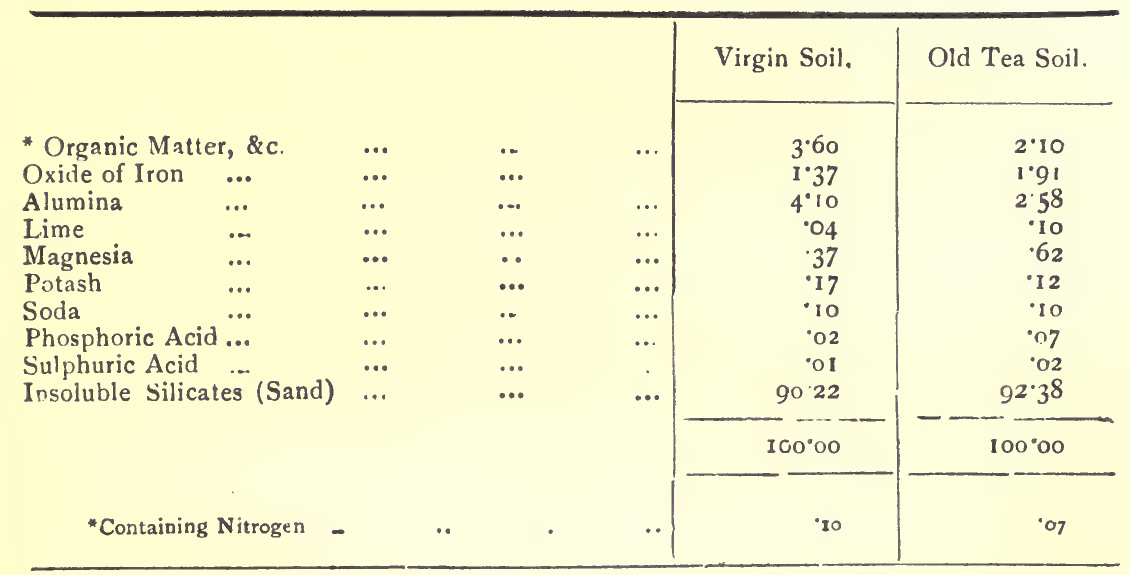

The first of these, for a virgin soil, is very deficient in Phosphoric Acid, so much so that I could hardly advise it being put out under tea unless the probability of phosphatic manuring being early necessary was faced. The old tea soil has done excellently up to date, yielding six maunds per acre of fairly fine plucked tea. It is liable, however, to rapid deterioration if organic and nitrogenous manures 
he not applied in the near future by means of green manuring with matikalai, or, better, this treatment combined with cattle manure at the rate of ten tons to the acre.

The third section of this district, and probably the best type of soil, embraces a great part of Joyhing and Dejoo gardens, the balance of the former being not dissimilar to the lower gardens at Tezpur. The best part of Joyhing lies on a bank of land similar to those at Tezpur and Bishnauth, but here the bank goes right up to the base of the hills This bank soil is a paradise for white ants, but nevertheless is exceedingly good for tea, but owing to a certain deficiency in phosphates seems hardly capable of producing quite the quality of Dibrugarh, though the climate is here approaching that of the upper valley. The Dejoo soil, both virgin and 35-40 years old, gives the fcllowing figures on analysis :-

\begin{tabular}{|c|c|c|c|c|c|}
\hline \multirow{2}{*}{\multicolumn{2}{|c|}{ *Organic Matter, \&c. }} & \multirow{2}{*}{$\cdots$} & Virgin Soil. & Old Tea Soil. & $\begin{array}{l}\text { Percentage loss } \\
\text { in } 35-40 \text { years. }\end{array}$ \\
\hline & & & $6 \cdot \mathrm{II}$ & $4 \cdot 25$ & 30.4 \\
\hline Oxide of Iron & $\ldots$ &.. & $2 \cdot 78$ & 272 & $\ldots .$. \\
\hline Alumina & $\ldots$ & $\ldots$ & $5 \cdot 63$ & $5 \cdot 60$ & $\ldots \ldots$ \\
\hline Lime $\quad \ldots$ & $\ldots$ &.. & 11 & $\cdot \mathrm{C}_{2}$ & $8 \mathrm{~s} \cdot 8$ \\
\hline Magnesia & $\ldots$ & $\ldots$ & 33 & 33 &... \\
\hline Potash .. & $\ldots$ & $\ldots$ & $\cdot 24$ & $\cdot 19$ & $20 \cdot 8$ \\
\hline Soda $\quad \ldots$ & $\ldots$ & $\ldots$ & 12 & 14 &... \\
\hline Phosphoric Acid & $\ldots$ & $\ldots$ & $\cdot 06$ & $\circ 3$ & $50 \circ$ \\
\hline \multirow{2}{*}{\multicolumn{2}{|c|}{$\begin{array}{l}\text { Sulphuric Acid } \\
\text { Insoluble Silicates (Sand) }\end{array}$}} & .. & .02 & .02 & $\cdots \ldots$ \\
\hline & & $\cdots$ & $84^{\circ} \cdot 60$ & $86 \cdot 70$ & $\cdots \cdot$ \\
\hline & & & $100 \cdot 00$ & $100 \cdot 00$ & $\ldots \ldots$ \\
\hline - Containing Ni & trogen &.. & $\cdot 20$ & 69 & $55^{\circ} \mathrm{o}$ \\
\hline
\end{tabular}

That such scils as these, therefore, bccome much exhausted by the growth of tea, can therefore be no longer dcubted, and even here manure will be required on land more than to to I 5 years old. This will, I fancy, be best applied as recommended on the Tezpur bank, save that phosphates are hardly so absolutely requisite at once. Good top-dressing soil is not, I think, available to the same extent as at Tezpur, hence one is driven to oilcake and super. phosphate, or even oilcake alone. Ten maunds of this would give 40 lbs, of nitrogen per acre, and if this were applied once in three years, and supplemented by green manuring with a leguminous crop, little more would be needed, except that in every sixth year the addition 
of 3 maunds per acre of superphosphate should be made to the cake application. We should thus have :-

Ist year-Oilcake and superphosphate applied as above in March, Mati Kalai sown in August, hoed in at the commencement of October.

2nd year-Nothing.

3rd year-Green manure in spring with mati kalai.

4th year-Oilcake applied as above, in March.

5 th year--Green manure in spring, say with mustard.

6 th year-Nothing.

7th year-Oil cake and superphosphate.

To the application of oilcake in the tenth year $5 \mathrm{cwt}$. per acre of wood ashes should be added, and, if the land shows sign of becoming sick of mati kalai so that less vigorous growth is obtained, mustard should be substituted for it occasionally.

DIBRUGARH DISTRICT.

East of the Subansiri on the north bank of the Brahmaputra there now exist practically no tea gardens. The whole country is low and more or less under the dominion of the waters. Almost immediately on crossing the Brahmaputra and its tributary, the Dibru, higher land is reached, and the land between this and the Dehing consists of a series of ridges, which form perhaps the best land in India for the growth of a large quantity of high class tea. On one of these ridges runs the Rangagora Road with its group of gardens. On another lies the railway, and near it another group, while still another lot of gardens are placed near the road to Jaipur. The whole configuration of the land in ridges, in many cases of different types of soil, of different vegetation, renders it impossible in this district to lay down distinct and definite rules for treatment and manuring as I have done on the north bank of the Brahmaputra, and I must restrict myself to those cases which I have personally examined.

Soon after leaving Dibrugarh on the Rangagora road, there is found in places the remains of an ancient forest buried beneath alluvial deposits between the road and the Dibru river. This was noticed at Mothola, and the material obtained is excellent as a top-dressing manurial application. It is worth while to put this note on record, as if such deposits occur extensively, they will become valuable to the gardens on which they are found. Further along the road the land apparently becomes more and more sandy, with a sudden descent into the bheel land near the Dibru. Such land as this, so far as can be seen without analysis, is deficient in organic 
matter, and would be benefitted by any cattle manure that may be available more than by anything else. In default of this, as recommended elsewhere under similar conditions, oilcake should be used, followed by green manuring crops.

Between the Rangagora road and the railway the country is extremely variable in character. Much of it consists of grass land which has produced some of the best tea gardens in the province; the soil of other parts is heavier in character and bears forest, itself altering in appearance with great frequency. One of the many gardens on this heavier forest land is Woodbine, the analyses of whose soil and subsoil follow. The land where these samples were collected had been under tea for 7 to 8 years and was yielding 6 maunds of tea per acre.

\begin{tabular}{|c|c|c|c|c|}
\hline & & $\begin{array}{c}\text { Soil to } \\
\text { I5 inches deep. }\end{array}$ & $\begin{array}{c}\text { Soil to } \\
8 \text { inches deep. }\end{array}$ & $\begin{array}{c}\text { Subsoil } 8 \text { to } \\
15 \text { inches deep. }\end{array}$ \\
\hline $\begin{array}{ll}\text {.Organic Matter, \&c. } \\
\text { Oxide of Iron } & \ldots \\
\text { Alumina } & \ldots \\
\text { Line ... } & \ldots \\
\text { Magnesia } & \ldots \\
\text { Potash ... } & \ldots \\
\text { Soda ... } & \ldots \\
\text { Phosphoric Acid } & \ldots \\
\text { Sulphuric Acid } & \ldots \\
\text { Insoluble Silicates } & \text { (Sand) }\end{array}$ & \begin{tabular}{l|}
$\ddot{.}$ \\
. \\
. \\
. \\
$\cdots$ \\
.. \\
. \\
$\cdots$ \\
$\cdots$
\end{tabular} & $\begin{array}{r}680 \\
3.54 \\
8 \cdot 85 \\
\cdot 12 \\
\cdot 65 \\
47 \\
\cdot 13 \\
\cdot 09 \\
\cdot 03 \\
79 \cdot 32\end{array}$ & $\begin{array}{l}7 \cdot 13 \\
3 \cdot 57 \\
7.81 \\
\cdot 11 \\
\cdot 65 \\
\cdot 40 \\
\cdot 13 \\
\cdot 10 \\
\cdot 03 \\
80 \cdot 08\end{array}$ & $\begin{array}{r}6.43 \\
3.50 \\
10.09 \\
13 \\
.66 \\
.54 \\
.14 \\
.08 \\
.03 \\
78.40\end{array}$ \\
\hline & & $100 \cdot 00$ & $1 \mathrm{CO} \cdot 0 \mathrm{~J}$ & $100^{\circ} 00$ \\
\hline${ }^{*}$ Containing Nitrogen & 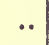 & $\cdot 15$ & י & $\cdot 13$ \\
\hline
\end{tabular}

These figures show most clearly that, in so far as chemical constituents are concerned, compared with some of the splendid virgin soils in some neighbouring gardens, the only deficiency is in the organic matter and the nitrogen, and both these can best be supplied by the bulky organic manures like cattle manure. Were the whole local supply of this material saved and used, there would be-for as good many years to come-little if any need of any other material, on the condition that the roots can be made to penetrate the subsoil yellow clay, and this can to a large extent be brought about by thorough subsoil drainage and heavy cultivation. There is a great tendency with such a clay subsoil for the roots to 
form a mat on top of the clay, and it is only by heavy cultivation that this state of affairs can be altered.

As above stated, between the Rangagora road and the line of railway, there lie immense stretches of grass land, which have produced some of the very best gardens in Assam. On this land, for instance, is the Panitola garden of the Jokai Company, on which the following analysis of the virgin soil was taken. By its side is the analysis of the same soil which has been under tea for 26 to 28 years.

\begin{tabular}{|c|c|c|c|c|}
\hline & & Virgin Soil. & Old Tea Soil. & $\begin{array}{l}\text { Percentage loss } \\
\text { in } 26-28 \text { years. }\end{array}$ \\
\hline $\begin{array}{ll}\text { - Organic Matter, \&c. } \\
\text { Oxide of Iron } & \ldots \\
\text { Alumina } & \ldots \\
\text { Lime ... } & \ldots \\
\text { Magnesia } & \ldots \\
\text { Potash ... } & \ldots \\
\text { Soda } \ldots \\
\text { Phosphoric Acid } & \ldots \\
\text { Sulphuric Acid } & \ldots \\
\text { Insoluble Silicates } & \text { (Sand) }\end{array}$ & $\begin{array}{l}\ldots \\
\cdots \\
\cdots \\
\cdots \\
\cdots \\
\cdots \\
\cdots \\
\cdots\end{array}$ & $\begin{array}{r}6.75 \\
2 \cdot 95 \\
5 \cdot 74 \\
.09 \\
\cdot 72 \\
\cdot 38 \\
\cdot 19 \\
.68 \\
.02 \\
83.08\end{array}$ & $\begin{array}{r}5 \cdot 61 \\
3 \cdot 28 \\
6 \cdot 23 \\
.05 \\
.79 \\
.31 \\
.14 \\
.06 \\
.03 \\
83.50\end{array}$ & $\begin{array}{l}16 \cdot 9 \\
\cdots \cdots \\
\cdots \cdots \\
44.4 \\
\cdots \cdots \\
184 \\
\cdots \\
25 \cdot 0 \\
\ldots\end{array}$ \\
\hline & & $100 \cdot 00$ & $100 \cdot 00$ & $\ldots \ldots$ \\
\hline${ }^{*}$ Containing Nitrogen &.$\cdot$ & $x_{4}$ & 'II & $2 \mathrm{I}_{4}$ \\
\hline
\end{tabular}

The one objection to grass land soils-that, being covered with a surface feeding root system, they are only rich near the surface, and are exhausted comparatively quickly -is shown by these numbers, and still more so by the following determinations of the avarlable plant-food material in the same virgin and old tea soils respectively.

\begin{tabular}{|c|c|c|c|c|c|}
\hline & & & Virgin Soil. & Old Tea Soil. & $\begin{array}{c}\text { Percentage loss } \\
\text { in } 26-28 \\
\text { years. }\end{array}$ \\
\hline $\begin{array}{l}\text { Potash ... } \\
\text { Phusphoric Acid } \\
\text { Lime ... } \\
\text { Manganese Oxide } \\
\text { Oxide of Iron }\end{array}$ & $\begin{array}{l}\cdots \\
\cdots \\
\cdots \\
\cdots\end{array}$ & $\begin{array}{l}\cdots \\
. . \\
. . \\
\cdots \\
\cdots\end{array}$ & $\begin{array}{r}\cdot 014 \\
010 \\
.023 \\
\cdot 018 \\
.327\end{array}$ & $\begin{array}{l}\cdot 007 \\
\cdot 007 \\
017 \\
\cdot 007 \\
\cdot 307\end{array}$ & $\begin{array}{l}500 \\
31 \cdot 1 \\
26 \cdot 1 \\
\cdots \cdots \\
6 \cdot 1\end{array}$ \\
\hline
\end{tabular}

The sesult of such exhaustion can only be a deterioration in quality as well as in yield. The former can be kept up for some time by continued closer and closer plucking, but even this will finally come to a point when plucking can become no closer and finer, and the value of the tea is bound to become less and less. 
In a quality district like Dibrugarh the use of real peat bheel soil as manure should be perhaps avoided where other materials are available, though, at present, there is no direct evidence that it has a deteriorating effect. If applied, it should rather be put on in the form of several small dressings than as a single large one. The rich surface soil from the adjoining virgin land may, however, be applied with perfect safety. Cattle manure should be used if available, but used sparingly and often, rather than heavily and rarely. I would not put more than five tons per acre on such tea land as the above in one year. In default of these methods, I should advise with a good deal of confidence, the application of 5 to 7 cwt. of basic slag per acre in the cold weather (and use all the wood ashes available in the same way at the same rate) with the deep hoeing, and follow this by a green manuring crop in the spring of mati kalui. The growth of this plant repeated every three years, not necessarily with the addition of basic slag every time, would improve the quality of the tea. A suitable rotation for gardens under similar conditions would be :-

Ist year-Basic Slag $5 \mathrm{cwt}$. per acre in the cold weather, followed by green manuring with a crop of mati kalai in the spring.

2nd year-Nothing.

$3^{\text {rd }}$ year-Cattle manure in spring, 5 tons per acre.

$4_{\text {th }}$ year-Mati kalai in spring as before, as green manure.

$5^{\text {th }}$ sear-Nothing.

6 th year-Oilcake 10 maunds per acre.

7 th year-Nothin

8: th year-Suipha of Polash $2 \mathrm{cwt}$. per acre in April, followed by matikalai as in the ist year.

9th year-Nothing.

oth year-Cattle manure in spring, 5 tons per acre.

It th year-Wood ashes $5 \mathrm{cwt}$. per acre, and mati kalai in spring as green manure.

Thus in ten years there would roughly be added to the land as follows, per acre, from outside sources.

\begin{tabular}{|c|c|c|c|c|c|c|}
\hline & & & & & Nitrogen. & Phosphoric Acid. \\
\hline Ist year & $\ldots$ & $\ldots$ & $\ldots$ & $\ldots$ & $\ldots \ldots$ & $84 \mathrm{lbs}$. \\
\hline $3^{\text {rd }}$ year & $\ldots$ & $\ldots$ & $\ldots$ & $\ldots$ & $28 \mathrm{lbs}$. & 2olbs. \\
\hline 6 th year & $\ldots$ & $\ldots$ & $\ldots$ & $\ldots$ & 4 olbs. & 2olbs. \\
\hline Ioth year & ... & $\ldots$ & $\ldots$ & $\ldots$ & $28 \mathrm{lbs}$. & 2olbs. \\
\hline
\end{tabular}


Now supposing a crop of mati kalai adds to the soil 50 lbs. nitrogen in each crop per acre, we have $246 \mathrm{lbs}$. nitrogen added per acre in ten years or $241 / 2 \mathrm{lbs}$. per annum, $14 \frac{1}{2} \mathrm{lbs}$ per annum of phosphoric acid, and rolbs. per annum of potash. The amount of potasls would be greater in the second ten years, and the phosphoric acid less, owing to the substitution of basic slag by wood ashes. It will be noted that the amount of nitrogen thus added is considerably less than that removed by the crop, and at a later date it may be necessary to increase the frequency with which oilcake or cattle manure is applied. Inasmuch as the amount of nitrogen fixed by tropical soils per annum independent of plant growth is as yet an unknown quantity, I do not feel called upon to recommend more than the above amount until actual experience in the field has proved it to be necessary.

The following are analyses of other soils from Balijan of the Eastern Assam Tea Company, on the same belt of grass land of which I have just spoken. Being all young tea no manurial appli. cation is needed at present, except perhaps to No. 2, but they will all be capable of treatment by a method similar to that just described.

\begin{tabular}{|c|c|c|c|c|c|c|}
\hline & & & No. I. & No. 2. & No. 3 . & $\mathrm{N}_{1} \cdot 4$. \\
\hline - Organic Matter, & $\& c$. & $\ldots$ & $7 \cdot 40$ & 6.44 & 4.93 & 6.55 \\
\hline Oxide of Iron & $\ldots$ & $\ldots$ & $4 \cdot 10$ & 3.42 & $2 \cdot 3^{8}$ & $4^{\circ} 02$ \\
\hline Alumina & $\cdots$ & $\ldots$ & $5^{\circ} 99$ & $5 \cdot 85$ & $3 \cdot 82$ & $5 \cdot 68$ \\
\hline Lime $\quad-$ & ... & ... & .07 & 13 & $\cdot 20$ & .06 \\
\hline Magnesia & $\cdots$ & .. & $\cdot 96$ & 74 & $\cdot 65$ & .67 \\
\hline Potash $\ldots$ & - & $\ldots$ & 31 & 30 & .23 & 30 \\
\hline Soda $\quad \ldots$ & $\ldots$ & ... & $\cdot 13$ & $\cdot 13$ & $\cdot 16$ & 19 \\
\hline Phosphoric Acid & $\cdots$ & $\ldots$ & .09 & .09 & 'o9 & 11 \\
\hline \multirow{2}{*}{\multicolumn{2}{|c|}{ Insoluble Silicates (Sand) }} & $\ldots$ & 8095 & $82 \cdot 90$ & 8754 & $82 \cdot 42$ \\
\hline & & & 10000 & 100 oo & $100 \cdot 00$ & $100 \cdot 00$ \\
\hline * Containing Nitroge & .. &.. & ' 15 & 12 & 10 & $\cdot 13$ \\
\hline
\end{tabular}

No. I is a virgin soil, the remainder have borne tea for longer or shorter periods.

On the other side (south) of the Sadya road lie a group of gardens put out on forest land, of which Chubwa may be taken as the type. Chubwa soil is a splendidly deep one, not so rich at the 
surface as those just discussed, but even in character down to four or more feet. It is somewhat more clayey than those of which we have just been speaking but on account of its depth is, usually extremely durable. The following are analyses of this soil in various stages of tea culture.

- Organic Matter, \&c.

Oxide of Iron ...

Alumina $\quad$...

Lime

Magnesia

Potash

Soda

Phosphoric Acid

Sulphuric Acid ..

Insoluble Silicates (Sand)

$\cdots$

...

... 
with the main course of the streams. Thus for instance, a heavier ridge runs perhaps from Woodbine (with an interval of lighter soil along the course of the Bara-hapian; through Hukanguri, and touches the corner of Hansara. Immediately to the north of this lies a ridge of very light character through Hilika, Pabbojan, Dhoedam and the bulk of Hansara and Beesocopi. To the north of this another heavier band, chiefly in jungle, occurs, and then the Tippuk line, again of somewhat lighter character, becoming a little heavier as one approaches Talup. Though different in physical character all these soils are of similar richness, but naturally the tea is most luxuriant in the soil of lighter character. The following are the analysses of some soils from these ridges. The first set are from the more sandy and lighter sections :-

- Organic Matter, \&c. Oxide of Iron $\quad$. Alumina ... $\quad$... Lime $\quad \ldots \quad$... Magnesia... Potash ... Soda ...

Phosphoric Acid $\quad \ldots$ Sulphuric Acid
Insoluble Silicates (Sand)

* Containing Nitrogen ..

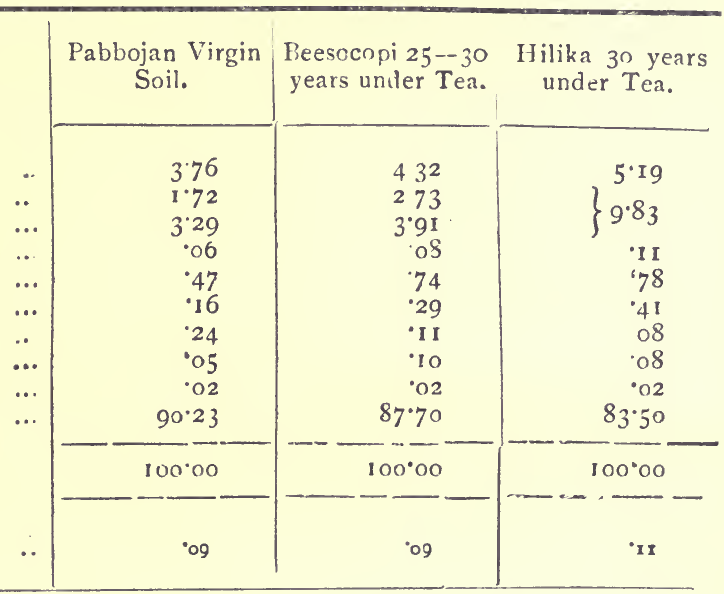

The heavier sections yield on analysis as follows :-

\begin{tabular}{|c|c|c|c|c|}
\hline & & $\begin{array}{c}\text { Hukanguri } 25 \\
\text { years under Tea. }\end{array}$ & $\begin{array}{c}\text { Talup } 3 \text { years } \\
\text { under Tea. }\end{array}$ & $\begin{array}{c}\text { Talup } 20-3^{\circ} \\
\text { years under Tea, }\end{array}$ \\
\hline - Organic Matter, \&c. & $\ldots$ & $4 \cdot 67$ & $4 \cdot 59$ & $3 \cdot 86$ \\
\hline Oxide of Iron & $\ldots$ & 319 & $2 \cdot 43$ & 2.42 \\
\hline Alumina ... & .. & $6 \cdot 28$ & 4.94 & $4 \cdot 19$ \\
\hline Lime $\quad \ldots$ & $\cdots$ & $\cdot 16$ & .10 & .10 \\
\hline Magnesia ... & ... & $\cdot 59$ & 51 & $\cdot 60$ \\
\hline Potash ... & ... & .50 & $\cdot 29$ & $\cdot 24$ \\
\hline Soda $\quad \ldots$ & $\ldots$ & I0 & $\cdot 15$ & $\cdot 15$ \\
\hline Phosphoric Acid & $\ldots$ & .07 & 09 & .08 \\
\hline Sulphuric Acid & $\ldots$ & 'O2 & .02 & $\cdot 02$ \\
\hline Insoluble Silicates (Sand) & ... & $84^{\circ} \cdot 2$ & $86 \cdot 88$ & $88 \cdot 34$ \\
\hline & & $100 \cdot 00$ & $100^{\circ} 00$ & $100^{\circ} 00$ \\
\hline * Containing Nitrogen .. & - & '10 & •و & .09 \\
\hline
\end{tabular}


The soils, whether light or heavy, are therefore very similar in chemical composition. As a whole they form a district as rich as, or richer than, any in the valley in phosphoric acid, and to this, combined with the perfect climate, which allows of very close plucking, I attribute in large measure the pre-eminence for quality, which this district has obtained. Nevertheless, the soils need, as a whole, organic matter and nitrogen, unless they are to deteriorate. In some places as at Hilika, fairly good hullah soil is obtainable and is of course used for top-dressing. On the whole, however, whether hullah soil be available or not, green manuring should be carried out extensively on the heavier portion of the land, and cattle manure utilised on the lighter sections, combined in both cases with dressings of oil cake. On the lightest land potash manuring will become essential occasionally after a few years under tea. A manurial scheme which would probably be suitable is here set out :-

\section{Lighter Sections-}

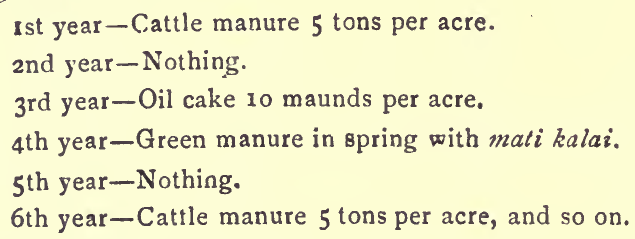

This would give about $25 \mathrm{lbs}$, of Nitrogen per annum per acre to the soil. In the $4^{\text {th }}$ year, in alternate rotations of five years each, and therefore once in ten years, 2 cwt. of sulphate of potash or $5 \mathrm{cwt}$. of wood ashes per acre should be added before putting in the mati kalai seed.

\section{Heavier Sections-}

st year-Green manure with mati kalai in spring.

2nd year-Cattle manure 7 tons per acre, or Oilcake ro maunds per acre.

$3^{\text {rd }}$ year - Nothing.

$4^{\text {th }}$ year-Green manure as in the 1st year, and so on.

This would give about $30 \mathrm{lbs}$. of Nitrogen per acre per annum, and would in addition spen up the land to a considerable extent.

It must be recognised that in spite of the original perfection of a great deal of this land combined with a great depth, it is becoming necessary, yєar by year, to pluck closer and closer in order to maintain quality. I was assured of this fact during my visit last December. This can only be due to the exhaustion even of these deep lands in crganic matter, and unless some such scheme as I have 
suggested be adopted there will ultimately be an almost unavoldable loss of the quality now so specially characteristic of the Sadya Ruad.

\section{SIBSAGAR DISTRICTS.}

From the Dehing to the west on the south bank of the Brahmaputra lie the various sections of the Sibsagar district of the province. Underneath the Naga Hills from the Dehing to the Dekko is the Sonari group of gardens ; between this and the Brahmaputra lie a few gardens comparatively isolated, among the most important of which are the gardens of the Moran Tea Co. and of the Rajmai Tea Co.; to the west of the Dekko lie a string of gardens, chiefly old, skirting the Naga Hills on a range of low teelas and on the adjoining flat land and till the Jhanzie river is crossed the gardens are except near Nazira, all but restricted to these lands. After passing the Jhanzie river, however, the land cultivable in tea spreads out and extends much nearer the river in Noakachari, Meleng, Cinnamara and finally Nigriting on the banks of the Brahmaputra. From here the high land forms a series of ridges of red soil, more or less at right angles to the river, till the Dhunsiri is reached. Beyond this is a plateau of red soil running westward to the base of the Mikir hills.

The character of the land in this huge Sibsagar district $i^{s}$ extremely variable. I have not been able to analyse the soils in the Sonari section, but even here it varies to an extraordinary extent. To the extreme east of the tea in this circle (Towkok, Jaboka, \&c.) the land at the base of the hills forms a plateau of very fine tea soil, most of it only recently opened out. It consists of a black medium loam with a yellowish brown subsoil. Most of it is forest, but some grass land accurs. None of the gardens on this land are as yet old enough to need manuring to any extent, but the method recommended for the grass land at Dibrugarh (see page 122) would probably answer very well.

Commencing at Sonari, the plateau of which I have just been speaking, is replaced by a range of low teelas which skirt the base of the hills from this point as far as Amgoorie. Many of them were put out in the early days of tea, and generally speaking the slopes have been very much washed, the tea bushes stand right out of the soil, and are very deficient in vigour. In fact in several cases I was told that they hardly paid for keeping in cultivation. Nevertheless, originally, they must have formed an excellent tea soil-the 
following being an analysis of the soil on newly opened out teelas of this character at Borsillah.

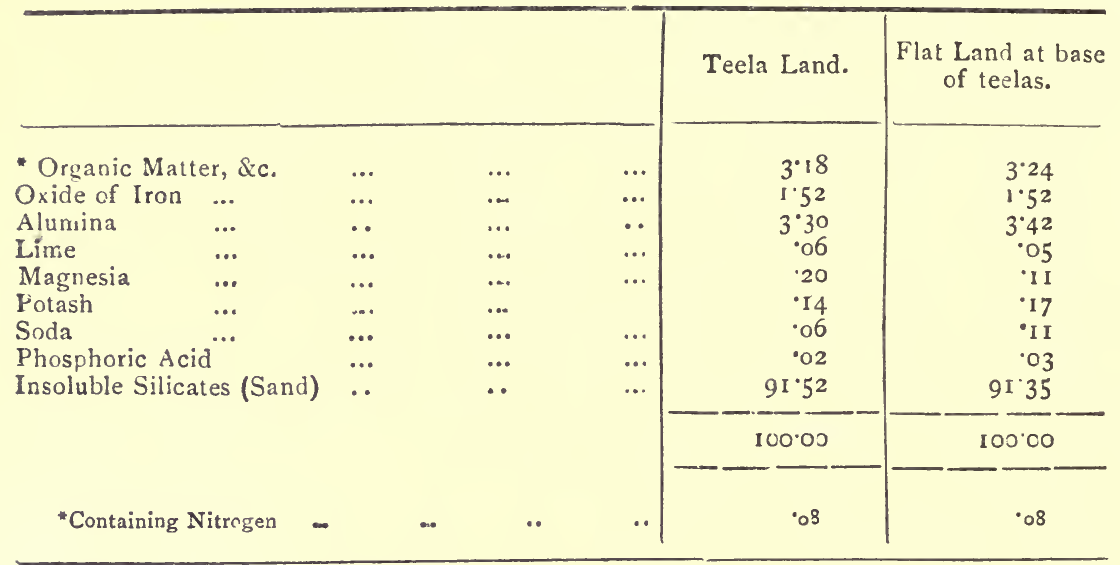

or calculating on the soil less the sand, we have-

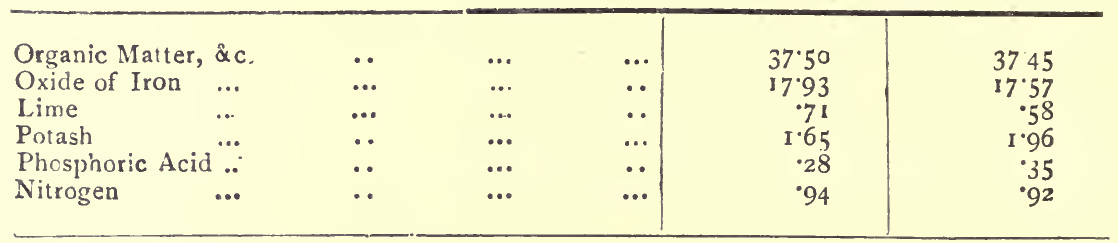

Hence this would, and does, produce very luxuriant tea and although rather deficient in Phosphoric Acid and in Potash, and requiring manuring at a fairly early date, would do much better than many gardens actually in existence. But, as stated above, most of these teelas are badly washed, as no attempt was made in the early days to preserve the soil, and now they form eyesores in most of the gardens. One could not recommend much expense in connection with them in most cases-mthey would be more profitable to the gardens under trees than under tea, - - but if they are to be reclaimed the best plan would probably be to sacrifice the summit of the hill, fill up the washed slopes into terraces with soil from the base or the summit, holding this soil up by jungle previously placed on the line of the terraces,-plant the slopes with Sau trees-and put on all the cattle manure that can be spared. Whether this is worth doing in any particular case can only be decided on the spot, but where the deterioration has not gone too far, it would be distinctly worth while, as the soil in its original condition is admirable for tea.

Further from the hills the snil, where high enough to grow tea, is much stiffer. It even forms plateaux of stiff red soil rising 
almost abruptly from the plain in places. On stiffer land in this section are some of the older gardens of the Assam Tea Co. Below are analyses of those which have borne tea for many years.

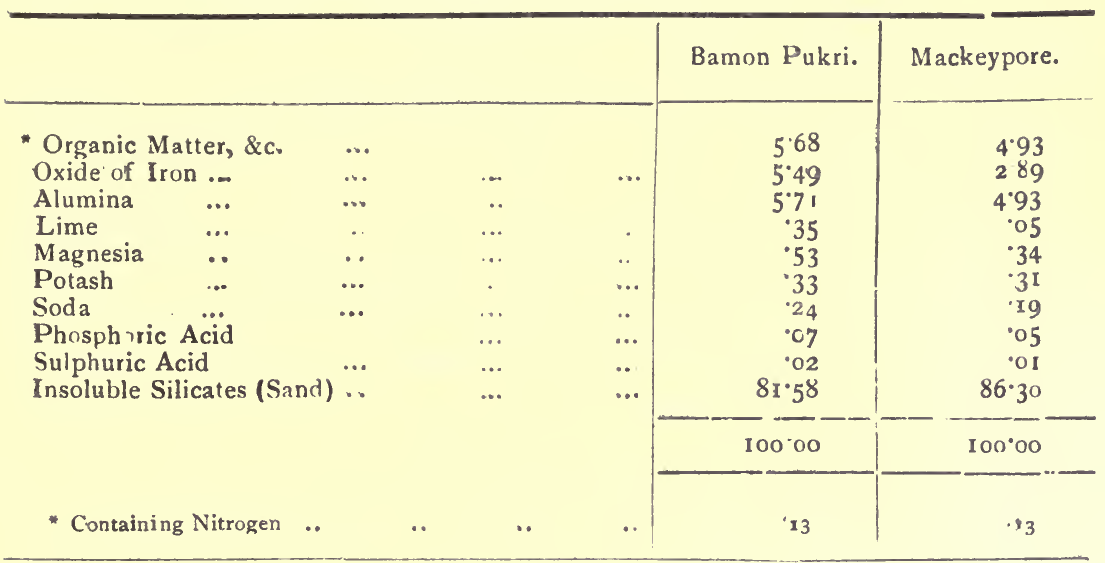

The most effective dressing hitherto applied on these gardens has apparently been hullah soil, and anything seemed to be of benefit, provided it was of lighter character than the land on which it was put. Relative to this, Mr. Hulbert writes me concerning Bamon Pukri:-

"The top-dressed section shows up uncommonly, but this is by no means the exception. It is really wonderful the way in which tea treated in this way has improved in all our gardens, even on old worn-out places like Ligri, where the soil used is not much, better than the garden itself, the bheels it is taken from having been utilised several times."

The reason for this success in the use of poor top-dressing soil as manure I can only ascribe to the fact that the top-dressing renders the soil lighter and in better condition than before, and as the above analyses show the Mackeypore soil, at any rate, to be anything but exhausted, the addition of the lighter materials has rendered the plant more capable of getting at the stores of food in the soil. Where the material was more clayey than the land on which it was placed, as in one experiment at Bamon Pukri, little, if any, good resulted. Green manuring with mati kalai has here resulted in marked benefit, and on all the gardens of this type should do great good. But great benefit could hardly be expected to accrue, unless the application was a recurring one, say once in three years on the same plot, with the addition, if possib!e, of a little (say one ton per acre) cattle manure before sowing in May. By this means a much more luxuriant plant of the green manuring crop is obtained, 
with very much increased manurial value. We might have for instance :-

ist year-One too cattle manure per acre in April, sow mati kalai in May, hoe in in June.

2nd year-Nothing.

3rd year-Five tons cattle manure or Io maunds oil cake in April, sow mustard in May, hoe in in June.

4 th year-Nothing.

5th year-As in the ist year, and so on.

There lie in this district occasional gardens on small banks of raised soil surrounded by rice land. Such a garden is Rajmai. They may well be treated by the methods recommended for the Bishnauth and Tezpur banks.

\section{JORHAT DISTRICT.}

The conditions above described, in general, practically reach west to the Jhanzie river. Beyond this the low teelas skirting the hills and bearing tea seem to be no longer found, and gradually the land suitable for tea extends further and further out into the plains, till at Jorhat there occur a special bank or series of banks of sandy land for many miles towards the river. There is found here, in fact, the first of a series of ridges, which from this point on to the Dhunsiri run from the hills towards the river Brahmaputra. The Jorhat ridge forms one of the deepest, most friable, and sandiest sections of Assam tea soil. The analyses attached show how sandy it is, and to what extent exhaustion has taken place during long growth of tea :-

\begin{tabular}{|c|c|c|c|c|c|c|c|}
\hline & & 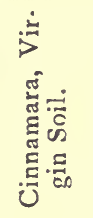 & 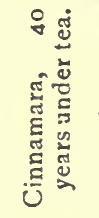 & 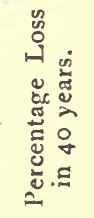 & 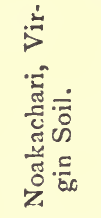 & 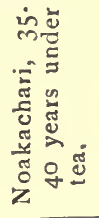 & 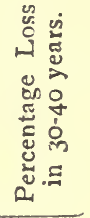 \\
\hline "Organic Matter, \&c & . & $2 \cdot 87$ & 2.55 & II I I & 274 & $1 \cdot 82$ & $33 \cdot 5$ \\
\hline Oxide of Iron & $\ldots$ & 9I & 1.10 & $\ldots$ & .80 & .80 & $\ldots$ \\
\hline Alt mina & $\ldots$ & $2 \cdot 13$ & $2 \cdot 12$ & $\ldots$ & 1.92 & 177 & ... \\
\hline Lime & .. & 04 & 04 & ... & .06 & 04 & $33^{\circ} 3$ \\
\hline Magnesia & & $\cdot 18$ & $\cdot 16$ & ... & $\cdot 16$ & 18 & $\cdots$ \\
\hline Potash ... & ... & $\cdot 10$ & .13 & .. & . & 09 & .. \\
\hline Soda & .. & 02 & •c6 & . & .09 & 10 & \\
\hline Phosphnric Acid ... & $\ldots$ & 03 & .03 & . & .03 & .02 & $33 \cdot 3$ \\
\hline Sulphurc Acid $\quad \ldots$ & $\cdots$ & 02 & $\begin{array}{ll}01, \\
01\end{array}$ & $\cdots$ & $\circ$ OI & ○I & $\cdots$ \\
\hline \multirow[t]{2}{*}{ Inscluble Silicates (Sand) } & .. & 93.70 & 93.80 & .. & $94^{\circ} 10$ & $95^{117}$ & $\cdots$ \\
\hline & & $100 \cdot 03$ & $100 \cdot 00$ & $\cdots$ & $100 \cdot 00$ & $100 \cdot 00$ & $\cdots$ \\
\hline - Containing Nitrogen.. & .. & "09 & 07 & $22 \cdot 3$ & .0 & 07 & $22^{\prime} 2$ \\
\hline
\end{tabular}


If these figures be calculated on the basis of the soil less the sand, we have-

\begin{tabular}{|c|c|c|c|c|c|}
\hline & & $\begin{array}{l}\text { Cinnamara, } \\
\text { Virgin Soil. }\end{array}$ & $\begin{array}{c}\text { Cinnamara, } \\
40 \text { years } \\
\text { under tea. }\end{array}$ & $\begin{array}{l}\text { Noakachari, } \\
\text { Virgin Soil. }\end{array}$ & $\begin{array}{l}\text { Noakachari, } \\
35-4 \text { J years } \\
\text { under tea. }\end{array}$ \\
\hline 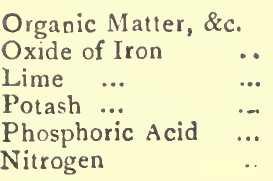 & \begin{tabular}{l|}
$\cdots$ \\
$\ldots$ \\
$\cdots$ \\
$\cdots$ \\
$\cdots$ \\
$\cdots$
\end{tabular} & $\begin{array}{r}45.56 \\
14.44 \\
.63 \\
1.59 \\
.48 \\
1 \cdot 43\end{array}$ & $\begin{array}{r}41 \cdot 13 \\
17 \cdot 74 \\
.65 \\
2 \cdot 10 \\
.48 \\
1 \cdot 13\end{array}$ & $\begin{array}{r}46.44 \\
13.56 \\
1.02 \\
1.53 \\
.51 \\
1.53\end{array}$ & $\begin{array}{r}37.68 \\
16.57 \\
.83 \\
1.86 \\
.41 \\
1.45\end{array}$ \\
\hline
\end{tabular}

Though the exhaustion is evident, and becomes much more evident if the quantity of actually available materials be considered (see pp. 50, 53,54,56,58), and though the great depth of the soils has protected them from deterioration to anything like the same extent as many others, nevertheless the means for renovating sandy tea soils should distinctly be used here. Mr. Showers, at Cinnamara, informs me that he is building cowsheds, in which an effort is being made to retain the urine for manurial purposes. This is distinctly a step in the right direction. Mustard cake can also, I believe, be obtained in this district in fair quantity. Furthermore green manuring with mati kalai has already proved a decided success at Cinnamara, both in increasing the luxuriance of the bushes and in keeping off green fly. The hullahs here usually possess a rich surface, but the valuable material is not very deep, as the following analyses of hullah soil from Cinnamara testify, and too much reliance should not be placed upon them as sources of manure.

\begin{tabular}{|c|c|c|c|c|}
\hline & & $\begin{array}{l}\text { Hullah Soil, } \\
\text { Surface Soil. }\end{array}$ & $\begin{array}{l}\text { Hullah Soil, } \\
\text { Subsoil Sand. }\end{array}$ & $\begin{array}{c}\text { Hullah Soil, } \\
\text { previously scraped. }\end{array}$ \\
\hline Organic Matter, \&c. ... & $\ldots$ & 6.05 & $2 \cdot 04$ & 331 \\
\hline Nitrogen & $\ldots$ & $\cdot 25$ & .06 & . II \\
\hline
\end{tabular}

A suitable treatment would therefore be-

1st year (the year before heavy pruning)-Cattle manure 5 tons per acre in spring. 2nd year (heavy pruning)-mati kalai sown in May, hoed in in June.

3 rd year-Nothing.

$4^{\text {th }}$ year - Nothing.

5 th year $-5 \mathrm{cwt}$. per acre wood ashes and mati kalai sown in May, hoed in in June. 
6th year-Cattle manure 5 tons per acre, or preferably mustard cake ro maunds per acre, with $\mathbf{I}-\mathbf{2}$ cwt. per acre of superphosphate.

7 th year-Mati kalai as in the 2nd year.

8 ih year-Nothing.

9 th year-Nothing.

10th year-Mati kalai as in the 5 th year, and so on.

The whole of the land under tea from Heeleaka on the west, to Noakachari on the east, could well be treated by the above method.

A few miles to the west of the district just discussed is a ridge of much heavier character embracing Duflating, Panbarrie and Moabund, and perhaps several more gardens. Although it contains pieces of sandy land, yet, as a whole, it is a finely divided, rather heavily working loam. The following analyses show its general character :-

\begin{tabular}{|c|c|c|c|c|c|}
\hline \multirow{3}{*}{$\begin{array}{l}\text { *Organic Matter, \&c. } \\
\text { Oxide of Iron }\end{array}$} & \multirow{3}{*}{$\begin{array}{l}. . \\
\ldots\end{array}$} & \multirow[b]{2}{*}{.. } & \multirow[b]{2}{*}{.. } & \multirow{2}{*}{$\begin{array}{r}\begin{array}{r}\text { Moabund, } \\
\text { Virgin soil. }\end{array} \\
4.89\end{array}$} & \multirow{2}{*}{$\frac{\begin{array}{c}\text { Duflating, } \\
3 \text { years under tea. }\end{array}}{4^{\prime} 95}$} \\
\hline & & & & & \\
\hline & & 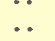 & 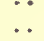 & $2 \cdot 94$ & $\begin{array}{r}493 \\
2.99 \\
\end{array}$ \\
\hline Alumina $\quad \ldots$ & .. & .. & .. & 494 & 3.94 \\
\hline Lime & $\ldots$ & & $\ldots$ & 01 & .05 \\
\hline Magnesia & & $\ldots$ & ... & $\cdot 32$ & $\cdot 27$ \\
\hline Potash & .. & .. & $\ldots$ & $\cdot 35$ & 25 \\
\hline Soda & $\ldots$ & $\ldots$ & $\cdots$ & .19 & .17 \\
\hline Phosphoric acid ${ }^{\cdots}$ & $\ldots$ & $\ldots$ & $\ldots$ & .06 & .05 \\
\hline Sulphuric Acid ... & & $\ldots$ & $\ldots$ & $\cdot 02$ & .04 \\
\hline \multirow[t]{2}{*}{ Insoluble Silicates (Sand) } & $\ldots$ & $\cdots$ & .. & $86 \cdot 28$ & $87 \cdot 29$ \\
\hline & & & & $100 \% 00$ & $100^{\circ} \mathrm{Co}$ \\
\hline "Containing Nitrogen & .. & .. & .. & 74 & $7_{3}$ \\
\hline
\end{tabular}

If the burial of prunings will be advantageous anywhere, it will be probably worth doing in non-blighted pieces of tea on this group of gardens, combined of course with basic slag or with the application of quick lime to the buried prunings (see page 97). At any rate every effort should be made to lighten the character of the soil and subsoil. Sau trees will be advantageous. So will the burial of green manuring crops, as also cattle manure. Oilcake has been advantageously used.

\section{GOLAGHAT DISTRICT.}

To the west of Moabund are found a series of ridges, or remnants of ridges, of red soil, which are rich and excellent for tea. Nigriting lies on the extremity of one of these ridges, which includes (with 
breaks) the Brahmaputra Co.'s gardens, Badulipar, Rangagora, \&.c. At Nigriting there is plenty of silt in the hullahs, which is excellent as manure, and no other is needed. Likewise the soil is very rich, as the following figures for the virgin land show :-

-Organic Matter, \&c. ...

Oxide of Iron

Alumina

Lime

Magnesia

Potash

Soda

Phosphoric Acid

Sulphuric Acid

Insoluble Silicates (Sand)

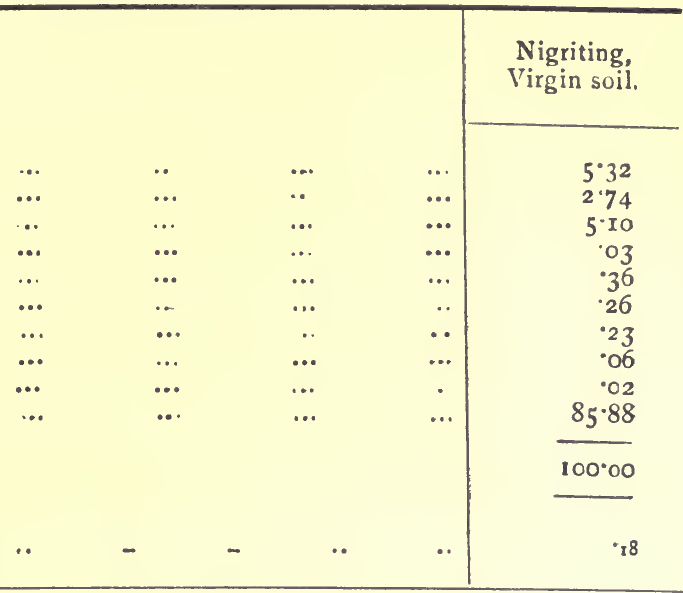

There seems no reason why this land should not make as good tea as any in the district, if the method of plucking were adapted to this purpose.

The other gardens on these ridges are not very different in character among themselves. The following analyses of the soil as a whole, of the top soil, and of the subsoil from Rangagora, show the general character, but this particular sample is much poorer than the average.

- Organic Matter, \&c. Oxide of Iron

Alumina

Lime

Magnesia

Potash ..

Soda

Phosphoric Acid

Sulphuric Acid

Insoluble Silicates (Sänd)
Rangagora.

\begin{tabular}{|c|c|c|}
\hline Whole soil. & Top soil. & Subsoil. \\
\hline $4 \cdot 69$ & $4 \cdot 33$ & $5 \circ 6$ \\
\hline $2 \cdot 78$ & 222 & 3.34 \\
\hline $5 \cdot 96$ & 445 & $7 \cdot 47$ \\
\hline 05 & 05 & 05 \\
\hline$\cdot 24$ & 18 & 30 \\
\hline$\cdot 27$ & 21 & $\cdot 32$ \\
\hline 13 & 13 & 13 \\
\hline .05 & .05 & .05 \\
\hline .02 & $0^{\circ} 02$ & .02 \\
\hline $85 \cdot 81$ & 8836 & $89 \cdot 26$ \\
\hline 100.00 & $100 \%$ & $100^{\circ} 00$ \\
\hline و. & 10 & $\cdot 07$ \\
\hline
\end{tabular}


The plot from which this soil was taken would derive marked benefit from oilcake, and I should say generally for the gardens on these ridges oilcake, followed by mati kalai as green manure, would be as good a dressing as could be applied. These might be applied thus :-

Ist year-Ten maunds per acre castor, or 12 maunds per acre mustard cake, in March. 2nd year-Sow mati kalai in August, and hoe in at the end of September or the beginning of October.

3 rd year-Nothing.

$4^{\text {th }}$ year-Nothing.

5 th year-Wood ashes if obtainable, at $5 \mathrm{cwt}$. per acre, in the spring, followed by a crop of mati kalai in May, to be hoed in in June.

Cattle manure can replace, somewhat imperfectly, the oilcake recommended, at the rate of one ton of cattle manure for $2 \mathrm{cwt}$. of oilcake.

Nearer the hills, towards Golaghat station, the soil apparently loses its red tinge and becomes grey. I have not had any samples from this section of the district, and hence am at present unable to suggest methods of manuring it.

On the western side of the Dhunsiri river the soil suddenly rises into a plateau, which extends, gradually decreasing in height, to the Mikir hills. The soil is excellent for tea. Analyses are appended.

- Organic Matter, \&c.

Oxide of Iron

Alumina

L:me

Magnesia

Potash ...

Soda

Phosphoric Acid ...

Sulphuric Acid ...

Insoluble Silicates (

"Containing Nitrogen
Numaligarh.

Bor Sapori.

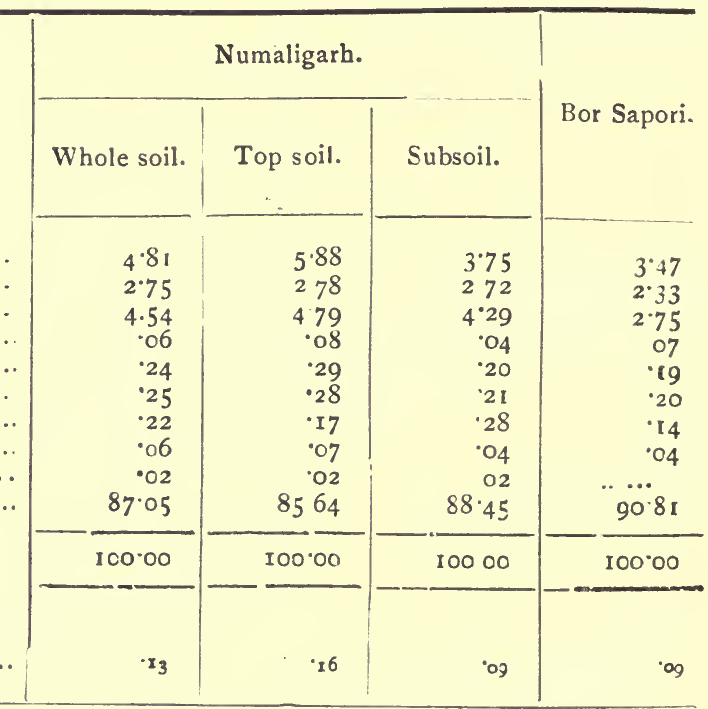


or calculating on the non-sandy part of the soil :-

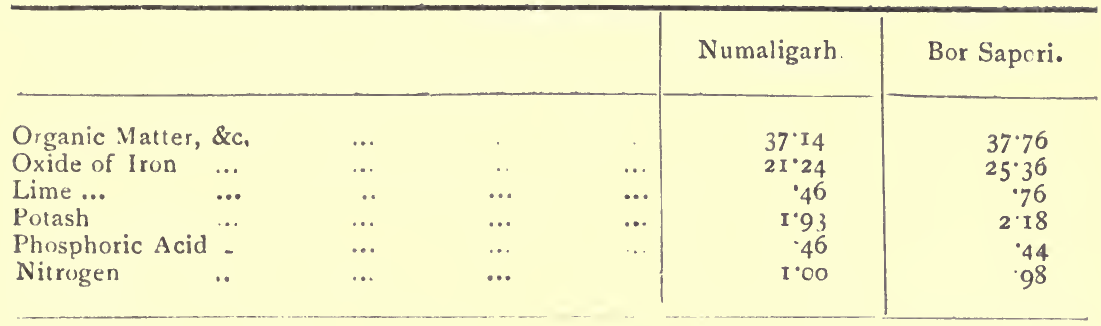

Neither of these soils is by any means exhausted, but both would benefit by oilcake as manure. In fact the whole of this section, so far as I have been able to examine it, should be treated by precisely the same methods as on the other side of the Dhunsiri.

\section{NOWGONG DISTRICT.}

The climate on the western side of the Mikir hills, where the Nowgong district is situated, seems quite different from that above this break in the valley. The soil too, except for a ridge of red soil running through Seconee, part of Solal and Kellyden, and appearing again at Rangamati, is heavier than is usual, and has very often a hard subsoil. Koliabar, near the river at Silghat, is more or less unique, and consists of heavy soil generally grazed in the past, but containing a large amount of phosphates. This leads to the growth of very good tea, but the land needs treatment, as often as possible, with green manure crops and cattle manure. Oilcake would also here be valuable. Phosphates, and potash also, would usually be wasted if more were added than is found in the cattle manure or the oilcake. But organic matter the soil must have. The following are analyses of two of these grazing lands:-

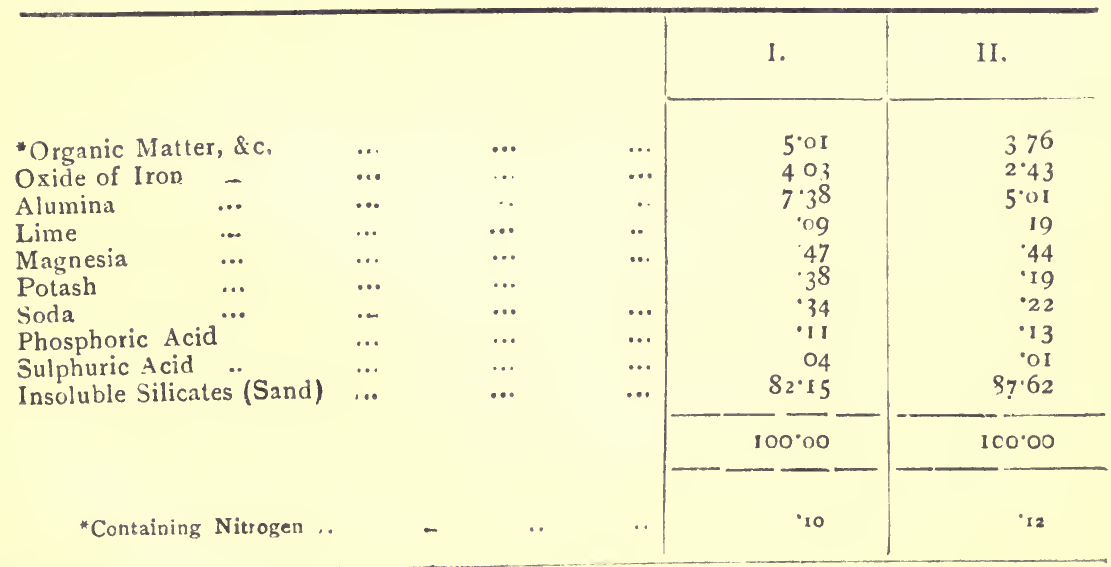


The soils on the red ridge above mentioned are very good and very deep. The following is an analysis of that of tea some twenty years old and yielding well, from Rangamati, top-dressed with bheel soil 5 years ago. There is a large amount of bheel soil in many parts of this district, and it should be used without stint. In its default apply cattle manure or oilcake at the rate of ten tons of the former or ten cwt. of the latter per acre, or the soil might well be treated by the scheme laid down for the gardens of the Golaghat district.

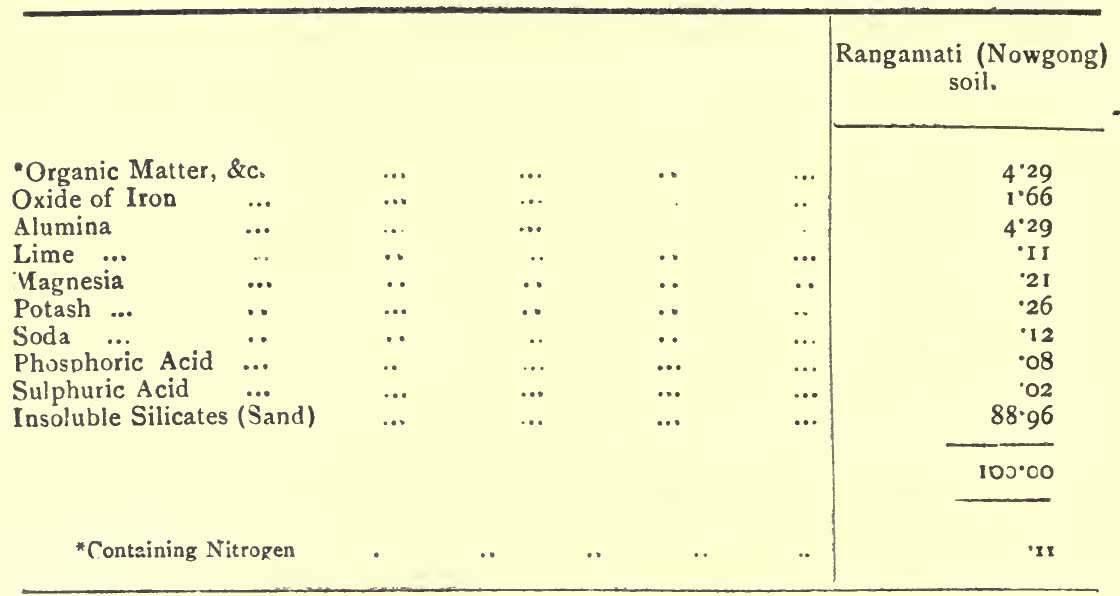

Much of the remaining part of the district is composed of stiff land, with a still stiffer subsoil, which suffers from drought and also from excess of rain, and being cut up much with very deep hullahs, there is, unless the land is drained across the slopes, a very great loss from wash. Drainage is here essential, by means of deep and narrow drains. The hardier jats of Manipuri plant are alone suitable here, as indeed in practically the whole district. Further, these are the circumstances under which green manuring would be most profitable, and this method can be recommended with much confidence, either in the spring or in August and September: More than this, sau trees will be of much value. I)eep trenching between the rows, especially if jungle or cattle manure could be buried, would be of great advantage. In view of the prevalence of red rust, I can in no wise recommend the burial of prunings. Where feasible, irrigation will be of advartage, but it could only be carried out in few cases. 
A typical soil of the district, which has been under tea for 15 to 20 years, gave on analyses the following figures:-

- Organic Matter, \&c.

Oxide of Iron

Alumina

Lime

Magnesia

Potash

Soda

Phosphoric Acid

Sulphuric Acid

Insoluble Silicates (Sand)

\begin{tabular}{|c|c|c|c|c|}
\hline & & & & $\begin{array}{c}\text { Salonah } \\
\text { Typical Soil. }\end{array}$ \\
\hline$\cdots$ & .. & $\ldots$ & ... & $5 \cdot 14$ \\
\hline$\ldots$ & $\cdots$ & $\cdots$ & $\ldots$ & 3.29 \\
\hline .. & $\ldots$ & $\cdots$ & ... & $6 \cdot 84$ \\
\hline.. & $\ldots$ & $\ldots$ & $\ldots$ & $\cdot 05$ \\
\hline .. & $\ldots$ & .. & $\because$ & $\cdot 27$ \\
\hline & . & $\ldots$ & ... & $3^{2}$ \\
\hline . & $\cdots$ & $\ldots$ & .. & $\cdot 15$ \\
\hline .. & $\ldots$ & $\ldots$ & $\ldots$ & $\cdot \mathrm{c} 4$ \\
\hline$\ldots$ & $\ldots$ & $\ldots$ & $\ldots$ & .02 \\
\hline$\cdots$ & $\ldots$ & $\ldots$ & $\ldots$ & 83.88 \\
\hline & & & & $100^{\circ} 00$ \\
\hline
\end{tabular}

*Containing Nitroger.

og

\section{CONCLUSION}

Such are the various districts of Assam. The methods of manuring recommended are based on the necessity for the addition of organic matter and nitrogen in almost every case, of phosphates often, and occasionaliy of potash. In a heavy soil generally speaking green manuring crops previously manured with phosphates give the best method; in a light one usually cattle manure or oilcake, also with green manuring, form the best addition, taking into consideration the ultimate object of all manuring, the maximum improvement of the crop at the minimum of cost. 



\section{INDEX.}

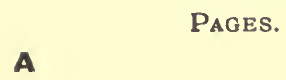

Acid, Citric

Acidity of Soil

Addabari

Adhatoda vasica

Aeration of Soil

Ageratume.

"Agricultural Ledger":

Albizzia odoratissima-See Koroi

Albizzia stipuiata- " Sau

Algae

Alluvium

Alumina in Tea Soil

Amgoorie

Amluckie

Ammonia, Salts of

- supplied by rain

Analyses of Soil-See Soil Analyses

André (and Berthelot)

Anniesbari

Artificial Manures

Ash of Tea

Ashes - See Wood Ashes

Assam Company

$$
\text { ... } 68,79,92,129
$$

\section{B}

Bacteria in Soil

Bacterium fixing Nitrogen in Soil 43,45

- - of root nodules

Badulipar

Balijan Bamber, Mr., Observes nodules on
roots of 'Sau'

$3,83,133$ $3,41,123$

...

On burial of prunings ...

$$
\text { Tea Soils ... }
$$

On Green Manuring

... 75,79

On Lime in Tea Soil

... 75, 79

- On Lower Oxide of Iron in Soil $\ddot{\text { in }}$ So

...

On Manganese in Soil ...

- On Nitrogen supplied by

- On Phosphoric Acid in Soil

- On Oilcakes ... ...

- On Shade for tea ...

- On Trees among tea $\quad . .$.

_- On Trenching $\ldots$ Relation of Soil to quality

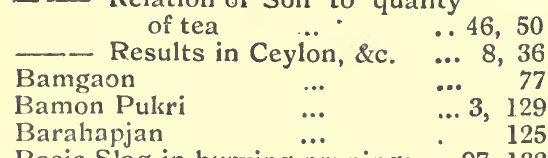

Basic Slag in burying prunings

97, 132

-.._ with green manuring $97,98,113$,

$115,122,123$

PAGes.

Basic Slag is useless alone $\quad \ldots \quad 98$

- - substituted by lime $95, \quad 0,99$

Bassia miscellaneous - 95, 100, 101, 102

Bassia latifolia $\quad$.. $\quad$... 88

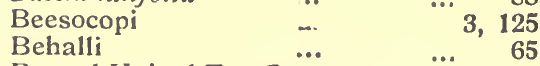

Bengal United Tea Co. $\quad$... 90

Berthelot (and André) ... $\quad \ldots .45$

$\begin{array}{lll}\text { Bessemer process (Basic) } \quad \text {... } & 95\end{array}$

$\begin{array}{llll}\text { Bhabur } \quad . . & \ldots & \ldots & 105\end{array}$

Bheels-suffer from drought $\quad \ldots 2,25$

-- will not produce good tea 46

Bhcel Soil-See Peat Bheel Soil, also Top-dressing Soil

Bheel Soiling ...

$\quad . .2,31,41,106,107$

Bindukuri $\quad$.. $\quad . . \quad 2,90$

Bishnauth Bank $\quad$... $114115,118,130$

Bishnauth District $\quad \ldots 2,41,49,65,86$,

104, 165, 113-116

$\begin{array}{llll}\text { Bishnauth Tea Co. } & \text {... } & \text {... } & 114\end{array}$

Blister Blight $\quad$... $\quad$... 84

Bogga Medeloa $\quad \ldots \quad 86,115,124$

Bones-as Manure $\quad \ldots \quad 86,87,100$

- Analysis of $\quad . . \quad 87$

- D Dissolved $\quad \ldots \quad 87,94,98$

- Steamed $\quad \ldots \quad \quad \ldots \quad 87$

$\begin{array}{lll}\text { Bone Meal } & \cdots & 87,89,90\end{array}$

$\begin{array}{llll}\text { Bordeobam } & \ldots & \ldots & 117\end{array}$

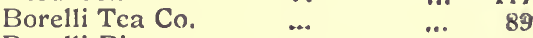

Borelli River $\quad$... $\quad \dddot{112,113}$

Borghat $\quad$...

Bor Sapori $\quad$... $\quad 3,41,134$

$\begin{array}{lllll}\text { Borsillah } & \ldots & \ldots & \text {.. } & 129\end{array}$

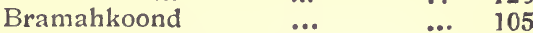

Brahmaputra Company $\quad \ldots 67,133$

British Assam Tea Co. $\quad$... 64

Brown, Prof, Campbell $\quad$... 34

Buckingham, Mr.-78, 79, 80, 82, 83, 85, 86

Buckwheat $\quad$... $\quad . . \quad 75$

Burdwan $\quad \ldots \quad \ldots 3$

Bushes among tea $\quad \ldots \quad 85,86,100$

"Busti" Soil _... $\quad \ldots 47,79$

45

50

82

82

21

Cachar

Caffeine

Calcutta

California-Experimental Station-

Canker on Tea

$\begin{array}{lll}\cdots & \cdots & 25 \\ \cdots & \cdots & 71\end{array}$

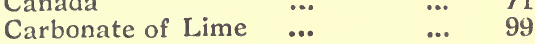

Cardamoms (Wild) $\quad$.. $\quad \ldots .66$

Carolina $\quad . . \quad$.. 95

Castor Cake-88, 89, 90, 91, 100, 101109 
PAGE.

Cattle Manure-4, 70-74, 92, 95, 100, 101, $102,103,107,108,113,115,118,120,122$, $123,126,129,130,131,132,134135,136$,

Cattle Manure-Buried in trenches 22, 102 Collection of $\quad$... 71 Conditions of preserving 72 Effect on quality 72,73 Importance of … 70 In filling in vacancies 73,74 Keeping urine in $\quad . . \quad 72$ Loss by exposure in ... 71 Objections to 73 Preservation of $71,72,99$ Should be returned to the land ... $\quad \ldots .61$ Quantity available ...7 70,71

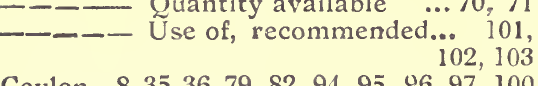

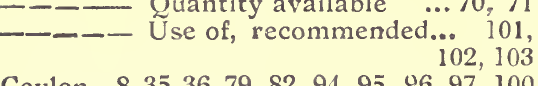

Ceylon-8, $35,36,79,82,94,95,96,97,100$
- Tea Soils $\quad .$.

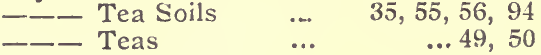

Chamney, Mr. I. $\quad \ldots . \quad \ldots 6,64$

Chemical Manures $\quad$... $\quad .92-99$

Chemical Society, Journal of the ... 34

Chittagong $\quad \ldots \quad$... 64

Chubwa $\quad \ldots \quad 3,42,123$

Cinnamara- $3,41,42,50,51,53,54,56,58$

Citric Acid

Clay in Soil

Clover

Cocoanut Cake

Collar-pruning;

Colombo

Composts

$67,77,127,130,131$

Cotton-Soil constituents removed by

\section{Cake}

... $\quad \ldots, 48,92$

Cressivell \& Co., Messrs. W. S.

Crotolaria striata $\ldots . .79,85$

Cultivation-Very deep 19, 20, 21, 22, 120

- Very deep, in young tea ... 20

- Deep, in Autumn

- Causes loss to Soil

"Cyclopædia, Tea" ...

\section{D}

Dalbergia Assamica-See Medeloa

Darjeeling ... 51

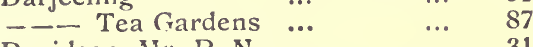

Davidson, Mr. R. N. ‥ $\quad \ldots \quad 31$

Dehing $\quad \ldots \quad 65,105,119,124,127$

Dejoo $\quad 3,41,42,50,51,53,54,56.58$, 116,118

Dekko

... 127

Depth of Soil for Tea .... $10,1 \dddot{1}, 16-23$

Desmodium polycarpum

"Devil" Disintegrator

Dhoedam

Dhunsiri River

Dhubri

... 79, 85

... 86

... 125

Dibru River

134,135

$3,13,41,49,80 \quad 82$ $105,106,118,119-124,127$
Dikorai

Dinagepore

PAGES.

Bones-See Bones, Dissolved.

Dooars $\quad \ldots \quad \ldots 44,75$

Doolahat

... 116

Doom Dooma District $\quad 3,41,49,106$.

Doom Dooma Ridge $\quad 124-127$

Dooria

Drainage $16,18,19,24,25,30,107,109$,

- In Cachar, \&c. Bheels

- - - Purpose of

- Sub-soil $\quad \ldots 18,19,24,25,120$

Drains - Width of $\quad \ldots \quad \ldots, 30$

Duflating $\quad \ldots . \quad \ldots 3,132$

Dunlop, Mr. C, T. $\quad \ldots . \quad \quad \ldots .84$

Dung-See Cattle Manure

\section{$E$}

Eastern Assam Tea Co.

Edwards, Mr. F. H. ...

Edwards, Mr. W. N. ...

Erythrina Indica . ...

... 81,85

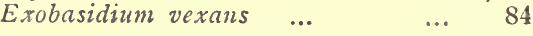

\section{F}

$\begin{array}{llll}\text { Faggot Worms } & \ldots & \ldots & 84\end{array}$

Farmyard Manure-See Cattle Manure

Ferguson, Mr. $\quad$... $\quad 104,105$

Fertility of Soil-Methods of Measuring 36

Ficul elastica $\quad$... $\quad \ldots . \quad 85$

$\begin{array}{llll}\text { Florida } & \ldots & \ldots & 95\end{array}$

"Flushes," as measure of soil value 35

Forest land $\quad$... $\quad \ldots .57$

- Soil as manure $\quad \quad \dddot{63}, 68,69$

Fowl manure $\quad$.. $\quad$... 71

French Beans, as green manure ... 79

$\begin{array}{llll}\text { Frost } & \ldots & \ldots & 15\end{array}$

Fungi, spores of $\quad \ldots . \quad \ldots .97$

Ganges

G

Gauhati District _. $\quad 114,105$

3, 104, 105

Geological Survey or India 104, 105

$\begin{array}{llll}\text { Germany } & \text {.. } & \ldots & 87\end{array}$

$\begin{array}{llll}\text { Gneissic Rock } & \text {.. } & \text {.- } & 104\end{array}$

$\begin{array}{llr}\text { Goat manure } & \\ \text { Golaghat District } 3,41, & 49,68,76, & 83,105\end{array}$

Golaghat District $3,41,49,68,76,83,105$
$106,132-135,136$

Gotoonga $\quad \ldots \quad \ldots 67$

Grasses - are shallow rooted $\quad \ldots 44,75$

- - not suited for green manur-

ing $\quad \ldots \quad \ldots, \quad 75$

Grass land 49, 57, 106, 115, 116, 120, 121,

Gravel $\quad \ldots \quad \ldots 107,110,112,124$

"Green Fly" • $\quad \ldots \quad 77,80,131$

Green Manuring, 5, 15, 30, 74-80, 97, 98, $100,108,109,112,113,115,117$ $118,119,120.122,124,126,129$, $131,132,134,135,136,137$ By means of weeds $\quad . . \quad 76$ Choice of plants for $\quad \ldots 23,75$ 


\section{PAGES.}

Grcen manuring,-Importance of 7 Not useful in cold weather 30,77

_. Time for ... $\quad . .76,77$ _ - To prevent loss of nitrates 43,44 $\begin{array}{lll}\text { Grevillea robusta } & \ldots & 23,82,84\end{array}$ Grey blight ... $\quad$... 96 H

Hannay, Col.

Hansara

Harchurah

Hard pan sub-soil

Harmutty

Hathibari

Hattigor

Hautley

Hay, Meadow

Heeleaka

Henderson, Mr.

Hilika

Hilgard, E. H.

Himalayas

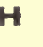

Hoeing, Deep, in autumn

Hoogrijan

Hoolmarie ...

Hooper, Mr. D

Hudson, Mr. W. A.

Hughes, Mr. J. $\quad$...

Hukanguri

Hulbert, Mr. F. E. ...

"Hullah" Soil 4. $66-68,126,129,131,132$

_ - containing river silt

_ when valuable

Humus
Hutchison, Mr. W. $\quad \ldots$

$\because$

..66, 68

66

... 41

$\ldots 76,78$

I

Ilami

India Rubber tree $\quad \ldots$

Indian Tea Association

$\begin{array}{lllr}\text { Insecticides } & \ldots & \ldots & 86 \\ \text { Iron, in Tea Soils } & \ldots & 40,55-57,59\end{array}$ __. Oxide of, in "Tea Soils

$40,48,53,55,56,57$

- L Lower Oxide of, in Tea Soils 47, 56 ,

- Phosphate of, in Tea Soils 35

- Exhaustion of available, in

Tea Soils

Iron Compounds in Basic Slag ... 95

Iron Pyrites

Irrigation for tea

$$
\text { ... } 30-32,107,136
$$

\section{J}

Jaboka

Jaintia Hills

Jaipur

Jhanzie Tea Co.

Jhanzie River

Jokai Company

\begin{tabular}{|c|c|}
\hline$\ldots$ & $\ldots .3,127$ \\
\hline ... & 104 \\
\hline & 105,319 \\
\hline & $\cdots$ \\
\hline & 127,130 \\
\hline
\end{tabular}

Jorhat District 2, 3, 16, 17, 41, 49, 55, 65, 67
PAGES.

Joyhing

... 3,118

"Juming"

... 5,6

Jungle, Burying of $15,16,22,97,102,136$

- As manure $\quad 61,97,102,103$

\section{K}

Kalai-See Mati Kalai

Kamrup ...

Kellyden

Keyhung

Kharif crop

Khasia Hills

Koliabar

$\cdots$

$\ldots 31,105$

... 3,135

... 3

$\begin{array}{ll}\cdots & 3,49,135\end{array}$

Korkani land $\quad . . . \quad 68,115,116$

Koroi (Albizzia odoratissima) 23, 81,84

Kotalguri $\quad \ldots \quad \ldots \quad 3$

Kurseong and Darjeeling Tea Co. 87

Lawes, Sir John

Leather, Dr J. W.

Leguminos $x$

Leguminous plants

- trees

Ligri Pukri

Lilabari

$\begin{array}{lll}\ldots & \ldots 29,94 \\ \ldots & \ldots . & 72\end{array}$

... $45,81,84,86$

$76-86,107,108$

... 80,85

... $3,41,117$

Lime in tea soils $\quad \ldots 34,35,54,55,59$

_- large percentage injurious 54

—_ necessity of $\quad \ldots 40,48$

-_ in "busti" soils ...

__ relation to quality ... 55,59

-

- - ures ... $\quad$-.. 95

_- removal by cropping 62 of Ammonia 93

as manure $97,99,100,101,132$

to improve tilth

Line Sweepings as manure $\quad$... 61

Linseed Cake $\quad . . . \quad$... 88, 91

Loughridge, R.H. $\quad$.. $\quad \ldots .826$

Lupins $\quad \ldots \quad \ldots 23,79$

\section{M}

Mackeypore $\quad$... $\quad$... 3, 129

Maercker (and Steffek) $\quad$... $\quad 87$

$\begin{array}{llll}\text { Maize } & \ldots & \ldots & 75\end{array}$

Magnesia in Tea Soils... $\quad \ldots 440,48$

$\begin{array}{llll}\text { Mahua Cake } & \text {... } & \text {... } & 88\end{array}$

Majulighur $\quad \ldots . \quad \ldots 2,90$

Mangaldai District 2, 31, 41, 49, 105, $106-108$

Manganese in Tea Soils $34,35,57,58,59$

- _ - in Tea Ash ... 35

Manure, Artificial $\quad \ldots \quad 4,62,92-99$

- Cattle-See Cattle Manure

—— Goat $\quad$... $\quad$... 71

$\begin{array}{llll}- \text { Fowl } & \ldots & \ldots & 71 \\ \text { Manure pit } & \ldots & \ldots & 71\end{array}$

Manuring-general considerations

$\begin{array}{llll}\text { on } & \ldots & \ldots & 100,103\end{array}$ - Green-See Green Manuring

Manures, general $\quad . \quad \quad .60,63$

$\longrightarrow$ nitrogenous $-46,63,92,93,94,100$ 
Margosa Cake

Mati Kalai

\section{Deep rooted plant}

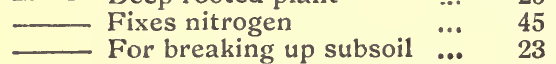

- For green manuring 75-80, 85, $97,101,102,103,107,112,114,115$ $118,119,122,123,126,129,130$, $131,132,134$

_ـ In 'uprooting and replanting' 78

Ceed $\quad$ Sazen 102,103 Medeloa (Dalbergia Assamica)

Medlicott, Mr.

Meleng

Merbheel

Mesua ferrea

Micaceous sand

Mijika Jhan

Mikir Hills

Mimosa pudica

Minimum, Law of the ...

Mitchell, Mr. J. C H. ..

Moabund

Money, Col.

Monobarie

Moran Tea Co.

Mosquito blight

Mothola

Mulching

Muriate of Potash

$23,81,84,86$

104,110

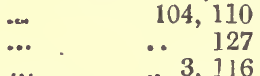

... .. 3,116

$\ldots \quad 85,110$

... $\quad \ldots \quad 105$

‥ $\quad \cdots \quad 3$

$104,106,127,134,135$ ... $15,45,78.79$

Crop, amount water dissipated by

- $\begin{array}{lll}\text { is deep rooted ... } & \ldots & 25\end{array}$

… 24

- - grown for producing cake $69,88,98$ or green manuring. 76, 79, 80, 101 $103,115,119,130$

- Cake 88, 90, 91, 100, 101, 109, 112 ,

- - Seed $114,131,132,134$

Mutrapore

$$
\text { ... }
$$$$
102,103
$$

N

Naga Hills

Naganijan

Nagrijuli

Nahor

Nahorhabi

Nahor Rani

Napuk

Nazira District

Nectria Camelliae on Tea

Neilgherries

New York State

Niger Cake

Nigriting

Nitrate of Potash-Temporary Action of Action of, for tea ...

...

$\ldots$
$104,106,127$

…

$41,106,107$

... $85,110,117$

… $\quad 3$

$\begin{array}{lll}\cdots & \cdots & \\ \cdots & \cdots & 2\end{array}$

3

$\quad \ldots 3,49$

... 25

... 34

... 28

88

$104,127, \dddot{132}, 133$ Nitrate of Soda-Temporary Action
of

$61,62,92,93$

$92,93,94,100$

Nitrates in Tea Soils-Function of 40

$\begin{array}{lll}- \text { Loss of } & \ldots & 43 \\ \text { not formed in Bheels } & \ldots & 64\end{array}$
Nitrates-Relation to flavour $\quad$... $4 \mathrm{l}$ Supplied by rain $\quad$... 45 Value of determination of 40,41 Nitrogen in Cattle Manure .. 71, 72 — in Dissolved Bones $\quad \ldots .99$ - in leaf of Adhatoda Vasica $\quad 86$ — in Oil Cakes .. $\quad$... 91

_- in Peat Bhecl Soil $\quad$... 64

—_ in Prunings ... $\quad \ldots 96,97$

- - in Tea leaf ... ... 46

_- in Tea Soils $35,40-48,49,58,59$, $94,107,108,111,112,122$, $123,126,137$

- - - loss of $\ldots . \quad 42,43,44$

- - $\quad$ supplied by rain $\ldots \quad 45$

- supplied by legumin. ous plants $\quad \ldots 45,76$

- - fixation of, $45,76,77,82,83,86$

- - - relation to quality $45,46,58$

- - removed by cropping 62

_ - in Top-dressing Soil $64,65,66-70$

Nitrogenous manures $46,63,92,93,94,100$, $107,117,120$

Noakachari, $3,41,42,50,51,53,54,56,58$, $127,130,131,132$

Nodules on plant roots $\quad \ldots 76,81$

Noholia

$$
\text { ... } 3
$$

North Lakhimpur District $3,41,49,82$, $116-119$

Nowgong District $2,3,16,23,31,41,49$, $64,68,77,81,106,135-137$

Numaligarh

... 3, 134

Oak Silver-Sec Silver Oak

Oil Cake 5, 88-92, 98, 100, 103, 107, 109 , $112,115,118,119,120,122,123$, $126,130,132,134,135,136,137$

- Local Production of $88,89,91$

___ Value of, for tea 89, 92, 93, 95

_ - Experiments with $\quad . .89,90$

Old Tea, Deterioration of $\quad \ldots \quad 3,4$

$\begin{array}{lll}\text { Orangajuli } & . . & 2, \dddot{106}, 107\end{array}$

Orange Beetle $\quad \ldots . \quad \ldots \quad$ - $\quad 73$

Organic Matter in Bones $\quad$... 87

- in Cattle Manure $\quad$... 71, 72

- - in Peat Bheels ... 64

_- in Tea Soils $40,48,49,56,58,59$,

$107,108,111,112,120,126,135,137$

-_- in Top dressing Soil 64, 65, 66 -70

Oxide of Iron-See Iron, Oxide of

\section{$\mathbf{P}$}

Pabbojan

Panbarrie

$3,41,125$

Panitola

... 3, 132

Pan in Soil

? $41,42,50,51,53,54,56,58$,

Pathalipam...

'Patta' land"

120,124

Peal, Mr. S. E.

$\ldots \quad 18,18-33$
117

$63, \ddot{64}, 70,100, \ddot{i 11} 34$

Perfect on quality

.. 64,65

Pertabgurh
-.. 
PAGES.

Phaseolus aconitifolius $15,23,45,75,76$, 77, 78, (See also Mati Kalai)

Phaseolus velutinus

Phosphate of Lime ... in Oil Cakes ... in Basic Slag ...

- in Bones ...

__ Mono basic ..

- - Tribasic ..

_ of Iron

Phosphates $4,92,94,95,107,135,137$

Phosphatic Manures

$63,94-98,117$

Phosphoric Acid added to soil

$126,128,137$

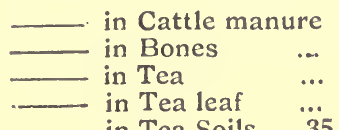

... 71,72

... 87, 95

... 87, 95

52

- in Tea Soils $\quad \dddot{35}, 48,-52,58,59$, $111,117,122,123,126,128,135$

absorbed by green
crops

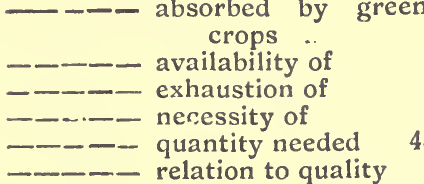

98

50

.. 50,51

... 40, 48

$48,49-52$

... 49,50 ,

$51,58,59$

- - - - removal by cropping

Physical Analyses of Soil

Physical properties of soil

- - and quality

"Plowsole"

Poppy Cake

Potash, Function in Plänt

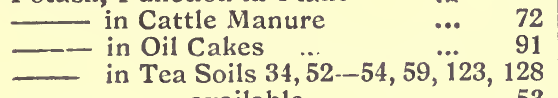

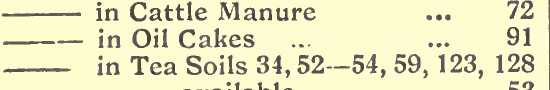

... 11,13

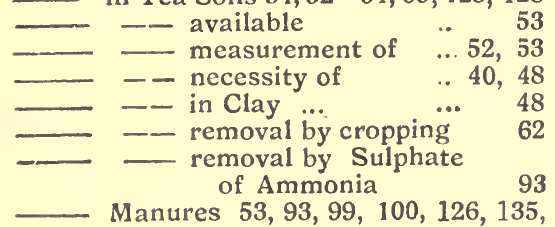

137

Pruning $\quad \cdots \quad 7,100,115$

Prunings-Burial of $16,95-97,98,99$,

$\begin{array}{cccc} & & 132,136 \\ \text { Pyrites (Iron) } & \ldots & \ldots 96,97 \\ & & \ldots & 66\end{array}$

Rainfall-Distribution of

- Contains Nitrogen

Rajmai Tea Co.

Raj Mahal

Rangagora Road ...

Rangagora (Golaghat)

Rangamati (Nowgong)

104,105

Rape-Amount water dissipated by 24

Red Rust on Tea $\quad$... 18, 96, 109, 126

Red Spider on Tea ...

Refuse (Tea) as manure

Replanting Tea $\begin{array}{rr}18,109 \\ \ldots . . & 61 \\ . . & 6,78\end{array}$
Rice, not suitable for green manur-

ing ... $\quad$...

PAGES.

Road sweepings, as manure $\quad$.. $\quad 61$

Rotation of Crops $\quad . . \quad 1 . .100$

Rotation of manures $\quad{ }^{\prime} 100-103,114,126$

Rothamsted

Sadya

105

Sadya Road

Salonah

Salts in Tea Soils

123,127

Samaguri ... $\quad . .67$

Sand-use of, for top-dressing ... 13, 14

Sangsua $\quad \ldots . . .676$

Sau tree (Albizzia stipulata) 23, 80-85, 86,

$107,113,115,124,128,132,136$

Seconee $\quad \ldots \quad \ldots 3,135$

Seleng $\quad . \cdots \quad$... 3, 84

Sensitive Plant (Mimosa pudica)

Sesamum Cake

Shade for tea $\quad \ldots . . \quad 29,81,82,84$

Showers, Mr. St. J. $\quad \ldots \quad 131$

Sibsagar District 16, 49, 82, 105, 106, 127

Silghat $\quad \ldots \quad 104,105,135$

Silica in Soil $\quad \ldots . . . .40$

Sillonibari $\quad \ldots .3$

Silver Oak (Grevillea robusta) $\quad 23,82,84$

Simul $\quad \ldots . \quad \ldots \quad 85$

Singrimari $\quad \ldots . \quad \ldots 2,108$

Soda, in Tea Soils $\quad \ldots . \quad \ldots 34,40$

Soil Analyses, $36,37,38,39,64,65,66,83$, $90,106,107108,109,110,111$, $112,113,114,115,116,117,118$, $120,121,123,124,125,128$, $129,130,131,132,133,134$.

$135,136,137$

\begin{tabular}{llcr} 
Constituents & $\ldots$ & $39,40,46$ & -58 \\
\hline- Acid- & $\ldots$ & $\ldots$ & 47 \\
- - Aeration of & $\ldots$ & $\ldots$ & 43
\end{tabular}

- - Bheel-See “ $\dddot{\text { Peat Bheel }}$ Soil" and "Top-dressing Soil"

___ "Busti" $\quad$...

- - Depth of $\quad$... 10, 16, 23

- - Hygroscopic moisture in ... 26

- L Looseness of 11-16, 27, 28

_- Near leguminous trees .. 83

- - Physical properties of $10-33,47$

- - Physical Analyses of ... 11, 13

- - - Samples $\quad . . \quad$... 39

- - Top.dressing - See Top-dressing Soil

Soils, Water

bacco

Solal

$\cdots$

...

$23-32$
26

Sonajuli $2,41,42,51,53,54,56,58,13$

112,11

$\ldots \quad 3,16,12$ ?

South America

Spider, Red-See Red Spider

Steffek (and Maercker)

Subansiri

Sub-soil

$165, \dddot{116} 11$ ?

$17-23, \& c$ $\ldots 65,6$

- Character of, for Tea 1, 10, 17-2

_... Clay

- - Drainage

$18,19,12$ 
PAges.

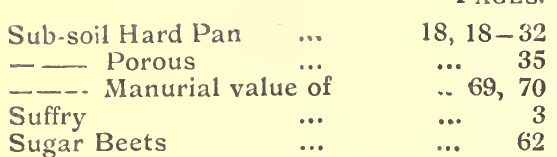

Sulphate of Ammonia-Impover.

ishes Soil $\quad$.. $61,93,94$

-_ Temporary action of 62,94

- To be avoided

_- Use for tea $\quad \begin{array}{ccr}-. . \\ -\end{array}$

_- of Manganese .... $\quad \ldots .69$

Sulp of Potash ....

Sulphates in Tea Soils

Sulphur

Sulphuretted Hydrogen

Sulphuric Acid ...

Suntok

…

Superphosphate of Lime

$112,118,119,132$

Sweepings as manure ...

Sylhet

...

$\mathbf{T}$

Talup

Taylor, Mr. C. B

"Tea Cyclopædia"

"Tea Manure" ...

Tea Refuse as Manure...

Teelas-Planting of trees on

_- Washed Soil of

_... Under Naga Hills

Tephrosia candida

Tezpur Bank $85-86,115$ $105,113,108,110-112,50,56,64,90$,

Tezpur District, 2, 20, 41, 49, 56, 64, 65, $67,77,104,105,108-113,114,115,118$

Thread Blight

Tilth

Tingri

Tippuk

Tippum Range

Tobacco-Analogy with Tea

... 3, 125

$\ddot{2}, 25,47$

$48,66,109$

... 66,108

$35, \dddot{40}, 94,95$

Ulu grass

United States, Department of Agriculture

Uprooting and replanting

Uraria crinita

Urine in Cattle Manure

Pages.

Trenches, for burying prunings $\quad 95-97$

Trenching

$21,22,102,103,114,136$

"Tropical Agriculturist"

... 45

... 50

... 81,85

\section{V}

Vacancies-Filling in ...

Village Soil-See Busti Soil

$\ldots 73,74$

Vitriolized Bones-See Bones, Dis. solved

Voelcker, Dr. J. A.

\section{$\mathbf{w}$}

Warington, $\mathrm{R}$.

... 26, 33

$6,73,78$

... 72

‥ $\quad$... 10

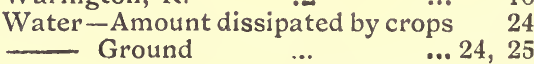

- In the Soil $-\mathrm{See}$ Soil Water

Retention of, by Soil ... 26

Watt, Sub-soil

(1)

- - Soils suitable for $\quad \ldots 26,32$

Top-dressing-Cost of .. 68, 69, 102, 103 Soil, as Manure $4,14,63-70,92$, $160,101,102,107,111,114,119$, $126,129,131,136$

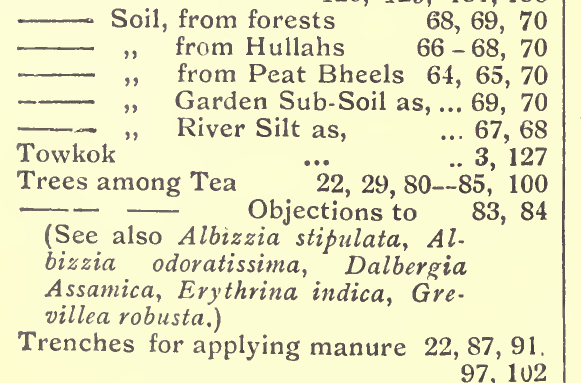

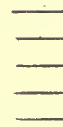

On Adhatoda Vasica On burial of Prunings On rotation of Crops

On Green Manuring

Opinions on Drainage

Weeds - Advantages of

- … - and Green Manuring

- "Cold weather weed"

—_ Dangers of .... Remove Soil moisture

Wheat

White Ants

Whitney, M.

Wind belts

Winogradsky

$1,24,62,75$

Wood Ashes-as manure, 6186, 98, 99, 100,

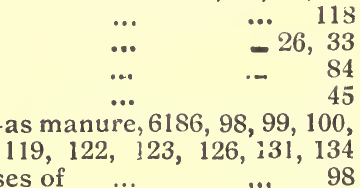

$\begin{array}{llll}\text { Analyses of } \ldots & \ldots & 98 \\ \text { Loss on exposure of } & \ldots & 98 \\ \text { Produced from prunings, } & \text { as } & \end{array}$

Woodbine

$\begin{array}{llrr}\text { manure } & \ldots & \ldots & 61 \\ \text { e } & \ldots & 2, \dddot{120}, 125 \\ \text { r. } & \ldots & \ldots & 77\end{array}$

Wylde, Mr. 






THIS BOOK IS DUE ON THE LAST DATE STAMPED BELOW

AN INITIAL FINE OF 25 CENTS WILL BE ASSESSED FOR FAILURE TO RETURN THIS BOOK ON THE DATE DUE. THE PENALTY WILL INCREASE TO 50 CENTS ON THE FOURTH DAY AND TO \$1.00 ON THE SEVENTH DAY OVERDUE.

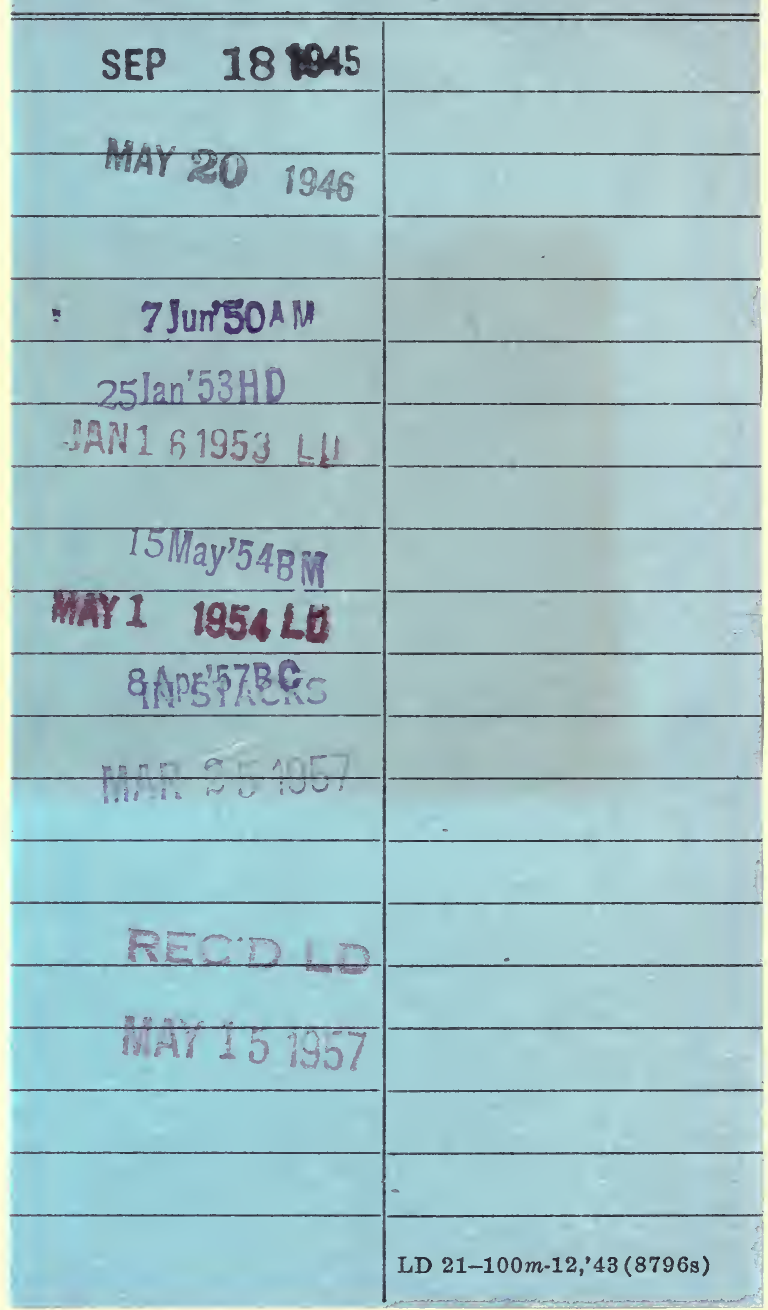




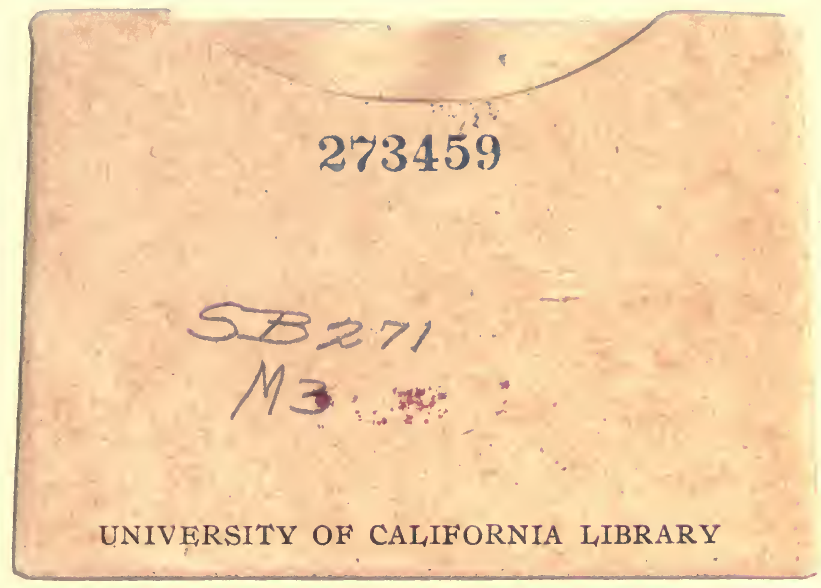


